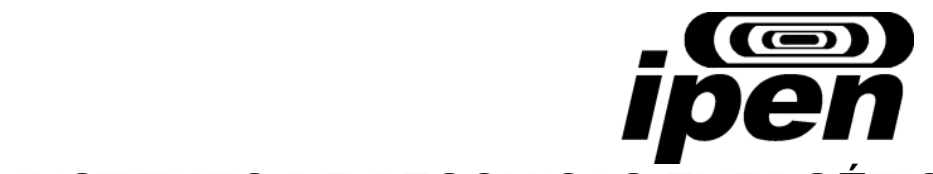

INSTITUTO DE PESQUISAS ENERGÉTICAS E NUCLEARES

Autarquia associada à Universidade de São Paulo

\title{
AVALIAÇÃO DO EFEITO DE TRATAMENTOS SUPERFICIAIS NA RESISTÊNCIA À CORROSÃO DE MAGNETOS DE Nd-Fe-B
}

\section{EMERSON ALVES MARTINS}

Dissertação apresentada como parte dos requisitos para obtenção do grau de Mestre em Ciências na Área de

Tecnologia Nuclear - Materiais

Orientadora: Dra. Isolda Costa 


\section{AGRADECIMENTOS}

Primeiramente a Deus, por me permitir realizar este trabalho, concedendo-me paciência, saúde e proteção. Também por colocar no meu caminho pessoas altamente capacitadas que tanto contribuíram para meu crescimento intelectual e pessoal.

À Dra Isolda Costa pela oportunidade, dedicação e empenho em orientar-me. Pelas sugestões e apoio na execução desta dissertação.

Também pela confiança que me conferiu para elaborar este trabalho e principalmente pela amizade e liberdade.

Meu eterno agradecimento por sua orientação e ajuda no direcionamento deste trabalho.

Ao Dr Hercílio Gomes de Melo, por me apoiar neste desafio, pelas sugestões relativas ao trabalho, pelo incentivo, por acreditar na minha capacidade $\mathrm{e}$ principalmente pela amizade e dedicação. Sua ajuda e incentivo foram primordiais para realização deste trabalho.

À Dra Mara Cristina Lopes de Oliveira pela amizade, cooperação, paciência e carinho dedicados a mim para realização deste trabalho durante todas as fases.

À Dra Fernanda Martins Queiróz pela amizade e pelo auxílio para a realização deste trabalho.

À Pós Doutoranda Solange de Souza pela amizade, paciência e cooperação.

Ao Dr Sérgio Luiz de Assis pelas sugestões.

Ao Olandir Vercino Corrêa pelo auxílio e cooperação, sempre disposto a ajudar durante todo o período deste trabalho. 
Aos meus amigos do Laboratório de Corrosão do IPEN e demais pessoas que direta ou indiretamente contribuíram na execução desta dissertação.

Aos meus amigos do Laboratório de Corrosão da POLI (Engenharia Química) pelo carinho e constante incentivo desde o início da realização deste trabalho.

Aos técnicos do Laboratório de Microscopia Eletrônica de Varredura do IPEN pela obtenção das micrografias exibidas neste trabalho.

À CNEN (Comissão Nacional de Energia Nuclear) pelo suporte financeiro e ao Instituto de Pesquisas Energéticas e Nucleares pelo uso das instalações e equipamentos para realização deste trabalho. 


\section{DEDICATÓRIA}

Ao meu Pai (in memoriam) e à minha Mãe que sempre me apoiaram e incentivaram-me desde a infância até a minha formação acadêmica e principalmente por me ensinarem os valores básicos para uma boa formação pessoal e intelectual.

Meu eterno agradecimento.

Ao Julio pelo apoio, pela amizade e também pelo grande incentivo e dedicação.

À Mara pela amizade e cooperação.

Aos meus irmãos, em especial à minha irmã Eliane, pelo incentivo constante.

À Ava, minha grande companheira durante muitas noites de estudo e também durante a confecção de grande parte desta dissertação.

Fight with determination, embrace life with passion, lose with class and win with daring, because the world belongs to those who dare and life is "very" to you be insignificant. 


\section{BEIJE MUITO. Chore com}

vonkade. DE GENEROSAMENTE. 3'?2: Faça aquilo que mais teme. GRITE! Harmonize-se mais. Importe-se menos. DCNUE MVISES LUTEPELO QUEACREDTA. Rudo do

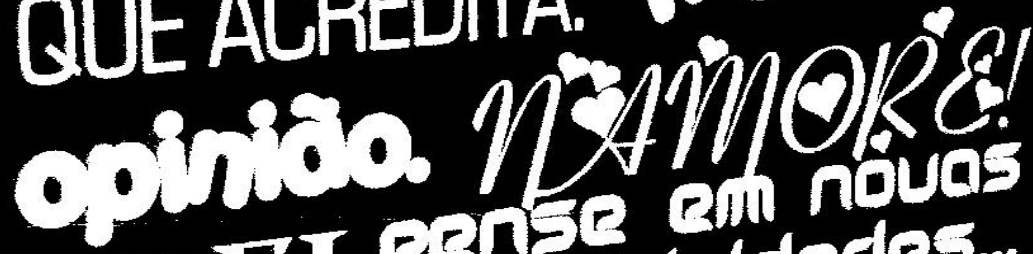
OREI possibilidades... Queira loucamente. Ria frequentemente. SONHE! Trabalhe com prazer use a imaginaçăo. V e N

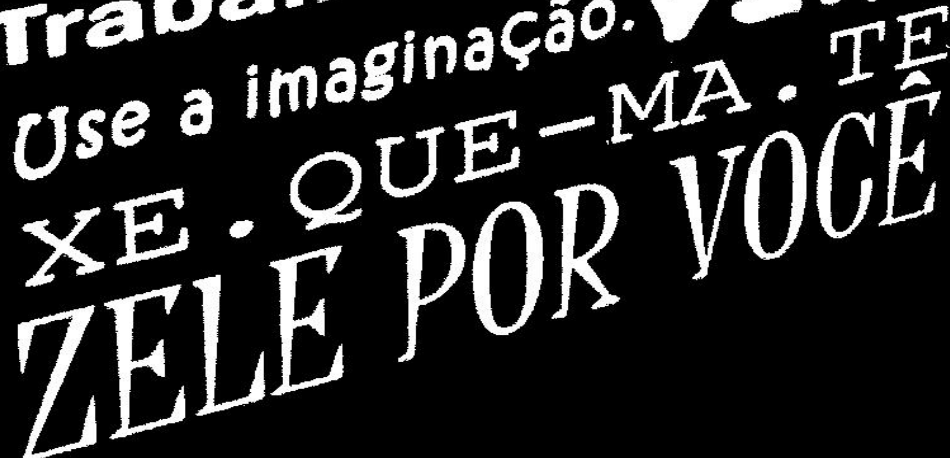

No great victory is possible without have been preceded by small victories over ourselves. 


\section{RESUMO}

Magnetos de Nd-Fe-B produzidos por metalurgia do pó são altamente susceptíveis à corrosão devido à porosidade intrínseca e à sua microestrutura complexa. Por outro lado, tais ímãs apresentam excelentes propriedades magnéticas tendo por isso várias aplicações.

$\mathrm{Na}$ área nuclear, os ímãs permanentes à base de terras raras-metais de transição-boro (Nd-Fe-B) são utilizados na fabricação de suportes magnéticos (levitação magnética) para ultra-centrífugas utilizadas no enriquecimento isotópico do urânio natural de utilização em reatores nucleares.

Em Odontologia são utilizados para fixar próteses totais e parciais sobre implantes, em Ortodontia, para corrigir maloclusões e fazer movimentações dentárias e em Cirurgia buco-maxilo-facial para fixar próteses de grandes defeitos da face. Em equipamentos eletrônicos, os magnetos são utilizados em balanças, cadeados, motores elétricos e principalmente na confecção de discos rígidos de computadores.Diante disso, o objetivo deste trabalho foi avaliar o comportamento de corrosão do magneto e testar tratamentos superficiais a fim de substituir principalmente os tratamentos com cromato que hoje em dia não estão sendo mais utilizados principalmente devido à sua toxicidade e altos custos dos tratamentos dos resíduos. A avaliação da resistência à corrosão foi feita através da análise de curvas de polarização potenciodinâmica, espectroscopia de impedância eletroquímica, medidas de potencial de corrosão versus tempo e microscopia eletrônica de varredura a fim de associar a microestrutura ao comportamento de corrosão apresentado pelas amostras. Os resultados obtidos mostram que estes magnetos são altamente susceptíveis à corrosão e esta ocorre preferencialmente na fase rica em $\mathrm{Nd}$, localizada nos contornos da fase matriz e magnética $(\varphi)$. Tratamentos para proteção da superfície com revestimento de silano, revestimento de conversão de cério, moléculas autoorganizáveis (SAM), Cr hexavalente, fosfato tricatiônico seguido por passivação em solução de trióxido de cromo, e revestimento de fosfato obtido por imersão por $24 \mathrm{~h}$ em solução de $\mathrm{NaH}_{2} \mathrm{PO}_{4}(\mathrm{pH}=3,8)$ seguido de imersão em solução de sulfato de zinco não melhoraram a resistência à corrosão do magneto.

Dentre os tratamentos utilizados, o de fosfatização por $24 \mathrm{~h}$ em solução de $\mathrm{NaH}_{2} \mathrm{PO}_{4}(\mathrm{pH}=3,8)$ foi muito superior, conferindo maior proteção contra corrosão quando comparado com os outros tipos de tratamentos testados. 


\begin{abstract}
Nd-Fe-B magnets produced by powder metallurgy are highly susceptible to corrosion due to their complex microstructure and intrinsic porosity due to their fabrication process. Moreover, these magnets have excellent magnetic properties and find many applications. In the nuclear area, permanent magnets based on rare earth transition-iron-boron ( $\mathrm{Ne}-\mathrm{Fe}-\mathrm{B})$ are used in the manufacture of magnetic media (magnetic levitation) for ultra-centrifuges used for isotopic enrichment of uranium employed in nuclear reactors.

In dentistry these types of magnets are used to fix total and partial prostheses on implants; in orthodontics to correct dental malocclusion and make moves; in bucomaxillo-facial surgery for setting facial prostheses of large defects of the face. In electronic equipment, they are used in scales, locks, electric motors and particularly in the manufacturing of hard drives of computers.

The objective of this study is to evaluate the corrosion resistance of the magnet tested and surface treatments that could replace chromating that generates toxic residues and present high cost of processing waste with treatments that are environmentally friendly.

The evaluation of the corrosion resistance was carried out through the analysis potentiodynamic polarization curves, electrochemical impedance spectroscopy, monitoring of corrosion potential as a function of test time and scanning electron microscopy to try to correlate the magnet microstructure with its corrosion resistance. The results show that these magnets are highly susceptible to corrosion that occurs preferentially in the $\mathrm{Nd}$-rich phase, located in the boundaries of the magnetic matrix phase $(\varphi)$. Treatment with silane, cerium, sam, $\mathrm{Cr} 6^{+}$, tricationic phosphate followed by bath of chromium trioxide and in $\mathrm{NaH}_{2} \mathrm{PO}_{4}$ solution for 24 hours followed by bath of zinc sulphate did not improve the corrosion resistance of the magnet. Among the treatments used, immersion in $\mathrm{NaH}_{2} \mathrm{PO}_{4}$ solution for 24 hours $\mathrm{pH}=3.8$ was the one that provided the best corrosion protection against corrosion, when compared with the other types of tested treatments.
\end{abstract}




\section{SUMÁRIO}

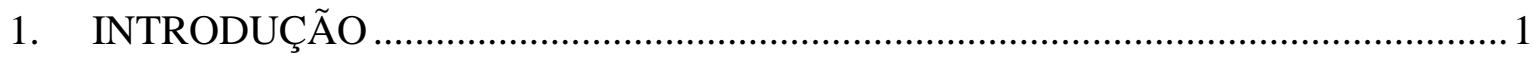

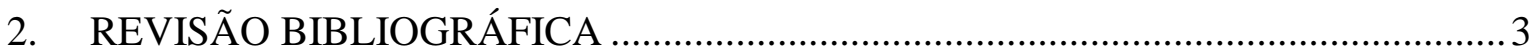

2.1. HISTÓRICO DOS MAGNETOS DE Nd-Fe-B................................................. 3

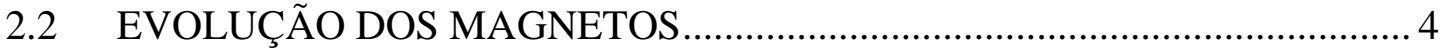

2.3 PRINCIPAIS TIPOS DE CORROSÃO ...................................................... 7

2.3.1. TIPOS DE CORROSÃO .........................................................................

2.4. INFLUÊNCIA DO ESTADO DE MAGNETIZAÇÃO NA RESISTÊNCIA À

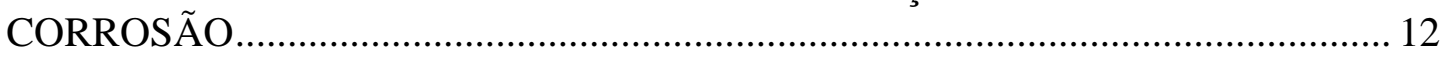

2.5. APLICAÇÕES DOS MAGNETOS DE Nd-Fe-B ........................................... 13

2.6. MEDIDAS DE PROTEÇÃO CONTRA A CORROSÃO .................................. 14

2.6.1. TRATAMENTOS POR FOSFATIZAÇÃO …................................................. 14

2.6.2. TRATAMENTOS COM FOSFATO TRICATIÔNICO ................................... 15

2.6.3. MOLÉCULAS AUTO-ORGANIZÁVEIS - SAM .......................................... 18

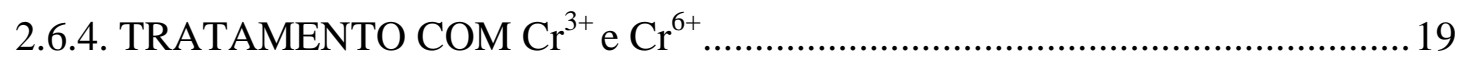

2.6.5. TRATAMENTOS À BASE DE CÉRIO .......................................................... 21

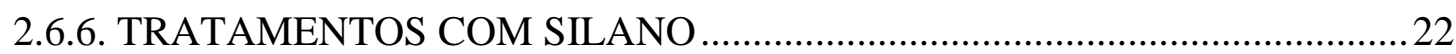

2.7. ASPECTOS FÍSICOS DOS MATERIAIS MAGNÉTICOS............................. 24

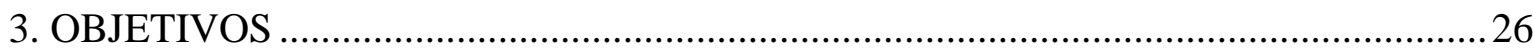

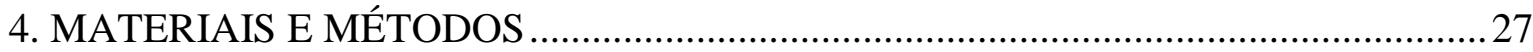

4.1. CARACTERIZAÇÃO QUÍMICA DO MAGNETO DE Nd-Fe-B ...................... 27

4.2 PREPARAÇÃO DAS AMOSTRAS DO MAGNETO DE Nd-Fe-B PARA ENSAIOS ELETROQUÍMICOS .............................................................................. 27

4.3. SOLUÇÃO PARA ENSAIO ELETROQUÍMICO ........................................... 27

4.4. MEDIDAS DO POTENCIAL DE CORROSÃO VERSUS TEMPO .................. 28

4.5. ENSAIOS DE ESPECTROSCOPIA DE IMPEDÂNCIA ELETROQUÍMICA (EIE)

4.6. CURVAS DE POLARIZAÇÃO POTENCIODINÂMICA ............................... 29

4.7. MICROSCOPIA ELETRÔNICA DE VARREDURA COM MEDIDAS DE ENERGIA DISPERSIVA DE RAIOS-X (SEM/EDS) ............................................ 29

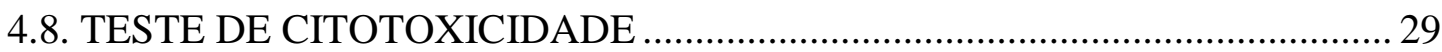

4.9. TRATAMENTOS SUPERFICIAIS INVESTIGADOS COM O OBJETIVO DE AVALIAR SEUS EFEITOS NA RESISTÊNCIA À CORROSÃO DO MAGNETO30 


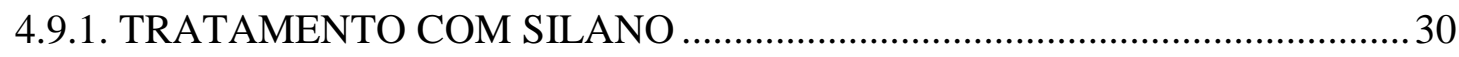

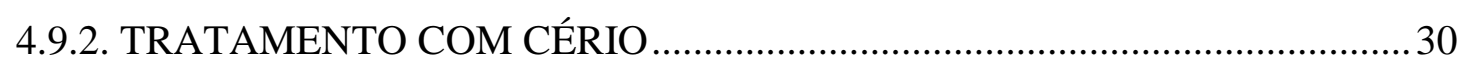

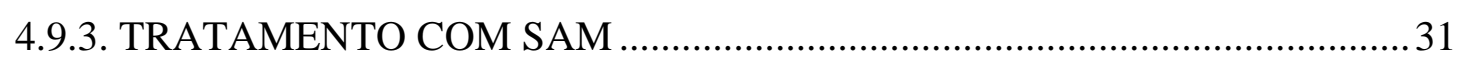

4.9.4. TRATAMENTO COM CROMO TRIVALENTE E HEXAVALENTE ............31

4.9.5. TRATAMENTO COM FOSFATO TRICATIÔNICO......................................... 31

4.9.6. TRATAMENTO COM FOSFATO TRICATIÔNICO (30 min) E BANHO DE

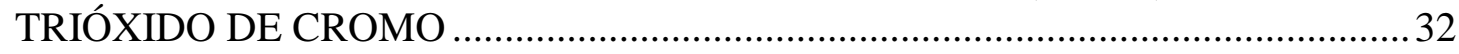

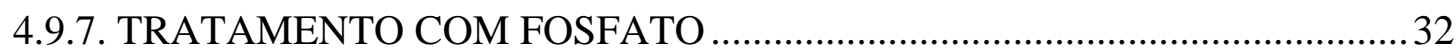

4.9.8. TRATAMENTO COM FOSFATO (24h) + SULFATO DE ZINCO...................33

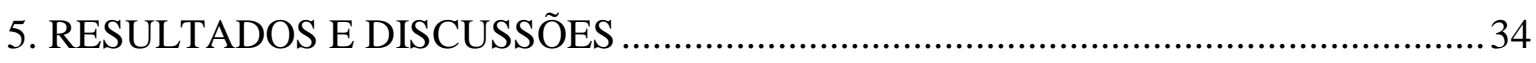

5.1. CARACTERIZAÇÃO MICROESTRUTURAL E ELETROQUÍMICA DO MAGNETO EM IMERSÃO EM SOLUÇÃO DE PBS …………………………........ 34

5.1.2. CURVAS DE POTENCIAL DE CORROSÃO VERSUS TEMPO......................36

5.2 TRATAMENTO DE PROTEÇÃO COM SILANO ………………………....... 40

5.3 PROTEÇÃO POR CAMADA DE CONVERSÃO DE CÉRIO …………......... 44

5.4 PROTEÇÃO POR TRATAMENTO COM SAM............................................ 48

5.5 TRATAMENTO COM CROMO TRIVALENTE E HEXAVALENTE.......... 51

5.6 TRATAMENTO COM FOSFATO TRICATÔNICO ....................................... 54

5.7 TRATAMENTO DE FOSFATIZAÇÃO POR IMERSÃO EM SOLUÇÃO DE

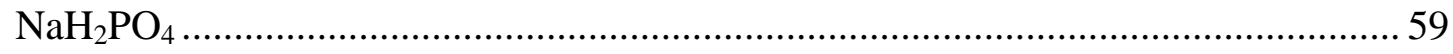

5.8 TRATAMENTO COM FOSFATO + SULFATO DE ZINCO.......................... 65

5.9 COMPARAÇÃO DOS RESULTADOS DE TRATAMENTOS AUMENTAM A RESISTÊNCIA À CORROSÃO DO MAGNETO DE Nd-Fe-B …………………........ 67

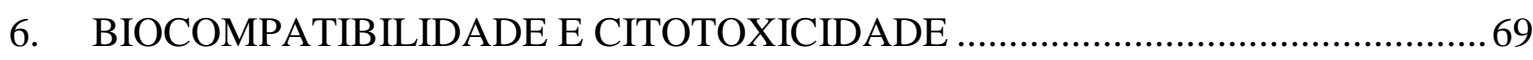

7. EFEITO DO TEMPO DE IMERSÃO NA SOLUÇÃO DE FOSFATIZAÇÃO

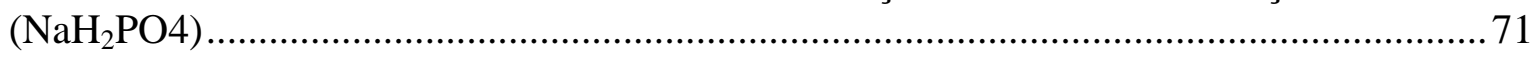

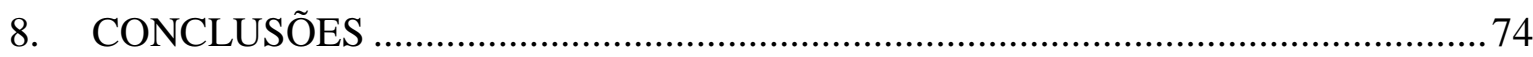

9. SUGESTÕES PARA TRABALHOS FUTUROS …………………………................

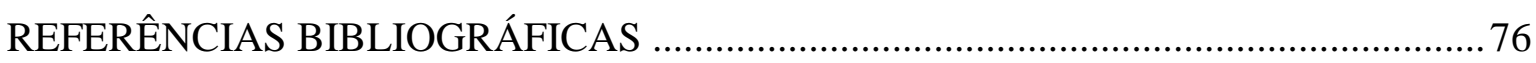




\section{LISTA DE TABELAS}

\begin{tabular}{|l|l|l|}
\hline Tabela 1 & $\begin{array}{l}\text { Composição química (peso\%) do magneto de Nd- } \\
\text { Fe-B usado neste estudo. }\end{array}$ & p.27 \\
\hline Tabela 2 & $\begin{array}{l}\text { Composição da solução de PBS usada nos } \\
\text { ensaios de corrosão. }\end{array}$ & p.28 \\
\hline Tabela 3 & $\begin{array}{l}\text { Composição\% em volume do banho de conversão } \\
\text { à base de Cério. }\end{array}$ & p.31 \\
\hline Tabela 4 & $\begin{array}{l}\text { Composição da solução concentrada de fosfato } \\
\text { (Xarope) }\end{array}$ & p.32 \\
\hline Tabela 5 & $\begin{array}{l}\text { Resultados de análise semi-quantitativa por EDS } \\
\text { (em porcentagem atômica) do ímã de Nd-Fe-B } \\
\text { como recebido, nas regiões de fase rica em Nd } \\
\text { (branca) e fase magnética ( } \varphi \text { ). }\end{array}$ & p.35 \\
\hline Tabela 6 & $\begin{array}{l}\text { Teores médios de Ce e Nd (em porcentagem } \\
\text { atômica) determinados nas regiões craqueadas } \\
\text { de amostras do magneto Nd-Fe-B imersas 10 ou } \\
\text { 30 minutos em banho de conversão de Cério. }\end{array}$ & p.47 \\
\hline Tabela 7 & $\begin{array}{l}\text { Resultados da porcentagem de viabilidade celular } \\
\text { no ensaio de citotoxicidade. }\end{array}$ & p.69 \\
\hline
\end{tabular}




\section{LISTA DE FIGURAS}

\begin{tabular}{|c|c|c|}
\hline Figura 1 & $\begin{array}{l}\text { Evolução cronológica do produto energético de } \\
\text { magnetos }\end{array}$ & p.5 \\
\hline Figura 2 & Etapas envolvidas no processo de fosfatização & p.17 \\
\hline Figura 3 & $\begin{array}{l}\text { Micrografia por MEV do magneto de Nd-Fe-B } \\
\text { usado neste estudo lixado com lixa de SiC até } \\
\text { granulometria } 1200 \text {. }\end{array}$ & p.35 \\
\hline Figura 4 & $\begin{array}{l}\text { EDS da área branca (rica em Nd) do magneto de } \\
\text { Nd-Fe-B, antes da imersão na solução PBS }\end{array}$ & p.36 \\
\hline Figura 5 & $\begin{array}{l}\text { Curva de potencial versus tempo de ensaio da } \\
\text { amostra polida em solução PBS por } 4 \mathrm{~h} \text {. }\end{array}$ & p.37 \\
\hline Figura 6 & $\begin{array}{l}\text { Micrografia obtida por MEV da amostra polida. } \\
\text { Regiões } 1 \text { e } 2 \text {, fases ricas em } \mathrm{Nd} \text {, e região } 3 \text {, fase } \\
\text { magnética. }\end{array}$ & p.37 \\
\hline Figura 7 & $\begin{array}{l}\text { Micrografias obtidas por MEV da amostra de Nd- } \\
\text { Fe-B imersa por } 4 \text { horas em solução de PBS. }\end{array}$ & p.38 \\
\hline $\begin{array}{l}\text { Figura } 8(a) \\
\text { (b) e (c) }\end{array}$ & $\begin{array}{l}\text { Diagramas de (a) Nyquist, (b) ângulo de fases e } \\
\text { módulo da impedância para o magneto de Nd-Fe- } \\
\text { B após } 30 \text { min, } 1 \text { hora e } 4 \text { horas de imersão em } \\
\text { solução de PBS e Diagrama obtido após uma } \\
\text { hora de ensaio evidenciando ângulos entre os } \\
\text { arcos capacitivo e o eixo real do diagrama de } \\
\text { Nyquist. }\end{array}$ & p.39 \\
\hline Figura 9 & $\begin{array}{l}\text { Diagramas de impedância (a) Nyquist (b) ângulo } \\
\text { de fase de Bode e Módulo de impedância das } \\
\text { amostras com revestimento de silano e sem } \\
\text { revestimento (polida) }\end{array}$ & p.41 \\
\hline Figura 10 & $\begin{array}{l}\text { Micrografia obtida por MEV do magneto de Nd- } \\
\text { Fe-B com revestimento de silano. }\end{array}$ & p.42 \\
\hline Figura 11 & EDS da amostra revestida com silano BTSE. & p.43 \\
\hline Figura 12 & $\begin{array}{l}\text { Curvas de polarização anódica obtidas em } \\
\text { solução de PBS para amostras de magnetos Nd- } \\
\text { Fe-B polida e revestida com BTSE. }\end{array}$ & p.43 \\
\hline Figura 13 & $\begin{array}{l}\text { Diagramas de impedância (a) Nyquist (b) ângulo } \\
\text { de fase de Bode e Módulo de impedância das } \\
\text { amostras com revestimento de silano e sem } \\
\text { revestimento (polida) após } 30 \text { minutos de imersão } \\
\text { na solução de PBS. }\end{array}$ & p.44 \\
\hline $\begin{array}{l}\text { Figura } 14 \\
\text { (a) e (b) }\end{array}$ & $\begin{array}{l}\text { Micrografia obtida por MEV da superfície da } \\
\text { amostra do ímã Nd-Fe-B tratada com Cério por } 10 \\
\text { minutos(a) e } 30 \text { minutos(b). }\end{array}$ & p.45 \\
\hline
\end{tabular}




\begin{tabular}{|c|c|c|}
\hline Figura 15 & $\begin{array}{l}\text { Espectro EDS da amostra de Nd-Fe-B imersa em } \\
\text { banho de conversão de cério por } 10 \text { minutos. }\end{array}$ & p.46 \\
\hline Figura 16 & $\begin{array}{l}\text { Espectro EDS da amostra de Nd-Fe-B imersa em } \\
\text { banho de conversão de cério por } 30 \text { minutos. }\end{array}$ & p.46 \\
\hline Figura 17 & $\begin{array}{l}\text { Curvas de polarização anódica para amostras do } \\
\text { magneto Nd-Fe-B apenas polida e polida e } \\
\text { revestida com cério } 10 \text { minutos. }\end{array}$ & p.48 \\
\hline Figura 18 & $\begin{array}{l}\text { Diagramas de (a) Nyquist e (b) ângulo de fase e } \\
\text { módulo de impedância para amostras do magneto } \\
\text { de Nd-Fe-B com revestimento de SAM e amostra } \\
\text { sem revestimento (polida) na solução de ensaio } \\
\text { (PBS). }\end{array}$ & p.49 \\
\hline $\begin{array}{l}\text { Figura } 19 \\
\text { (a) e (b) }\end{array}$ & $\begin{array}{l}\text { Micrografias obtidas por MEV do magneto de Nd- } \\
\text { Fe-B após imersão durante } 5 \text { minutos em solução } \\
\text { de SAM. }\end{array}$ & p.49 \\
\hline Figura 20 & $\begin{array}{l}\text { Espectro EDS da superfície do magneto de Nd- } \\
\text { Fe-B tratado com SAM durante } 5 \text { minutos. }\end{array}$ & p.50 \\
\hline Figura 21 & $\begin{array}{l}\text { Curvas de polarização anódica para amostras do } \\
\text { magneto Nd-Fe-B polida e revestida com SAM } \\
\text { após imersão durante } 1 \text { hora na solução de PBS. }\end{array}$ & p.50 \\
\hline Figura 22 & $\begin{array}{l}\text { Diagramas de (a) Nyquist, (b) ângulo de fase e } \\
\text { módulo de impedância para amostras do magneto } \\
\text { de Nd-Fe-B com revestimentos de } \mathrm{Cr}^{3+}, \mathrm{Cr}^{6+} \mathrm{e} \\
\text { amostra sem revestimento (polida). }\end{array}$ & p.51 \\
\hline $\begin{array}{l}\text { Figura } 23 \\
\text { (a) e (b) }\end{array}$ & $\begin{array}{l}\text { Micrografias das amostras do magneto de } \mathrm{Nd}-\mathrm{Fe}- \\
\mathrm{B} \text { tratadas com (a) Cromo }{ }^{3+} \text { e (b) com Cromo }\end{array}$ & p.52 \\
\hline Figura 24 & $\begin{array}{l}\text { Curvas de polarização anódica para amostras do } \\
\text { magneto de Nd-Fe-B polida e tratadas com } \mathrm{Cr}^{3+} \mathrm{e} \\
\mathrm{Cr}^{6+} \text {. }\end{array}$ & p.54 \\
\hline Figura 25 & $\begin{array}{l}\text { Espectro EDS da amostra de magneto Nd-Fe-B } \\
\text { revestida por } \mathrm{Cr}^{3+} \text {. }\end{array}$ & p.54 \\
\hline Figura 26 & $\begin{array}{l}\text { Espectro EDS da amostra de magneto Nd-Fe-B } \\
\text { revestida por } \mathrm{Cr}^{6+} \text {. }\end{array}$ & p.54 \\
\hline Figura 27 & $\begin{array}{l}\text { Diagramas de (a) Nyquist, (b) ângulo de fase e } \\
\text { módulo de impedância para amostras do magneto } \\
\text { de Nd-Fe-B com tratamento de Fosfato } \\
\text { tricatiônico por } 10 \text { minutos e por } 30 \text { minutos e } \\
\text { amostra sem revestimento (polida). }\end{array}$ & p.55 \\
\hline Figura 28 & $\begin{array}{l}\text { Micrografia obtida por MEV da amostra do } \\
\text { magneto de Nd-Fe-B tratada com fosfato } \\
\text { tricatiônico por } 30 \text { minutos. }\end{array}$ & p.56 \\
\hline
\end{tabular}




\begin{tabular}{|c|c|c|}
\hline Figura 29 & $\begin{array}{l}\text { Espectro EDS da superfície da amostra do } \\
\text { magneto de Nd-Fe-B tratado com fosfato } \\
\text { tricatiônico. }\end{array}$ & p.57 \\
\hline Figura 30 & $\begin{array}{l}\text { Curvas de polarização anódica de amostras do } \\
\text { magneto Nd-Fe-B polida e polida e tratada com } \\
\text { fosfato tricatiônico por } 30 \text { minutos. }\end{array}$ & p.58 \\
\hline Figura 31 & $\begin{array}{l}\text { Diagramas de (a) Nyquist, (b) ângulo de fase e } \\
\text { módulo de impedância para amostras do magneto } \\
\text { de Nd-Fe-B com pré-tratamento de fosfato } \\
\text { tricatiônico por } 30 \text { minutos, e amostras com o } \\
\text { mesmo tratamento seguido de imersão no banho } \\
\text { passivante de trióxido de cromo por } 30 \text { minutos e } \\
1 \text { hora. }\end{array}$ & p.59 \\
\hline Figura 32 & $\begin{array}{l}\text { Diagramas de (a) Nyquist e (b) ângulo de fase e } \\
\text { módulo de impedância para amostras do magneto } \\
\text { de Nd-Fe-B imersas na solução de Fosfato } \\
\mathrm{NaH}_{2} \mathrm{PO}_{4} \text { por } 1 \mathrm{~h}, 4 \mathrm{~h}, 8 \mathrm{~h} \text { e } 24 \text { horas. }\end{array}$ & p.60 \\
\hline Figura 33 & $\begin{array}{l}\text { Micrografia obtida por MEV da amostra } \\
\text { fosfatizada por 1hora. }\end{array}$ & p.61 \\
\hline Figura 34 & $\begin{array}{l}\text { Micrografia obtida por MEV da amostra } \\
\text { fosfatizada por } 4 \text { horas. }\end{array}$ & p.61 \\
\hline Figura 35 & $\begin{array}{l}\text { Micrografia obtida por MEV da amostra } \\
\text { fosfatizada por } 8 \text { horas. }\end{array}$ & p.62 \\
\hline Figura 36 & $\begin{array}{l}\text { Micrografia obtida por MEV da amostra } \\
\text { fosfatizada por } 24 \text { horas. }\end{array}$ & p.62 \\
\hline Figura 37 & $\begin{array}{l}\text { Curvas de polarização anódica das amostras do } \\
\text { magneto de Nd-Fe-B tratadas com fosfato por } \\
1 \mathrm{~h}, 4 \mathrm{~h}, 8 \mathrm{~h} \text { e } 24 \mathrm{~h} \text {. }\end{array}$ & p.63 \\
\hline Figura 38 & $\begin{array}{l}\text { Espectro EDS da amostra tratada na solução de } \\
\text { fosfatação por } 24 \text { horas. }\end{array}$ & p.64 \\
\hline Figura 39 & $\begin{array}{l}\text { Diagramas de (a) Nyquist, (b) ângulo de fase e } \\
\text { módulo de impedância para amostras do magneto } \\
\text { de Nd-Fe-B com tratamento de fosfato } 24 \text { horas e } \\
\text { amostra polida. }\end{array}$ & p.64 \\
\hline Figura 40 & $\begin{array}{l}\text { Curvas de polarização anódica para amostra } \\
\text { polida e fosfatizada } 24 \mathrm{~h} \text {. Obtidas após } 30 \text { minutos } \\
\text { de imersão na solução de PBS. }\end{array}$ & p.65 \\
\hline Figura 41 & $\begin{array}{l}\text { Diagramas de (a) Nyquist, (b) ângulo de fase e } \\
\text { módulo de impedância para amostras do magneto } \\
\text { de Nd-Fe-B tratadas em solução de fosfato } 24 \\
\text { horas e seguido por imersão em sulfato de Zinco } \\
\text { e apenas por fosfatização } 24 \text { horas. }\end{array}$ & p.66 \\
\hline Figura 42 & $\begin{array}{l}\text { Curvas de polarização anódica em solução de } \\
\text { PBS para amostras do magneto Nd-Fe-B polida, } \\
\text { fosfatizada por } 24 \mathrm{~h} \text { e fosfatizada por } 24 \mathrm{~h}+\text { banho } \\
\text { de sulfato de zinco. }\end{array}$ & p.66 \\
\hline Figura 43 & $\begin{array}{l}\text { Diagramas de (a) Nyquist, (b) ângulo de fase e } \\
\text { módulo de impedância para amostras do magneto } \\
\text { de Nd-Fe-B tratados com fosfato } 24 \text { horas e } \mathrm{Cr}^{3+}\end{array}$ & p.67 \\
\hline
\end{tabular}




\begin{tabular}{|l|l|l|}
\hline Figura 44 & $\begin{array}{l}\text { Curvas de polarização anódicas para as amostras } \\
\text { polida, tratada com } \mathrm{Cr}^{3+} \text { e fosfatizada por 24h. }\end{array}$ & p.68 \\
\hline Figura 45 & $\begin{array}{l}\text { Curvas de viabilidade celular do ensaio de } \\
\text { citotoxicidade de amostras de Nd-Fe-B e Nd-Fe-B } \\
\text { fosfatado por 24 horas. }\end{array}$ & p.70 \\
\hline Figura 46 & $\begin{array}{l}\text { Curva de Potencial x Tempo da amostra } \\
\text { submetida a ensaio de impedância na solução de } \\
\text { fosfatização. }\end{array}$ & p.71 \\
\hline Figura 47 & $\begin{array}{l}\text { Diagrama de Nyquist e bode ângulo de fase para p.72 } \\
\text { as amostras na solução de fosfatização por } \\
\text { 1h,4h,8h,16h e 24h. }\end{array}$ & \\
\hline
\end{tabular}




\section{INTRODUÇÃO}

A corrosão é um processo de destruição do metal, progredindo através de sua superfície, com formação de seus íons nos locais da com características de potencial mais ativo ou anódico (menos nobre), e a redução de uma espécie oxidante, presente no meio, nos locais com características de potencial menos ativo ou catódico (mais nobre).

No mecanismo de corrosão eletroquímica, o metal age como redutor, cedendo elétrons que são recebidos por uma substância, o oxidante, existente no meio corrosivo. A reação anódica de interesse, em um processo de corrosão, é a oxidação do próprio metal, e caracteriza a corrosão ou desgaste deste, sendo assim fonte de elétrons que são consumidos na área catódica.

É amplamente conhecido que a resistência à corrosão dos magnetos de $\mathrm{Nd}-\mathrm{Fe}-\mathrm{B}$ depende tanto de sua composição química como de sua técnica de processamento.

Magnetos produzidos por meio de metalurgia do pó estão sujeitos a ataques corrosivos, pois os seus poros constituem caminhos preferenciais para penetração do eletrólito. Por isso, são altamente susceptíveis à corrosão devido à porosidade intrínseca e à sua microestrutura complexa ${ }^{1}$.

Os magnetos de Nd-Fe-B apresentam custos relativamente baixos de produção, altos valores de anisotropia magnetocristalina, coercividade e produto $\mathrm{BH}_{\text {máx, entretanto, }}$ estes têm baixa resistência à corrosão e baixa temperatura de Curie $\left(T_{c} 373 \mathrm{~K}\right)$.

Por outro lado, tais ímãs apresentam excelentes propriedades magnéticas tendo por isso várias aplicações: discos rígidos de computador, motores eletrônicos, cadeados, balanças eletrônicas, biomateriais, e na área nuclear.

$\mathrm{Na}$ área nuclear, os ímãs permanentes à base de terras-raras-metais de transição-boro (Nd-Fe-B), são utilizados na fabricação de suportes magnéticos (levitação magnética) para ultra-centrífugas utilizadas no enriquecimento isotópico do urânio natural para utilização em reatores nucleares. Além das aplicações anteriormente mencionadas, os magnetos de Nd-Fe-B também são usados em Odontologia como ajuda na retenção de próteses totais, próteses parciais removíveis implanto-suportadas, em ortodontia nas correções de maloclusões e em tratamentos de dentes não erupcionados.

$\mathrm{Na}$ área de prótese maxilo-facial os magnetos têm sido usados por décadas na reconstrução de componentes para próteses usadas no caso de grandes defeitos de 
face. Os magnetos também podem ser aplicados em raízes de dentes com finalidade protética, em base de dentaduras, em ambos os casos para ajudar na fixação. ${ }^{2}$

Devido às inúmeras aplicações dos magnetos de $\mathrm{Nd}-\mathrm{Fe}-\mathrm{B}$ e seu papel de destaque na tecnologia moderna, torna-se necessário conhecer seu comportamento de corrosão bem como estudar tratamentos superficiais buscando melhorar sua resistência aos ataques que estes magnetos possam vir a sofrer.

Os pré-tratamentos investigados neste trabalho têm sido utilizados para proteção contra a corrosão em outros metais, entretanto, ainda não haviam sido testados em magnetos de Nd-Fe-B.

O tratamento com fosfato já havia sido testado como revestimento nos magnetos de Nd-Fe-B por pesquisadores do laboratório de corrosão do IPEN, no entanto, ainda não havia sido testado variando o tempo de imersão por períodos de até 24 horas. 


\section{REVISÃO BIBLIOGRÁFICA}

\subsection{HISTÓRICO DOS MAGNETOS DE Nd-Fe-B}

O magnetismo, fenômeno segundo o qual os materiais impõem uma força atrativa ou repulsiva sobre outros materiais, é conhecido há milhares de anos. Entretanto, os princípios e os mecanismos subjacentes que explicam o fenômeno magnético são complexos e sutis e foram os primeiros a despertar a curiosidade do homem sobre 0 interior da matéria. ${ }^{3}$

Uma versão sustenta que muitos séculos antes de Cristo, na Ásia menor, numa região conhecida como Magnésia, existiam quantidades muito grandes de uma pedra, de coloração escura, um tipo de minério de ferro, a qual possuía a propriedade de atrair a si outros minérios de ferro. Essa pedra recebeu o nome de Magnetita, uma extensão do nome da cidade onde fora encontrada.

No entanto, vários séculos antes da era cristã, (800 a.C), os gregos também já conheciam os ímãs de pedra, demonstrados em diversos trabalhos por Aristóteles (322-384 a.C), Platão (377-429 a.C) e Homero (850 a.C).

Mais tarde, nas primeiras décadas do século II d.C, a marinha chinesa chegou a entender as propriedades direcionais do ímã natural e usava essas pedras para localizar e manter a direção dos navios.

Nos primeiros anos do século XVI, o alquimista Philipus Aureolus Paracelsus, (14931541 d.C) foi o marco fundamental na história do magnetismo sendo suas estas palavras: "O que exerce isso o que nós chamamos de ímã é uma força de atração que vai além de nossa compreensão, mas isso, ou apesar disso, causa atração sobre o ferro e sobre outras coisas."3 Paracelsus, porém, disse que no poder e nas características do ímã existia a propriedade de curar enfermidades, e descobriu que eram aconselháveis em casos de inflamações, feridas, infecções internas e externas dos intestinos e do útero.

Vários outros cientistas levaram a cabo experiências importantes em relação ao magnetismo e difundiram suas experiências pelo mundo.

Por volta da metade do século XIX, o físico inglês Michael Faraday levou adiante descobertas e revelações como a demonstração do comportamento de um ímã sobre influência de uma corrente elétrica. Essas investigações de Faraday enriqueceram a 
ciência do magnetismo, como o eletromagnetismo, as linhas de força, a polarização rotativa e a indução eletromagnética, mantendo as suas experiências acima de 16.000. Faraday também investigou a relação entre o magnetismo e a biologia, sendo considerado o fundador do Biomagnetismo e a Magnetoquímica. Também baseou suas experiências em investigações prévias de outros grandes cientistas como A. M. Ampère (1755-1836), H.C. Oersted (1777-1851) e J.B. Biot (1774-1862), demonstrando que toda a matéria é de certo modo magnética, ou seja, toda matéria é atraída ou repelida por um campo magnético. ${ }^{4}$

\subsection{EVOLUÇÃO DOS MAGNETOS}

Apesar dos magnetos serem utilizados há muitos anos, estes eram ímãs naturais. Foi no início do século XIX que surgiram os primeiros magnetos produzidos pelo homem devido a avanços em pesquisas científicas nesta área. A partir daí, foram surgindo lentamente novos materiais para obtenção de melhores magnetos permanentes ${ }^{5}$. No campo de pesquisas dos ímãs permanentes, as propriedades que tornam um material viável para aplicação dividem-se em dois grupos: propriedades intrínsecas e extrínsecas. As propriedades intrínsecas são aquelas relacionadas à estrutura e composição da fase magnética principal e são independentes da microestrutura do magneto. Dentre estas, as mais importantes para o desenvolvimento de magnetos de alta qualidade são: alta temperatura Curie (Tc), alta magnetização de saturação (Ms) e alto campo de anisotropia magneto cristalina $(\mathrm{Ba})$. As propriedades extrínsecas são aquelas criticamente dependentes da microestrutura, processamento, alinhamento magnético, e as mais importantes são: indução ou magnetização remanente $(\mathrm{Br})$ e campo coercivo $(\mathrm{Hc})$.

A evolução cronológica dos magnetos permanentes, desde o final do século XIX até os dias atuais, estão apresentadas na Figura 1. Essa evolução é medida pelo produto de energia máxima ou densidade de energia do ímã ( $\mathrm{BH}_{\mathrm{Max}}$ ) que é o parâmetro mais usado na classificação destes dispositivos. Esse parâmetro fornece a quantidade de energia máxima por unidade de volume de um ímã permanente, obtida pelo ímã no momento da orientação dos grãos do material por um campo magnético. ${ }^{4}$ 


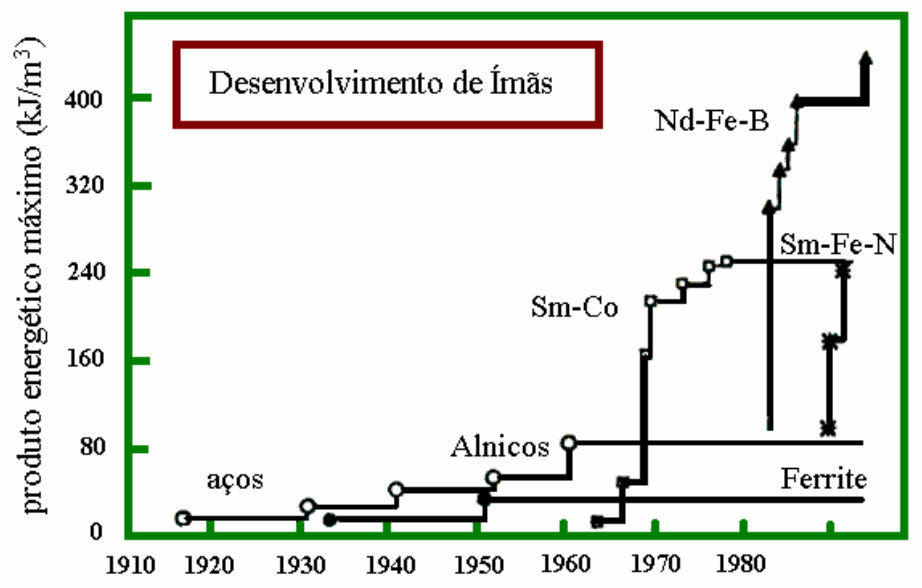

Figura 1 - Evolução cronológica do produto energético de magnetos. ${ }^{6}$

As ferritas, desenvolvidas em 1950, são os precursores da utilização da metalurgia do pó na fabricação de ímãs orientados. Os ímãs de terras-raras Sm-Co e $\mathrm{Nd}-\mathrm{Fe}-\mathrm{B}$, desenvolvidos a partir da década de 70 , são processados de forma similar às ferrites.

O desenvolvimento de materiais magnéticos alcançou grande avanço com a descoberta dos aços contendo $30 \%$ a $40 \%$ de Cobalto, juntamente com Tungstênio e Cromo.

No início dos anos 30 foram descobertas as primeiras ligas Alnico contendo $58 \%$ de $\mathrm{Fe}, 30 \%$ de $\mathrm{Ni}$, e $12 \%$ de $\mathrm{Al}$ endurecíveis por precipitação. Os Alnicos podem ser produzidos por fundição ou pela metalurgia do pó e são caracterizados pela alta remanência e baixa coercividade. Nessas ligas, a dureza é proporcionada por uma anisotropia de forma. A grande maioria dos alnicos é baseada em compostos que possuem estrutura cristalina cúbica, que, devido à sua alta simetria, apresentam uma baixa anisotropia magneto-cristalina. ${ }^{5}$

Entre 1938 e 1940 foram desenvolvidos os chamados Alnico 5 que contavam com o aumento do teor de Cobalto na liga associado a tratamentos térmicos para precipitação sob campos magnéticos, aumentando o produto de energia.

Uma vez observado pelos pesquisadores que as propriedades magnéticas podiam ser melhoradas a partir da estrutura do material usado, foram realizadas mais pesquisas nesta direção, que levaram, por volta de 1950, ao desenvolvimento de materiais magnéticos duros, baseados na anisotropia de forma de grãos do material. Os primeiros materiais dessa classe foram as ferritas de bário $\left(\mathrm{BaO} 6 \mathrm{Fe}_{2} \mathrm{O}_{3}\right)$ e de 
estrôncio $\left(\mathrm{SnO}_{6} 6 \mathrm{Fe}_{2} \mathrm{O}_{3}\right)$. Essas duas ferrites possuem estrutura hexagonal e uma razoável anisotropia magneto-cristalina. Desta forma, o $(\mathrm{BH})_{\text {Max }}$ apresentado por essas ferrites é de apenas $40 \mathrm{~kJ} / \mathrm{m}^{3}$ e mesmo assim ainda hoje apresentam uma grande importância econômica.

Mais tarde, surgiu uma nova classe de materiais magnéticos baseados em terras raras e cobalto (TRCo5). Pesquisas levaram à descoberta de uma liga com a fase $\mathrm{SmCO}_{5}$, cerca de 20 vezes mais magnética que as ferritas. ${ }^{7}$

No final dos anos 60, iniciou-se a fabricação de magnetos sinterizados de terras raras samário-cobalto de composição $\mathrm{SmCo}_{5}$ e $\mathrm{SmCo}_{17}$ com produtos de energia elevados, entretanto, o seu custo era alto. ${ }^{6}$ Devido a este problema, na década de 70 , pesquisas foram feitas a fim de encontrar compostos que fossem viáveis economicamente. $O$ resultado destas pesquisas foi a obtenção de ligas de $\mathrm{Nd}-\mathrm{Fe}-\mathrm{B}$, em especial a fase $\mathrm{Nd}_{2} \mathrm{Fe}_{14} \mathrm{~B}$, que apresenta excelentes propriedades magnéticas para aplicações em ímãs permanentes. ${ }^{8}$ Ligas com composição de $15 \%$ de $\mathrm{Nd}, 8 \%$ de $\mathrm{B}$ e $77 \%$ de $\mathrm{Fe}$ (porcentagem atômica) apresentam ainda melhores propriedades magnéticas, com valores de $(\mathrm{BH})_{\mathrm{Max}}$ superiores a $279 \mathrm{KJ} / \mathrm{m}^{3}$ (36,5 MGOe). As fases encontradas na liga são uma fase rica em $\mathrm{Nd}$, que apresenta um ferromagnetismo muito fraco à temperatura ambiente, uma fase $\mathrm{Nd}_{4} \mathrm{Fe}_{4} \mathrm{~B}_{4}$ não ferromagnética, e uma fase $\mathrm{Nd}_{2} \mathrm{Fe}_{14} \mathrm{~B}$ altamente anisotrópica, com estrutura tetragonal, de fácil magnetização, sendo esta última responsável pelas propriedades magnéticas. ${ }^{9}$

Sagawa e colaboradores ${ }^{9}$, em 1984,chegaram a resultados excelentes com um novo composto ternário á base de $\mathrm{Nd}-\mathrm{Fe}-\mathrm{B}$ com produtos de energia maiores que os produtos de energia dos magnetos de samário-cobalto. Este composto possui uma estrutura tetragonal, alta anisotropia uniaxial e uma temperatura de Curie de 580K.

Também em 1984, Sagawa e colaboradores, ${ }^{9}$ determinaram a composição do magneto $\mathrm{Nd}_{15} \mathrm{Fe}_{77} \mathrm{~B}_{8}$ por difratometria de raios-X e microscopia eletrônica de varredura onde foi verificada a presença de 3 fases: a fase rica em $\mathrm{Nd}$ ( 95\% at $\mathrm{Nd}$ ) encontrada ao longo do contorno de grão, uma fase rica em $\mathrm{B}\left(\mathrm{Nd}_{2} \mathrm{Fe}_{7} \mathrm{~B}_{6}\right)$ e uma fase matriz $\left(\mathrm{Nd}_{2} \mathrm{Fe}_{14} \mathrm{~B}\right)$.

Com o desenvolvimento das ligas de $\mathrm{Nd}-\mathrm{Fe}-\mathrm{B}$, a construção de um diagrama de fase exato para este sistema foi objeto de estudo em alguns trabalhos ${ }^{9} \mathrm{e}$ isto foi devido à forte influência da microestrutura do material sinterizado nas propriedades magnéticas do magneto permanente. 
Matsuura ${ }^{1}$ realizou um estudo mais completo sobre o sistema Nd-Fe-B obtendo um diagrama de fase através de uma investigação metalográfica utilizando microscopia ótica, microscopia eletrônica de varredura, micro-análise de sonda eletrônica (EPMA), difratometria de raios- $X$ e análise térmica diferencial (DTA).

Em 1988, estudos foram realizados sobre o controle microestrutural e as propriedades magnéticas dos magnetos de Nd-Fe-B. Uma nova técnica foi proposta para controle da microestrutura do magneto a qual se constituía na produção de ligas amorfas e posterior precipitação de seus cristalitos. Os resultados indicaram que o tratamento térmico é importante para melhorar as propriedades magnéticas destes materiais. ${ }^{10}$ Estes magnetos, apesar de apresentarem melhores propriedades magnéticas quando comparados aos magnetos de $\mathrm{Sm}-\mathrm{Co}$, apresentam menor resistência a ataques corrosivos. ${ }^{11}$

\subsection{PRINCIPAIS TIPOS DE CORROSÃO}

A corrosão pode ser definida como a deterioração de um material, geralmente metálico, por ação química ou eletroquímica com o meio no qual está sendo utilizado. Este processo pode estar associado ou não a esforços mecânicos. ${ }^{12}$

Os magnetos estão expostos a tensões e devem estar aptos para receber e transmitir força e também devem resistir às ações dos fluidos,no que diz respeito à corrosão e oxidação. ${ }^{13}$

O conhecimento e avaliação do comportamento eletroquímico dos magnetos de $\mathrm{Nd}-\mathrm{Fe}$ B são de grande interesse, uma vez que a resistência à corrosão e à oxidação são fatores preponderantes no desempenho funcional, na durabilidade e na biocompatibilidade destes materiais na sua gama de aplicações. ${ }^{14-15}$

A corrosão metálica pode ocorrer de acordo com vários mecanismos, sendo que a corrosão eletroquímica é, sem dúvida, a mais importante, pois está presente em mais de $95 \%$ das falhas por corrosão em materiais metálicos. ${ }^{16,17,18}$

No mecanismo de corrosão eletroquímica o metal age como redutor, cedendo elétrons que são recebidos por uma substância, o oxidante, existente no meio corrosivo. Portanto, a corrosão é um modo de destruição do metal, progredindo através de sua superfície, com formação de seus íons nos locais da superfície com características de potencial mais ativo ou anódico (menos nobre), e a redução de uma espécie oxidante, 
presente no meio, nos locais da superfície do metal com características de potencial menos ativo ou catódico (mais nobre). A reação anódica de interesse, num processo de corrosão, é a oxidação do próprio metal, e caracteriza a corrosão ou desgaste deste, sendo assim fonte de elétrons que são consumidos na área catódica. ${ }^{16,17}$

As regiões anódicas e catódicas que aparecem na superfície de um único metal são conseqüência da falta de homogeneidade na microestrutura do mesmo. Algumas das principais causas para a ocorrência destas regiões são deformação estrutural, composição variável, precipitados, segregações e inclusões, regiões mais ativas (contorno de grãos e inclusões) e regiões passivas ou nobres (regiões ou precipitados ricos no elemento mais nobre da liga). ${ }^{16}$

Os metais apresentam uma estrutura cristalina constituída por pequenos cristais (grãos). Durante o processo de resfriamento, a partir de sua temperatura de fusão, os cristalitos são nucleados em toda a massa metálica que resfria, e crescem com a velocidade que o resfriamento permite, até que a temperatura de solidificação seja atingida e toda a massa tenha que passar para o estado sólido. Como em qualquer processo de cristalização, ocorre a formação de cristais típicos da estrutura do metal e os elementos estranhos à rede cristalina são segregados nas superfícies externas dos cristais ou grãos. A massa sólida formada terá grãos que crescem até onde os grãos vizinhos permitem, e a região fronteiriça, entre os grãos, o contorno dos grãos, estará rica em impurezas, presentes na composição do metal. O contorno dos grãos é a região mais ativa da microestrutura do magneto, causando corrosão intergranular. Mesmo os metais puros possuem este tipo de região. 17,18,19,20,21

Apesar das composições básicas das ligas utilizadas como biomateriais serem bastante controladas, elas possuem várias estruturas metalúrgicas que aliadas aos processos de fabricação, tratamento térmico e tipo de superfície, podem afetar a resistência à corrosão do material. 17,21,22

Há dois tipos de corrosão: a corrosão generalizada, também conhecida como corrosão uniforme e a localizada. ${ }^{23}$

Na corrosão generalizada, o metal se oxida uniformemente, com perda de espessura e com velocidade de corrosão constante. Esse tipo de corrosão ocorre geralmente em meios em que o produto da corrosão é solúvel, permitindo à superfície do metal permanecer livre para continuar se oxidando. Este tipo de corrosão está geralmente associado a uma elevada perda de massa, e seu estudo não é importante em meios 
fisiológicos, uma vez que, metais que sofrem este tipo de corrosão não são adequados para uso em implante e como biomateriais. ${ }^{4,23}$

A corrosão localizada, como o nome indica, se dá em pontos determinados da superfície e é tão mais provável quanto maior a heterogeneidade da microestrutura do metal. A compreensão deste tipo de corrosão é de grande importância no estudo de biomateriais uma vez que os metais utilizados nestes meios formam películas passivas, estando sujeitos a este tipo de corrosão. ${ }^{21,23}$

Vários tipos de corrosão localizada são abordados na literatura, no entanto, os mais importantes são: corrosão por "pite", em fresta, galvânica, intergranular e mecânicoquímica. $^{23}$

\subsubsection{TIPOS DE CORROSÃO}

a) Corrosão por Pite

É uma forma de corrosão localizada, na qual o metal é removido preferencialmente de áreas vulneráveis na superfície. Pites também podem resultar do manuseio não apropriado do material, causando imperfeições superficiais, como riscos, onde é destruída a camada de óxido. Vale aqui lembrar que o óxido de cromo superficial é o maior responsável pela resistência à corrosão do aço. ${ }^{23}$

O uso de aços inoxidáveis especiais, mais ricos, por exemplo, em cromo, tem, entre outros objetivos, combater esse tipo de corrosão.

O pite pode se formar em fios e braquetes ortodônticos por que estes não apresentam uma superfície totalmente lisa a nível microscópico e estes podem aumentar a suceptibilidade à corrosão, devido a sua capacidade de acumular placas que abrigam microorganismos. Estes microorganismos causam redução localizada do $\mathrm{pH}$ e depleção do oxigênio, que por sua vez, afeta o processo de passivação. ${ }^{24}$

b) Corrosão em fresta

A corrosão em fresta, como o nome indica, ocorre no interior de aberturas estreitas que se encontram na junção formada entre duas peças metálicas, que podem ser do mesmo material, ou entre um metal e um não metal (polietileno, por exemplo), onde exista uma solução que não se renova ou se renova lentamente. ${ }^{23}$ 
A corrosão em fresta pode ocorrer nos implantes no contato entre os parafusos e placas mesmo quando estes são do mesmo material. O fluido biológico em contato com o implante contém substâncias oxidantes, por exemplo, o oxigênio. No interior da fresta, o fluido não é renovado, e à medida que a corrosão ocorre, o oxigênio vai sendo consumido, surgindo uma diferença de concentração do mesmo em pontos diferentes da fresta. Em consequência, surgem na superfície metálica regiões anódicas, mais pobres em oxigênio, situadas no interior da fresta, onde ocorre a corrosão do metal, e zonas de redução, mais ricas em oxigênio, situadas fora da fresta. ${ }^{23}$

A corrosão em fresta pode ocorrer também quando o material metálico é unido, soldado ou vedado com outro material metálico ou não metálico. Quando se coloca este conjunto em meio corrosivo, a região de junção se torna difícil ao livre acesso do eletrólito, o qual fica estagnado após conseguir ingressar. $O$ oxigênio, presente inicialmente nesta fresta, é consumido pelas reações de óxi-redução, gerando uma zona empobrecida nesta espécie, que se torna anódica em relação à região exposta livremente ao eletrólito. Este processo é agravado pela hidrólise dos produtos de corrosão gerando íons $\mathrm{H}_{3} \mathrm{O}^{+}$, acidificando a solução e rompendo o filme passivo pela acidez acentuada, ocorrendo então a aceleração da corrosão.

A fresta é frequentemente associada com pequenos volumes de solução estagnada devido a buracos, flanges, juntas de união e depósitos sobre a superfície metálica. Para funcionarem como sítios de corrosão, as frestas precisam ser suficientemente grandes para permitir a entrada de líquido, mas suficientemente pequenas para mantêlo estagnado, sua dimensão é de décimos de milímetros. Os casos mais frequentes envolvem ligas passivadas em meios contendo cloretos. Devido à deficiência de oxigênio no interior da fresta e à acidez elevada, o metal não tem chance de se repassivar tornando o ataque no interior da fresta mais intenso quando comparado com a entrada da mesma. ${ }^{17,20,25,26}$

A forma dos implantes pode influenciar no processo de corrosão. Implantes com pequenos espaços entre superfícies adjacentes podem criar focos para a iniciação de corrosão em fresta. ${ }^{17,27}$

A comparação do processo entre os dois tipos de corrosão localizada, fresta e pite, indica que a corrosão em fresta surge mais rapidamente e é mais freqüente que a corrosão por pite, apesar do eletrólito ser o mesmo. Uma liga é mais ativa na fresta do que na superfície aberta. ${ }^{27}$ 


\section{c) Corrosão galvânica:}

A corrosão galvânica ocorre sempre no contato entre dois materiais metálicos de reatividades diferentes instalados no mesmo meio. Surge uma diferença de potencial que acarreta o aparecimento de uma micro-pilha: o metal mais reativo, porção anódica, passa a ser corroído com maior intensidade, enquanto o metal mais nobre, porção catódica, passa a ser o local em que se dá a redução da substância oxidante, ficando este último menos sujeito ao processo corrosivo que se estivesse isolado. Nestes casos é essencial garantir um bom isolamento entre os metais conectados e o meio agressivo. ${ }^{23} \mathrm{Em}$ Ortodontia, a corrosão galvânica pode ocorrer onde dois metais diferentes são usados na confecção de fios ou braquetes ortodônticos. No caso de aparelhos removíveis, também pode ocorrer corrosão galvânica e esta pode ser exarcebada pela soldagem, onde, nesta região, que é mais mecanicamente ativa, a corrosão é mais acentuada. ${ }^{24}$

d) Corrosão Intergranular:

Metais e ligas metálicas, em geral, são materiais policristalinos e polifásicos. Por essa razão, a sua estrutura é constituída de diferentes cristais (grãos) que se desenvolvem com diversas orientações. A região limite dos diferentes grãos apresenta átomos em níveis maiores de energia do que aqueles que compõem o grão (em virtude das ligações químicas destruídas quando a superfície é criada), o que favorece o aparecimento da corrosão intergranular. Em aços inoxidáveis e ligas em geral esse tipo de corrosão ocorre em conseqüência da segregação de certos elementos de liga (solutos) que se difundem para o contorno do grão. Este tipo de corrosão pode ainda ser agravado por tratamentos térmicos inadequados. Serve de exemplo a segregação do carbono, que reage com o cromo, formando carbeto de cromo. ${ }^{23}$

No caso dos aços inoxidáveis, a corrosão intergranular pode ser minimizada a partir de tratamentos térmicos prévios aplicados e que permitam a dissolução dos carbetos de cromo. A atenuação desse tipo de corrosão também pode ser feita durante a fabricação de aços inoxidáveis, reduzindo o teor de carbono e adicionando outros elementos metálicos, entre os quais o nióbio. Este elemento combina preferencialmente com o carbono na formação de carbetos, deixando, dessa forma, o grão metálico mais enriquecido em cromo e, portanto, mais resistente. ${ }^{23}$ 
e) Corrosão Mecânico-química:

Dá-se o nome genérico de corrosão mecânico-química a processos de oxidação do metal quando submetido simultaneamente ao meio corrosivo e a esforços mecânicos.Destacam-se, no uso de implantes, a corrosão por atrito e fadiga. ${ }^{23}$

A corrosão por atrito ocorre quando duas peças metálicas são friccionadas uma contra outra, a ponto de o filme passivante perder as suas características de proteção.

A corrosão por fadiga se dá quando o material metálico, além de se encontrar no meio corrosivo, está sujeito a um esforço cíclico constante. Os danos causados ao material por esse tipo de corrosão são maiores do que os provocados apenas pela fadiga do metal, em igualdade de condições de esforço físico, ou pela corrosão química isoladamente no mesmo meio. ${ }^{23}$

\subsection{INFLUÊNCIA DO ESTADO DE MAGNETIZAÇÃO NA RESISTÊNCIA À CORROSÃo}

São relatados na literatura trabalhos relacionando o efeito do campo magnético com taxas de corrosão em alguns metais. ${ }^{29,35}$ A diferença de taxas de corrosão nos magnetos magnetizados e desmagnetizados é atribuída ao efeito do campo magnético no transporte de oxigênio na solução para o magneto/interface eletrolítica evidenciado pela resposta em alta freqüência nos diagramas de impedância e pela aderência de partículas na superfície das espécimes magnetizadas devido ao campo magnético. ${ }^{37}$

Alguns exemplos são a inibição da corrosão de Cu e Fe em solução de ácido nítrico por um campo magnético constante. ${ }^{9,28}$

Outros exemplos são a diminuição da taxa de corrosão do Fe puro em solução de sulfato e cloreto sob influência do campo magnético ${ }^{28}$; o efeito inibidor sobre a corrosão do zinco, latão e alumínio ${ }^{35}$ e sobre a corrosão do aço AISI 303 na solução de $\mathrm{FeCl}_{3}$. O efeito inibidor do campo magnético sobre a corrosão do aço AISI 303 foi explicado em termos do desenvolvimento de uma camada passiva favorecido pelo campo.

Por outro lado, o campo magnético também aumenta a taxa de corrosão de alguns materiais metálicos como, por exemplo, o titânio em solução de sulfato. ${ }^{30}$ Um efeito acelerador do campo magnético também foi relatado sob a reação catódica de um processo de corrosão relacionado ao aço $\mathrm{AISI} 303$ em solução de $\mathrm{FeCl}_{3}$, por exemplo a redução do $\mathrm{Fe}^{3+}$ para $\mathrm{Fe}^{2+}{ }^{28}$ 
Reporta-se na literatura que um campo magnético pode influenciar a corrosão metálica agindo sobre a cinética do eletrodo ${ }^{31}$, agindo no transporte de massa ${ }^{32}$, na formação de uma camada interfacial de óxido/ hidróxido ${ }^{33,34}$, e sobre a diferença de potencial na interface metal/solução. $28,31,32,33,34,35$

Em relação aos magnetos de terras raras, existem poucos trabalhos relacionando o campo magnético e o comportamento de corrosão. A maioria dos trabalhos não relata sobre o estado de magnetização das amostras avaliadas.

Um dos trabalhos que avalia a relação entre campo magnético e comportamento de corrosão em magnetos de terras raras foi realizado por Bala $(1990){ }^{36}$,onde foi avaliada a resistência à corrosão de três magnetos permanentes de Nd-Fe-B nos estados magnetizado e desmagnetizado através de ensaios gravimétricos e testes eletroquímicos. Constatou-se uma baixa resistência à corrosão para os três magnetos avaliados. Ocorreu uma tendência distinta de passivação para os três magnetos, porém com uma corrente anódica muito elevada para todos.

Posteriormente, em 1991, foi observado que o estado de magnetização do magneto de $\mathrm{Nd}$-Fe-B estudado $\left(\mathrm{Nd}_{15} \mathrm{Fe}_{77} \mathrm{~B}_{8}\right)$, exercia um efeito na dissolução deste magneto em soluções ácidas e em elevados potenciais catódicos. ${ }^{36}$ Essa dissolução em potenciais catódicos elevados foi denominada dissolução anormal, sendo atribuída à hidrogenação da superfície do magneto e sua degradação mecânica. Esta degradação anormal consiste na separação das partículas do magneto, com dimensão aproximada de $0,01 \mathrm{~mm}$, as quais posteriormente sofreriam dissolução na solução ácida.

Foi observado que a dissolução das partículas do magneto de $\mathrm{Nd}-\mathrm{Fe}-\mathrm{B}$ estudado no estado magnetizado era mais fraca e isso estaria relacionado ao efeito do campo magnético agindo na superfície do magneto e dificultando a separação das partículas. Entretanto, após os magnetos serem desmagnetizados, a superfície da liga anteriormente magnetizada mostrava o mesmo padrão de degradação que o da liga estuda em estado desmagnetizada.

\subsection{APLICAÇÕES DOS MAGNETOS DE Nd-Fe-B}

Os magnetos de $\mathrm{Nd}-\mathrm{Fe}-\mathrm{B}$ desempenham um papel de destaque na tecnologia moderna, pois encontram aplicações em um grande número de produtos e processos industriais nos mais variados setores ${ }^{7}, \mathrm{Na}$ área nuclear, os ímãs permanentes à base de terras raras-metais de transição-boro (TR-Fe-B) são,utilizados na fabricação de suportes magnéticos (levitação magnética) para ultra-centrífugas, utilizadas no 
enriquecimento isotópico do urânio natural, para utilização em reatores nucleares ${ }^{8}$.Estes magnetos também são utilizados em sistemas magnéticos em física nuclear (aceleradores de partículas), giroscópios (fabricação de radares - função estratégica), motores síncronos, geradores e motores elétricos, relógios, sensores, dispositivos eletro-acústicos, instrumentos de medida (galvanômetros e balanças), equipamentos médicos e diversos outros equipamentos científicos. ${ }^{8}$

Como biomateriais, estes magnetos são usados em Odontologia com a finalidade de retenção de próteses totais, próteses parciais removíveis e próteses maxilofaciais $^{2}$.Entre as várias aplicações, estes ímãs também são usados em Ortodontia nas correções de mal-oclusões e em tratamentos de dentes não erupcionados ${ }^{2}$. Na área de prótese maxilo-facial os magnetos têm sido usados por décadas na reconstrução de componentes para próteses usadas no caso de grandes defeitos de face. Os magnetos também podem ser aplicados em raízes de dentes com finalidade protética, em base de dentaduras, em ambos os casos para ajudar na fixação.

\subsection{MEDIDAS DE PROTEÇÃO CONTRA A CORROSÃO}

\subsubsection{TRATAMENTOS POR FOSFATIZAÇÃO}

A fosfatização é um processo de proteção de metais,que consiste em recobrir as peças

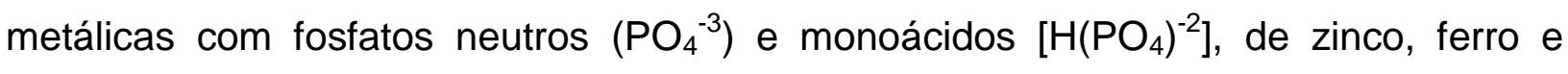
manganês. Como os fosfatos desses elementos são pouco solúveis em água, depositam-se sobre a superfície metálica em contato com soluções e fosfatos, sob a forma de fina camada de cristais. A velocidade de deposição, o retículo e a forma do revestimento dependem da germinação e crescimento dos cristais ${ }^{37}$. Fosfatização é um processo de proteção utilizado principalmente em metais ferrosos e também para o alumínio para melhorar sua resistência à corrosão. ${ }^{38}$

A proteção anti-corrosiva é a principal finalidade da fosfatização, entretanto, há outras utilizações como melhorar 0 isolamento elétrico de chapas elétricas, melhorar a lubrificação para aumentar a conformabilidade de chapas metálicas ou ainda melhorar a aderência de tintas ou camadas posteriores tais como epóxi ou tintas. ${ }^{38}$

\subsubsection{TIPOS DE FOSFATOS FORMADOS}

As categorias de superfícies formadas podem ser resumidas nos seguintes tipos: ${ }^{38}$ 
- Fosfatos de Ferro - camada fina, amorfa que não contém quantidades significantes de íons metálicos adicionados à solução.

- Fosfatos de Zinco - camada de espessura média, cristalina, que contém íons divalentes da solução e/ou do material metálico.

- Fosfatos pesados - (fosfatos de manganês): camada pesada, espessura grossa, cristalina e que contém os íons metálicos da solução e ou do substrato.

Os fosfatos de zinco e manganês crescem de forma cristalina com morfologia acicular, lenticular ou pontiaguda, gerando uma camada de fosfato irregular sobre a superfície metálica. Isso permite uma melhor retenção de óleos e graxas, bem como promove melhor aderência para tintas e revestimentos poliméricos. ${ }^{38}$

\subsubsection{TRATAMENTOS COM FOSFATO TRICATIÔNICO}

O banho de fosfato tricatiônico é o mais empregado industrialmente devido à sua maior eficiência na inibição da corrosão de metais ferrosos; contudo, é o de maior custo e o mais oneroso quanto ao tratamento do descarte industrial, devido à presença de metais pesados. ${ }^{53}$

No início, as camadas de fosfato tricatiônico eram obtidas em condições muito onerosas com relação ao consumo de energia, mas o estudo detalhado das reações envolvidas no processo de fosfatização permitiu a diminuição do tempo de imersão, e a obtenção de revestimentos em temperaturas menores, próximas da ambiente. A adequação do processo aconteceu devido à alteração das condições de operação para obtenção dos revestimentos,e, a principal modificação introduzida foi a alteração da composição dos banhos. Alguns aditivos são empregados para acelerar o processo e obter as melhores propriedades dos revestimentos.

Entre os parâmetros do processo que podem ser modificados, são importantes, o emprego de corrente, ${ }^{54,55,56}$ e a adição de aceleradores químicos ${ }^{57}$. Os aceleradores químicos podem ser substâncias oxidantes ou sais de metais mais nobres que o metal a ser fosfatizado. Os aceleradores químicos apresentam primordial importância, principalmente devido ao custo e consumo de energia, pois são menos onerosos.

Os aceleradores apresentam duas funções:

(1) despolarizar a superfície do metal, agindo em particular nas áreas de densidade eletrônica alta (micro-catódicas); 
(2) oxidar os metais dissolvidos na área de ataque micro-anódica, o que causa a precipitação de sais insolúveis de fosfato. ${ }^{13}$

Entre os aceleradores químicos, podem ser citados: o nitrito de sódio ${ }^{61,63}$, os nitratos $^{56,58,60,61,62,63,64,65}$ e os cloratos ${ }^{64,66}$. Além dos aceleradores químicos, outros aditivos podem ser usados para obtenção de propriedades específicas. Entre os aditivos utilizados podem ser citados os íons de cálcio ${ }^{57,66,69}$, íons de manganês ${ }^{63,66,69}$ ácido tartárico ${ }^{60,71}$, íons fluoreto ${ }^{58,59,61,71}$ íons de níquel ${ }^{54,62,63,71,73}$, íons de cobre ${ }^{74}$ e íons de molibdênio ${ }^{59,74}$.

A utilização de aditivos causa um problema devido à geração e descarte de resíduos que são inerentes ao processo de fosfatização. Entre os aditivos citados, o que proporciona maiores problemas é o níquel, pois seu uso torna o controle dos resíduos gerados problemático, visto que este elemento é agressivo ao meio ambiente. Devido aos problemas ambientais gerados a possibilidade de substituição do níquel por outros aditivos, orgânicos ou inorgânicos, tem sido estudada. ${ }^{54} \mathrm{O}$ emprego de aditivos menos agressivos ao meio ambiente pode se tornar uma inovação tecnológica de grande importância para a indústria de tratamento de superfícies metálicas. A potencialidade do uso de nióbio é uma alternativa para substituição do níquel em banhos de fosfatização. O banho de fosfato tricatiônico utilizado neste trabalho é um banho padrão já utilizado por pesquisadores no laboratório de corrosão do IPEN. ${ }^{37,54}$

\subsubsection{ETAPAS E FORMAS DE APLICAÇÃO}

A etapa de fosfatização dura entre 2 e 60 minutos e pode ser realizada por imersão ou spray, à temperatura ambiente ou em temperaturas próximas do ponto de ebulição da água, em soluções de banhos mistos com várias composições e elementos aditivos. Para obtenção de camadas de fosfato através do método de imersão requer-se um tempo mínimo de cinco minutos de imersão da peça na solução de fosfato. Como o tempo é mais longo nesses processos, os cristais são maiores e as camadas mais pesadas. O grande questionamento industrial sobre essa forma de aplicação é referente à agilidade de produção, que nem sempre é possível devido à necessidade de cumprir fielmente os tempos de imersão para garantir a eficiência do tratamento.

Os processos por imersão são mais econômicos, pois se tratam de processos manuais e, por isso, os custos com equipamentos e manutenção são reduzidos. Nesses processos, tem-se um constante cuidado com o lôdo gerado que permanece no tanque 
e pode aderir às peças, portanto, um processo de recirculação do fosfato para um decantador faz-se necessário com retirada constante do lôdo do tanque, evitando também arraste do mesmo nas peças.

As aplicações de camadas de fosfato obtidas por spray não excedem a 90 segundos no estágio de fosfatização, obtendo-se camadas mais finas e densas. Nessas aplicações, obtém-se alta capacidade de produção, melhor limpeza e arraste reduzido, porém exigem alta tecnologia com cabines e bombas para a aplicação e, muitas vezes, o alto custo é o fator que impede a utilização deste tipo de processo industrial. Todavia, essa técnica apresenta várias vantagens que podem justificar sua utilização, entre elas estão: o maior rendimento (maior número de peças fosfatizadas), agilidade de produção e automatização do processo.

Um processo normal de fosfatização é ilustrado na Figura 2 que indica as principais etapas envolvidas. ${ }^{54}$

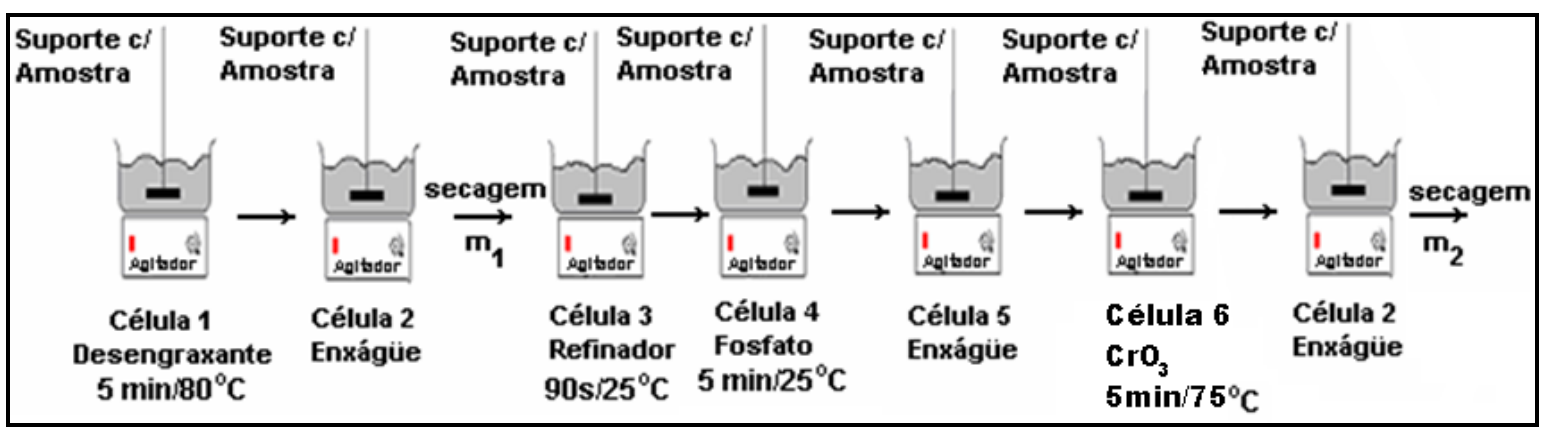

Figura 2 - Etapas envolvidas no processo de fosfatização (E.P. Banczek, 29‥ SBQ). (Figura cedida por E.P. Banczeck).$^{54}$

Os desengraxantes têm como finalidade remover todos os tipos de óleos e graxas das peças e, sem eles, a fosfatização não seria possível. O desengraxante mais usado no tratamento de superfícies é o desengraxante alcalino, não só pelas facilidades que apresenta como também pelo seu baixo custo. A composição e a natureza dos desengraxantes variam de acordo com o tipo de trabalho. Os chamados alcalinos pesados são usados em peças de aço ou ferro fundido, sendo ideais para grandes quantidades de sujeira de natureza severa. Já os alcalinos médios são usados em alumínio, latão e zinco, enquanto os alcalinos leves são totalmente isentos de alcalinidade por hidróxidos, e são indicados para metais e ligas facilmente atacáveis. ${ }^{77}$ 
As camadas de fosfato, apresentam, em geral, granulação grosseira e o refinamento destas pode ser obtido através de soluções coloidais de fosfato de titânio. Estas, aumentam o número de cristais de fosfato e diminuem o tempo de obtenção do revestimento. ${ }^{77,78}$

A fosfatização, propriamente dita, é a etapa que resulta no recobrimento do substrato metálico com fosfatos monoácidos e neutros de zinco, ferro, manganês ou cromo, aumentando a área superficial, o que permite uma boa penetração da tinta, aumentando sua aderência e a resistência da superfície à corrosão. Sendo pouco solúveis em água, os fosfatos depositam-se sobre a superfície metálica em contato com as soluções sob a forma de finas camadas de cristais.

Muitos processos de fosfatização empregam uma etapa de proteção final, que é um processo que tem como finalidade a selagem, ou seja, passivação da camada de fosfato. É um complemento e ao mesmo tempo um nivelamento dos cristais da camada de fosfato. A passivação deveria aumentar a resistência à corrosão das peças tratadas. Geralmente, a passivação é efetuada pela imersão das peças fosfatizadas em um banho de trióxido de cromo $\left(\mathrm{CrO}_{3}\right)$. No entanto, é necessário encontrar alternativas ambientalmente aceitas para o processo de passivação com trióxido de cromo, visto este produzir resíduos/descartes tóxicos.

\subsubsection{MOLÉCULAS AUTO-ORGANIZÁVEIS - SAM}

As moléculas auto-organizáveis modificam as propriedades superficiais e, consequentemente, a resistência à corrosão do metal em meios agressivos. Este tipo de revestimento pode ser aplicado em meios aquosos ou não aquosos e estas permanecem na superfície mesmo após a remoção do substrato do meio.

Monocamadas auto-organizáveis (Self - assembly monolayers - SAM) podem ser uma alternativa interessante para a proteção contra a corrosão em magnetos de $\mathrm{Nd}-\mathrm{Fe}-\mathrm{B}$. Estas moléculas, mesmo quando presentes em pequenas concentrações, conseguem modificar consideravelmente as propriedades superficiais de um material ${ }^{39}$. O estudo destas moléculas encontra-se no campo da nanotecnologia e desperta interesse em áreas tão diversas como biosensores, equipamentos eletro-ópticos, além da própria proteção frente à corrosão ${ }^{40,41}$.

Moléculas formadoras de filmes auto-organizáveis são de baixa solubilidade em fase aquosa. Estas moléculas são usualmente representadas em uma configuração cabeça- 
cauda, com a primeira sendo um grupo polar hidrofílico, e o segundo, geralmente, um radical alcano com cadeia longa, o qual é hidrofóbico. No mecanismo de ação das mesmas na proteção contra a corrosão, a parte hidrofílica da molécula irá interagir com a superfície metálica, enquanto a parte hidrofóbica irá se organizar em uma estrutura compacta vertical à superfície, devido às interações de natureza de força de Van der Waals entre as cadeias carbônicas de moléculas vizinhas. A presença de uma cadeia hidrofóbica organizada, aderida à superfície do metal, afasta as moléculas de água que transportam as espécies agressivas até a interface, acarretando a diminuição da corrosão interfacial.

A adsorção e subsequente organização das moléculas sobre a superfície metálica podem ocorrer pela simples imersão do material metálico em uma solução aquosa de baixa concentração da molécula de tensoativo escolhido, o que pode acontecer em um intervalo de tempo relativamente curto ${ }^{42}$. O processo de ordenação é favorecido para moléculas com cadeias orgânicas longas, devido à maior interação entre cadeias vizinhas ${ }^{43}$, e também a menor solubilidade das mesmas na solução aquosa.

Uma das grandes vantagens da utilização de moléculas com propriedades de autoorganização para a modificação de propriedades interfaciais dos metais é a possibilidade de sintetizar moléculas com grupos terminais que atendam a aplicações específicas ${ }^{44}$. Desta maneira, obtêm-se moléculas bifuncionais onde uma das extremidades irá interagir com a superfície metálica, enquanto que a outra extremidade irá cumprir outra função específica na aplicação em questão, o que aumenta de maneira considerável as possibilidades de aplicação destas moléculas em engenharia. Como exemplo, cita-se a possibilidade de sintetização de uma molécula onde um dos grupos terminais é constituído por um derivado fluorado, facilitando o escoamento de fluidos pela superfície do ímã, ou então, a substituição na extremidade hidrofóbica da molécula, de radicais que possuam afinidade com revestimentos orgânicos, fazendo com que a camada adsorvida atue como promotora de adesão entre substrato metálico e revestimento.

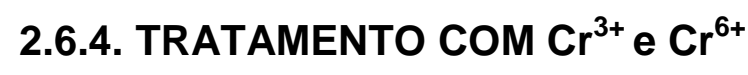

As camadas de conversão são formadas pela reação química entre o metal e uma solução com composição específica. Isto ocorre sem o auxílio de corrente elétrica, 
sendo observadas apenas determinadas características de temperatura, concentração e outras para que a reação ocorra.

A camada de conversão constituída por cromatos é produzida pelo tratamento químico da superfície metálica que produz uma película gelatinosa contendo um complexo do metal contendo cromo. A formação da película ocorre por reação química entre a superfície do metal,ativadores, catalisadores e cromo trivalente ou hexavalente. O processo é uma reação de oxi-redução, onde o metal é oxidado à sua valência normal $(2+$ ou $3+)$ e o cromo hexavalente é reduzido ao estado trivalente.

A reação interfacial pode ser sintetizada como se segue:

Metal $+\mathrm{Cr}^{6+}=>$ Metal $_{x}{ }^{\mathrm{y}+}\left(\mathrm{CrO}_{4}\right)_{\mathrm{y}}{ }^{\mathrm{x}-}+\mathrm{Cr}(\mathrm{OH})_{3}$

A película de cromato resultante adere ao metal formando uma barreira protetora contra corrosão. O grau de proteção conferido pela camada é aumentado pelo teor de cromato na película e também da espessura do depósito ${ }^{46}$. Este tipo de camada de conversão também pode ser aplicado sobre outros metais como o aço galvanizado e depósitos de cádmio.

Uma das vantagens de se usar camadas de conversão de cromo como protetor contra corrosão é sua capacidade de auto-regeneração. Na literatura, esta capacidade de auto-regeneração deve-se à presença de íons $\mathrm{Cr}^{6+}$ dissolvidos na camada de conversão, que seriam lixiviados para as regiões danificadas transformando-se em cromo trivalente. ${ }^{47,48}$

O $\mathrm{Cr}$ elementar e o $\mathrm{Cr}^{3+}$ são levemente tóxicos para o organismo humano sendo inclusive o $\mathrm{Cr}^{3+}$ responsável pelo metabolismo da glicose e do colesterol dependendo da concentração, onde baixos teores fazem parte da dieta ${ }^{48}$. Já o $\mathrm{Cr}^{6+}$ pode exercer efeitos tóxicos sobre os tecidos humanos. Estes efeitos tóxicos já eram conhecidos, contudo, recentemente foram confirmadas suas características carcinogênicas. Estes íons são perigosos quando em contato com a pele e quando são inalados sob a forma de pó, o que os torna um perigo no que se diz respeito à doença ocupacional ${ }^{49}$. Os efeitos tóxicos mais conhecidos do $\mathrm{Cr}^{6+}$ são: úlceras sobre a pele e mucosas, reações alérgicas e asmáticas, bem como o câncer de pulmão quando ocorre inalação da poeira contendo íons $\mathrm{Cr}^{6+}$. ${ }^{8}$ 
Outros problemas relacionados ao $\mathrm{Cr}^{6+}$ o seu transporte e armazenagem, constituindo assim riscos para o meio ambiente, podendo levar à problemas de poluição. Apesar disso, este tipo de revestimento ainda é bastante utilizado principalmente em ligas de Al para uso em aviação. ${ }^{49}$

Nos dias atuais, devido a pressões de organismos internacionais de saúde pública e ambientais, o tratamento com cromo hexavalente tem sido cada vez menos tolerado. $\mathrm{Na}$ Europa, desde 2007, o cromo não pode mais ser utilizado em tratamentos superficiais. $^{49}$

\subsubsection{TRATAMENTOS À BASE DE CÉRIO}

Atualmente, devido às restrições do uso do cromo trivalente e hexavalente, os tratamentos de conversão à base de Cério vêm sendo utilizados como uma alternativa ambientalmente aceitável ${ }^{50}$. As camadas de conversão com Cério começaram a ser investigadas por Hinton ${ }^{51}$ em meados dos anos oitenta, em trabalhos com a finalidade de proteger ligas de Al contra corrosão, sendo estas pesquisas realizadas na Divisão de Materiais dos Laboratórios de Pesquisas Aeronáuticas na Austrália.

Nestes experimentos, as ligas de Al foram imersas em soluções com pequenas quantidades de $\mathrm{CeCl}_{3}$, onde era formada então uma camada protetora sobre a superfície da liga que diminuía a velocidade de corrosão quando a mesma era imersa numa solução de $\mathrm{NaCl} \quad 0,1 \mathrm{M}^{51}$. Sugeria-se que a camada seria formada pela precipitação de um óxido de composição complexa, devido ao aumento local do $\mathrm{pH}$ provocado pela ocorrência de reações catódicas de redução do $\mathrm{O}_{2}$, ou do $\mathrm{H}^{+}$. Em 1988, estes mesmos autores publicaram que esta camada precipitada diminuía a intensidade do processo corrosivo principalmente devido à supressão da reação catódica do $\mathrm{O}_{2}$, bloqueando o acesso dessas espécies à superfície do metal ou, então, impedindo a troca de elétrons na superfície da liga. No início das investigações, a produção destas camadas de conversão de Cério, tinham o inconveniente de necessitar de um tempo excessivo (por volta de 100 horas), para formar a camada protetora, quando não era aplicada uma corrente externa, i.e, sem aplicação de corrente catódica, fazendo então que este método de proteção fosse inviável comercialmente.Em 1988 Hinton $^{51}$ e seus colaboradores solucionaram este problema adicionando $\mathrm{H}_{2} \mathrm{O}_{2}$ a este banho de conversão pois o agente oxidante provoca a oxidação da maioria dos íons $\mathrm{Ce}^{3+} \mathrm{a} \mathrm{Ce}^{4+}$ 
reduzindo o tempo de tratamento para alguns minutos, sendo obedecidas algumas condições, como $\mathrm{pH}$ acima de $2,5^{51}$

Arnot ${ }^{52}$, a partir dos trabalhos de Hinton ${ }^{51}$, verificou que uma adição de 1000 ppm de cloretos de terras raras uma solução de $\mathrm{NaCl} 0,1 \mathrm{M}$ provocava a diminuição de corrosão da liga de Al 7075-T6.

A partir daí, aumentou-se então o interesse em relação à melhoria das características das camadas de conversão à base de Cério uma vez que estas poderiam vir a substituir as camadas de conversão de cromo trivalente e hexalente.

\subsubsection{TRATAMENTOS COM SILANO}

Atualmente, como alternativa à cromatização e fosfatização em pré- tratamentos, os silanos vêm sendo analisados pois os mesmos são menos agressivos ao meio ambiente, requerem menos etapas no processo de pré- tratamento, e também, apresentam um custo baixo quando comparados a outros revestimentos citados anteriormente.Vários estudos mostram os silanos como pré-tratamento em metais, sendo muitos deles relacionados à proteção de $\mathrm{Al}^{79}$.

Os silanos foram citados como alternativa ao tratamento com óleos protetivos contra a corrosão, para melhorar a aderência em diversas aplicações, mostrando eficiência e promovendo a ancoragem em um grande número de substratos como metais e plásticos.Os trabalhos recentes têm proposto o uso de uma gama de organossilanos como métodos protetores contra a corrosão de diferentes substratos metálicos. Resultados positivos foram obtidos sobre o $\mathrm{Al}$ e suas ligas ${ }^{80}$, cobre $^{81}$, ferro e aço ${ }^{82}$, zinco $^{83}$ e até mesmo em ligas de magnésio ${ }^{84}$. Entre estes, o alumínio e o ferro são os metais mais estudados. Uma melhoria na proteção contra corrosão foi alcançada quando foi utilizado tratamento com silano seguido de tratamento por fosfatização. ${ }^{100}$

Os estudos direcionados à proteção de metais utilizando silanos indicam que os mesmos protegem eficientemente um metal contra diferentes formas de corrosão: (a) um filme de silano pode proteger um metal da corrosão atmosférica por 6 meses a 1 ano; e (b) silanos também podem ser usados como pré-tratamento superficial de metais antes da pintura, já que as ligações Me-O-Si e Si-O-Si são as responsáveis pela excelente ligação entre o filme e o substrato e pela proteção barreira conferida pelo filme ${ }^{85}$. Além do mais, como são também compostos orgânicos, conferem hidrofobicidade à superfície. 
Os silanos utilizados na proteção contra corrosão em metais são classificados em duas categorias, de acordo com estrutura química em: monossilanos e bissilanos sendo que a diferença entre eles é o número de grupos hidrolisáveis OR presentes na molécula e, obviamente, o número de grupos hidrolisáveis presentes em um bissilano é o dobro de um monossilano.

Os monossilanos e bissilanos podem ser divididos em funcionais e não-funcionais. Os mesmos, podem ser denominados funcionais quando há a presença de um grupo funcional R' na molécula e não funcionais, quando não há um grupo funcional presente na cadeia molecular.

Os silanos podem ser descritos como compostos de estrutura química do tipo R' $\mathrm{Si}(\mathrm{R})_{3}$ onde $\mathrm{R}$ ' é normalmente uma cadeia curta de carbonos, que pode conter alguma funcionalidade química capaz de reagir com uma resina da película de pintura, e R é o grupo final hidrolisável tal como um etóxi, metóxi ou cloro. Este grupo $\mathrm{R}$, na presença de água, e em condições de pH favoráveis, sofre hidrólise (a ligação Si-O e Si-Cl são relativamente fracas) dando origem a grupos terminais $\mathrm{OH}$.

O conjunto Si-OH é denominado de silanol. Quando o substrato metálico é imerso na solução contendo o silano hidrolisado estes grupos se ligam às hidroxilas da superfície por ligações de pontes de hidrogênio. Durante a etapa de cura do revestimento de silano, estas ligações sofrem condensação dando origem a ligações covalentes (Me-O$\mathrm{Si})$. Grupos silanóis ( $\mathrm{Si}-\mathrm{OH}$ ) também condensam entre si dando origem às ligações siloxano (Si-O-Si). Estas ligações conferem estabilidade e propriedades barreira à camada de silano.

Quando funcionalizado R' pode reagir com a resina da película de pintura formando ligações covalentes silanos/resina, além das ligações Metal-Si e são estas ligações as responsáveis pela excelente qualidade da aderência nestes tipos de sistemas.

O filme de silano pode ser obtido por pincel, spray, eletrodeposição ou imersão sendo o último o mais comum nos estudos sobre silanos. Os filmes são obtidos pela imersão do metal na solução de silano diluída e hidrolisada seguida pela etapa de cura.

Cada silano comporta-se de maneira diferente com um determinado tipo de metal, assim, não existe como prever o melhor e tudo dependerá da melhor relação encontrada experimentalmente para cada um.

Então, a combinação metal/silano não pode ser determinada, pois há varias razões para isso ${ }^{92}$ : 
$\checkmark \quad$ Óxidos metálicos apresentam alta energia de superfície e contêm hidroxilas reativas e neste caso os silanos podem ser adsorvidos de forma invertida, isto é, com o grupo funcional adsorvido pela hidroxila do metal não permitindo um bom desempenho na proteção contra corrosão bem como impossibilitando uma possível reação da camada polimérica (tinta) com o grupo funcional e geralmente os grupos funcionais formam somente ligações de hidrogênio, tendo, portanto, grande afinidade com a água. ${ }^{93}$

$\checkmark \quad$ As hidroxilas do metal são normalmente básicas e os grupos silanol são ácidos. A basicidade varia entre os metais e a acidez do grupo silanol depende do grupo funcional orgânico R' presente na molécula do silano.Por isso, nem todas a combinações metal/silano reagem formando ligações estáveis. ${ }^{93}$

$\checkmark$ Durante a hidrólise, as moléculas de silano podem sofrer reações de condensação, resultando em polimerização e eventual precipitação. Muitos silanos, em pH 4 hidrolisam rapidamente e condensam lentamente por isso são necessários conhecimentos sobre a velocidade das reações de hidrólise e condensação. $\mathrm{Em} \mathrm{pH}$ alto, ambas a $\mathrm{s}$ reações ocorrem rapidamente, não formando filmes de boa qualidade. ${ }^{93}$

Estudos realizados por Franquet ${ }^{79}$ usando a espectroscopia elipsométrica mostram que a espessura do filme de silano BTSE em alumínio não é uniforme e que a falta de homogeneidade é influenciada pela concentração da solução de silano utilizada e não pelo processo de cura e as concentrações baixas de silano além de proporcionarem a heterogeneidade do filme, também afetam a reprodutibilidade dos resultados de caracterização da camada.

\subsection{ASPECTOS FÍSICOS DOS MATERIAIS MAGNÉTICOS}

As propriedades magnéticas macroscópicas dos materiais são consequência dos momentos magnéticos que estão associados a elétrons individuais. Cada elétron em um átomo possui momentos magnéticos que têm sua origem a partir de duas fontes: uma está relacionada ao seu movimento orbital ao redor do núcleo e outra tem origem na rotação do elétron em torno do seu eixo. Desta forma, cada elétron em um átomo pode ser considerado como se fosse um pequeno ímã que possui momentos magnéticos permanentes orbitais e de spin. $^{3}$ 
O mecanismo da coercividade é determinado tanto pelo processo de fabricação como pelo material usado na preparação do magneto permanente e está intimamente relacionado com a movimentação das paredes do domínio. Definem-se domínios às regiões de volume de um material ferromagnético ou ferrimagnético em que todos os momentos magnéticos atômicos ou iônicos estão alinhados na mesma direção. ${ }^{3}$

Os materiais magnéticos são classificados nas seguintes categorias: diamagnéticos, paramagnéticos, ferromagnéticos, ferrimagnéticos, e antiferrimagnéticos. ${ }^{94}$

Diamagnetismo é uma forma fraca e não permanente de magnetismo. É característico de materiais que se alinham em um campo magnético não uniforme, e que parcialmente expelem de seu interior o campo magnético, no qual eles estão localizados. $^{94}$

Paramagnetismo é um tipo de magnetismo característico de materiais fracamente atraídos por ímã ${ }^{94}$. Por sua vez ferromagnetismo é um processo físico no qual certos materiais eletricamente descarregados atraem fortemente outros materiais ${ }^{94}$.

Ferrimagnetismo é o tipo de magnetismo permanente que ocorre em sólidos nos quais os campos magnéticos associados com átomos individuais se alinham espontaneamente, alguns de forma paralela, ou na mesma direção (como no ferromagnetismo), e outros geralmente antiparalelos, ou emparelhados em direções opostas (como no antiferromagnetismo). ${ }^{94}$

Em substâncias conhecidas como antiferromagnéticas, as forças mútuas entre pares de dipolos atômicos adjacentes são causadas por interações de troca, mas essas forças têm sinal diferente dos dipolos em materiais ferromagnéticos. Como resultado, os dipolos adjacentes tendem a se alinhar de forma antiparalela. ${ }^{94}$

O magneto utilizado neste estudo é ferromagnético. 


\section{OBJETIVOS}

Os objetivos deste estudo foram avaliar o comportamento de corrosão dos magnetos de Nd-Fe-B e avaliar a proteção contra a corrosão provida por diversos tratamentos superficiais, especificamente os obtidos por cromatização, de Silano (BTSE), fosfatização, camada de conversão de cério e SAM. Os estudos foram realizados em uma solução salina tamponada com fosfato (PBS - Phosphate buffered solution) para simular um meio fisiológico. 


\section{MATERIAIS E MÉTODOS}

\subsection{CARACTERIZAÇÃO QUÍMICA DO MAGNETO DE Nd-Fe-B}

O magneto utilizado neste experimento foi o ímã comercial $\mathrm{Nd}-\mathrm{Fe}-\mathrm{B}$, fornecido pela Crucible Metals Co. (U.S.A), e sua composição química, obtida por fluorescência de raios-X e absorção atômica, é apresentada na Tabela 1. Os elementos químicos presentes no ímã, $\mathrm{Dy}, \mathrm{Al}, \mathrm{Nb}, \mathrm{Co}, \mathrm{Si}$, e $\mathrm{Cu}$ são adicionados para melhorar as propriedades magnéticas e de resistência à corrosão. Por outro lado $\mathrm{Na}$, Ca e S são provavelmente impurezas.

Tabela 1 - Composição química do magneto de Nd-Fe-B (\% em massa ) usado neste estudo

\begin{tabular}{||c|l|l|l|l|l|l|l|l|l|l|l|l||}
\hline \hline Elemento & $\mathrm{Fe}$ & $\mathrm{Nd}$ & $\mathrm{B}$ & $\mathrm{Dy}$ & $\mathrm{Al}$ & $\mathrm{Co}$ & $\mathrm{Si}$ & $\mathrm{Cu}$ & $\mathrm{Nb}$ & $\mathrm{Na}$ & $\mathrm{Ca}$ & $\mathrm{S}$ \\
\hline$(\%)$ & 50,59 & 28,31 & 1,0 & 2,09 & 3,73 & 1,28 & 1,39 & 0,18 & 0,66 & 0,41 & 0,15 & 0,16 \\
\hline \hline
\end{tabular}

\subsection{PREPARAÇÃO DAS AMOSTRAS DO MAGNETO DE Nd-Fe-B PARA ENSAIOS ELETROQUÍMICOS}

Foram utilizadas amostras como pastilhas cilíndricas, com $12 \mathrm{~mm}$ de diâmetro e $4 \mathrm{~mm}$ de espessura. Estas foram embutidas em resina de cura a frio depois que o contato elétrico havia sido adequadamente estabelecido, deixando uma única face exposta para contato com o meio.

A superfície exposta das amostras foi então lixada com papel de SiC até grana \#1200 e enxaguada com água destilada e álcool antes dos ensaios de corrosão. Todos os ensaios foram conduzidos à temperatura ambiente $\left(25 \mathrm{C}^{\circ} \pm 2\right)$ em solução tamponada de fosfato (PBS), e o ímã foi utilizado no estado desmagnetizado.

\subsection{SOLUÇÃO PARA ENSAIO ELETROQUÍMICO}

A solução salina tamponada com fosfato (PBS- Phosphate buffered saline) é uma solução-tampão comumente utilizada em pesquisas biológicas.

Trata-se de uma solução salina contendo cloreto de sódio, fosfato de sódio, e, em algumas formulações, cloreto de potássio e fosfato de potássio. O tampão ajuda a 
manter o pH constante. A concentração iônica desta solução geralmente coincide com a do corpo humano (isotônica) sendo que por isso, os ensaios utilizados neste trabalho utilizaram esta solução.

Devido ao magneto de $\mathrm{Nd}-\mathrm{Fe}-\mathrm{B}$ ter aplicações como biomaterial em Odontologia, como mencionado anteriormente neste trabalho, optou-se por utilizar esta solução.

Tabela 2. Composição da solução de fosfato tamponada (PBS) usada nos ensaios de corrosão.

\begin{tabular}{|c|c|c|}
\hline $\begin{array}{c}\mathrm{NaCl} \\
\left(\mathrm{g} \cdot \mathrm{L}^{-1}\right)\end{array}$ & $\begin{array}{l}\mathrm{NaH}_{2} \mathrm{PO}_{4} \\
\left(\mathrm{~g} \cdot \mathrm{L}^{-1}\right)\end{array}$ & $\begin{array}{c}\mathrm{KH}_{2} \mathrm{PO}_{4} \\
\left(\mathrm{~g} \cdot \mathrm{L}^{-1}\right)\end{array}$ \\
\hline 8,77 & 1,42 & 2,72 \\
\hline
\end{tabular}

\subsection{MEDIDAS DO POTENCIAL DE CORROSÃO VERSUS TEMPO}

O potencial de corrosão (Ecorr) corresponde ao potencial que um determinado metal assume naturalmente quando está imerso num determinado meio corrosivo. Seu valor depende da natureza dos processos anódicos e catódicos envolvidos e das atividades das espécies envolvidas. $O$ eletrodo de referência empregado nas medidas foi o de $\mathrm{Ag} / \mathrm{AgCl}$.

\subsection{ENSAIOS DE ESPECTROSCOPIA DE IMPEDÂNCIA ELETROQUÍMICA (EIE)}

Os ensaios de espectroscopia de impedância eletroquímica (EIE) foram realizados utilizando um analisador de resposta de freqüência, Solartron ${ }^{\circledR}$ 1260, acoplado uma interface eletroquímica, Solartron® 1287.

Os ensaios foram realizados no potencial de circuito aberto (OCP) num intervalo de freqüência de $10 \mathrm{kHz}$ a $10 \mathrm{mHz}$. A taxa de aquisição foi de 10 pontos por década e a amplitude do sinal $\mathrm{AC}$ foi de $15 \mathrm{mV}$. O OCP foi medido, antes e depois da realização do experimento, para verificar se o requisito de estacionariedade era obedecido.

Para a aquisição dos dados foi utilizada uma célula de três eletrodos com contraeletrodo de platina com grande área superficial e eletrodo de referência de $\mathrm{Ag} / \mathrm{AgCl}$. 


\subsection{CURVAS DE POLARIZAÇÃO POTENCIODINÂMICA}

Curvas de polarização potenciodinâmica anódicas foram obtidas a uma taxa de varredura de $1 \mathrm{mV} \mathrm{s}^{-1}$ utilizando a mesma interface eletroquímica e célula empregada nos experimentos de EIE. As curvas foram obtidas após o término dos ensaios de EIE..

\subsection{MICROSCOPIA ELETRÔNICA DE VARREDURA COM MEDIDAS DE ENERGIA DISPERSIVA DE RAIOS-X (SEM/EDS)}

O equipamento utilizado para realizar as análises SEM/EDS foi um microscópio de Varredura Philips XL-30 equipado com um espectrômetro EDS. A tensão utilizada para realizar as análises de EDS foi $20 \mathrm{keV}$, proporcionando uma profundidade de penetração de aproximadamente $1 \mu \mathrm{m}$. Análises elementares semi-quantitativas foram realizadas utilizando padrões internos do equipamento.

\subsection{TESTE DE CITOTOXICIDADE}

A fim de verificar se o magneto de $\mathrm{Nd}-\mathrm{Fe}-\mathrm{B}$ apresentaria efeito citotóxico, foi realizado o teste de citotoxicidade conforme a norma ISO 10.993 - parte $5{ }^{95}$. Foram utilizadas duas amostras, uma amostra sem tratamento e outra tratada por fosfatização por 24 horas que foi a amostra que apresentou melhor resposta de proteção contra a corrosão dos magnetos avaliados neste estudo.

A avaliação in vitro da biocompatibilidade foi realizada pelo teste de citotoxicidade em cultivo de células de tecido conectivo de camundongos (NCTC Cole 929) da American Type Culture Collection, cultivadas em meio mínimo essencial de Eagle (MEM) à $37^{\circ} \mathrm{C}$, com adição de $10 \%$ do soro fetal bovino, $0,1 \mathrm{mM}$ de aminoácidos não essenciais e 1 $\mathrm{mM}$ de piruvato de sódio. ${ }^{96}$

As amostras foram esterilizadas por autoclavagem a $120^{\circ} \mathrm{C}$ por 20 minutos. Em seguida, foram imersas em MEM, duarante 10 dias a $37^{\circ} \mathrm{C}$, na proporção de $1 \mathrm{~mL} / \mathrm{cm}^{2}$, obtendo-se uma solução de ensaio $100 \%$ de concentração. Foi feita a diluição seriada desta solução para obtenção das concentrações de 50\%, 25\%, 12,5\% e 6,25\% da inicial. Cada concentração foi distribuída em quatro poços de $50 \mu \mathrm{L}$ e cada poço recebeu 250.000 células $/ \mathrm{mL}$ da linhagem Clone 929, permanencendo incubado durante $24 \mathrm{~h}$ sob atomosfera úmida de $5 \%$ de $\mathrm{CO}_{2}$. Após este período, foi adicionada uma solução de corante vermelho neutro a $0,1 \%$. A quantificação do corante foi 
realizada após $3 \mathrm{~h}$ em espectrofotômetro leitor de ELISA (marca Tecan - modelo Sunrise) no comprimento de onda de $540 \mathrm{~nm}$. O corante, que se caracteriza como identificador da viabilidade celular, é incorporado pela população de células e essa incorporação é diretamente proporcional ao número de células viáveis no meio de cultura. A análise colorimétrica permitiu investigar a viabilidade celular. Extratos das amostras, que induzem à toxicidade celular, foram avaliados em várias concentrações. A concentração que produziu redução de $50 \%$ na absorção do corante foi adotada como índice de toxicidade (IC ${ }_{50 \%}$ ). O IC ${ }_{50 \%}$ representa a concentração do extrato que induz $50 \%$ de lise ou morte celular e, como consequência, a inibição da incorporação do vermeho neutro. Foram utilizadas como medida de comparação uma solução de látex de borracha (controle postivo) e uma placa de titânio (controle negativo). O controle negativo é utilizado para comprovar uma resposta apropriada do sistema no teste.

\subsection{TRATAMENTOS SUPERFICIAIS INVESTIGADOS COM O OBJETIVO DE AVALIAR SEUS EFEITOS NA RESISTÊNCIA À CORROSÃO DO MAGNETO}

A fim de melhorar a resistência dos magnetos de $\mathrm{Nd}$ - $\mathrm{Fe}-\mathrm{B}$ contra processos corrosivos foram testados vários tipos de tratamentos. A maioria dos tratamentos testados neste trabalho já havia sido investigada em outros metais, entretanto, não no magneto de $\mathrm{Nd}$ Fe-B.

\subsubsection{TRATAMENTO COM SILANO}

O Tratamento com silano foi realizado em solução de 4\% (em massa) de silano BTSE, $96 \%$ (em massa) de solvente constituído de $50 \%$ de água destilada $+50 \%$ etanol. Foi feito ajuste do $\mathrm{pH}$ para 4 e a solução foi hidrolisada por 30 minutos. As amostras foram imersas por 2 minutos na solução hidrolisada e com pH ajustado. Após a remoção das amostras, a cura foi feita em estufa por 30 minutos a $100^{\circ} \mathrm{C}$, ou por 24 horas à temperatura ambiente.

\subsubsection{TRATAMENTO COM CÉRIO}

A composição da solução de conversão utilizada neste trabalho foi obtida a partir de dados da literatura ${ }^{50}$. A adição de íons Cério, sob a forma de $\mathrm{CeCl}_{3}$, obedeceu aos trabalhos iniciais desenvolvidos por Hinton e colaboradores(1984 e 1988) ${ }^{50}$, assim 
como a adição de $\mathrm{H}_{2} \mathrm{O}_{2}$. A solução de conversão foi acidificada com $\mathrm{H}_{3} \mathrm{BO}_{3}$, de acordo com a maioria dos trabalhos da literatura devido ao seu poder tamponante para manter o pH da solução em 3 e minimizar o ataque corrosivo ao metal. Após a preparação da solução, a mesma foi envelhecida por 24 horas antes da imersão das amostras. As camadas foram obtidas a temperatura ambiente.

Tabela 3 Composição\% em volume do banho de conversão à base de Cério (XINGWEN \& Cols, 2000). ${ }^{98}$

\begin{tabular}{|l|l|l|l|}
\hline $\mathrm{CeCl}_{3}$ & $\mathrm{H}_{2} \mathrm{O}_{2}$ & $\mathrm{H}_{3} \mathrm{BO}_{3}$ & Tempo (min) \\
\hline 2,46 & 0,3 & 0,02 & 10 e 30 \\
\hline
\end{tabular}

\subsubsection{TRATAMENTO COM SAM}

A formação da camada de moléculas auto-organizáveis (SAM) na superfície do magneto de $\mathrm{Nd}-\mathrm{Fe}-\mathrm{B}$ foi realizada por imersão dos eletrodos em solução aquosa de 90 mg. $\mathrm{L}^{-1}$ de alcanodifosfonado [PO $\left.(\mathrm{OH})_{2}-\left(\mathrm{CH}_{2}\right) \mathrm{n}-\mathrm{PO}(\mathrm{OH})_{2}\right]$, (Gardobond $\left.\mathrm{X} 4661\right)$.

As amostras lixadas foram imersas nesta solução durante 5 minutos a uma temperatura de $\left(30^{\circ} \mathrm{C} \pm 2\right)$.

\subsubsection{TRATAMENTO COM CROMO TRIVALENTE E HEXAVALENTE}

As amostras foram revestidas com cromo Hexavalente (SurTec 652) e trivalente (SurTec 650). A concentração utilizada foi $20 \mathrm{~g} \cdot \mathrm{L}^{-1}$ de acordo com o recomendado pelo fabricante (SURTEC, Ltda.). As amostras foram imersas por 3 minutos nas soluções de tratamento, à temperatura de $40^{\circ} \mathrm{C}$.

\subsubsection{TRATAMENTO COM FOSFATO TRICATIÔNICO}

Para o tratamento com fosfato tricatiônico, as amostras lixadas foram inicialmente desengraxadas com uma solução comercial alcalina (metassilicato de sódio). Após preparação da superfície as amostras foram fosfatizadas por imersão no banho de fosfatização. 
A composição base da solução de fosfato concentrada, (Xarope), utilizada para preparar o banho é apresentada na Tabela 4. Foi utilizada a solução padrão já utilizada no laboratório de corrosão por outros pesquisadores ${ }^{54}$.

Tabela 4 . Composição da solução concentrada de fosfato (Xarope).

\begin{tabular}{|c|c|}
\hline \multicolumn{2}{|c|}{ Composição (\% massa) } \\
\hline $\mathrm{H}_{3} \mathrm{PO}_{4}$ & 33 \\
\hline $\mathrm{HNO}_{3}$ & 23 \\
\hline $\mathrm{ZnO}$ & 16 \\
\hline $\mathrm{NiCO}_{3}$ & 0,5 \\
\hline $\mathrm{H}_{2} \mathrm{O}_{2}$ & 0,1 \\
\hline $\mathrm{H}_{2} \mathrm{O}$ & 27,4 \\
\hline
\end{tabular}

A composição do banho de fosfatização foi de $40 \mathrm{~mL}$. do xarope $+20 \mathrm{~mL}$ de $\mathrm{NaOH}+$ $940 \mathrm{~mL}$ de água. A amostra foi imersa neste banho por intervalos de tempo de 30 minutos e 1 hora em temperatura de $(25 \pm 2){ }^{\circ} \mathrm{C}$.

\subsubsection{TRATAMENTO COM FOSFATO TRICATIÔNICO (30 min) E BANHO DE TRIÓXIDO DE CROMO}

No tratamento com fosfato tricationico seguido de banho de trióxido de cromo, as amostras, após terem sido lixadas, foram imersas no fosfato tricatiônico por 30 minutos, que foi a condição que ofereceu melhor resultado na proteção dos magnetos. Posteriormente, foram imersas em um banho de trióxido de cromo $\left(200 \mathrm{mg} \cdot \mathrm{L}^{-1}\right)$, à temperatura de $(35 \pm 2)^{\circ} \mathrm{C}$ por 30 minutos e 1 hora.

\subsubsection{TRATAMENTO COM FOSFATO}

A fosfatização industrial de materiais ferrosos mostrou-se totalmente inadequada para os ímãs de $\mathrm{Nd}-\mathrm{Fe}-\mathrm{B}^{35}$ e em experimentos realizados, verificou-se que as soluções típicas para fosfatação de aços provocavam um ataque acentuado nos magnetos de 
$\mathrm{Nd}-\mathrm{Fe}-\mathrm{B}^{37}$, então, foram testadas composições diferentes para soluções de fosfatação do magneto de Nd-Fe-B.

A solução de fosfatação utilizada neste trabalho continha $10 \mathrm{~g} \cdot \mathrm{L}^{-1}$ de $\mathrm{NaH}_{2} \mathrm{PO}_{4}, \mathrm{pH}=3,8$, em temperatura de $(25 \pm 2){ }^{\circ} \mathrm{C}$. Esta concentração está de acordo com a literatura ${ }^{38} \mathrm{e}$ com o utilizado em trabalhos anteriores,onde já havia sido utilizada uma variação no $\mathrm{pH}$ da solução visando formar uma camada para melhor proteção dos magnetos.

Após lixadas, amostras foram imersas na solução por intervalos de tempo de 1h,4h ,8h e 24h e depois ensaios eletroquímicos foram realizados para verificar a eficácia deste tipo de tratamento.

\subsubsection{TRATAMENTO COM FOSFATO (24h) + SULFATO DE ZINCO}

Visando melhorar a resistência à corrosão foi também investigada a eficiência do tratamento do magneto de Nd-Fe-B utilizando-se fosfato $\left(10 \mathrm{~g} / \mathrm{L}^{-1}\right.$ de $\mathrm{NaH}_{2} \mathrm{PO}_{4}$, $\mathrm{pH}=3,8)$, seguido por imersão em solução de sulfato de zinco, a fim de avaliar se este tratamento resultaria em uma camada superficial mais protetora. A solução utilizada para tratamento posterior à imersão em $10 \mathrm{~g} / \mathrm{L}^{-1}$ de $\mathrm{NaH}_{2} \mathrm{PO}_{4}$ foi uma solução de $\mathrm{ZnSO}_{4}$, de concentração correspondente a $1,8 \times 10^{-2} \mathrm{M} O$ magneto após fosfatizado por 24 horas, foi imerso na solução de sulfato de zinco por 30 minutos à temperatura ambiente $(25 \pm 2)^{\circ} \mathrm{C}$. 


\section{RESULTADOS E DISCUSSÕES}

Neste capítulo serão apresentados e discutidos os resultados da caracterização microestrutural e dos ensaios eletroquímicos para o magneto de $\mathrm{Nd}-\mathrm{Fe}-\mathrm{B}$, sem tratamento, imerso na solução PBS, bem como do substrato revestido com os diversos tratamentos superficiais testados.

Esta parte foi dividida em seções. Na primeira seção serão apresentados os resultados de caracterização microestrutural do magneto de Nd-Fe-B. Esta etapa preliminar foi realizada a fim de identificar as fases presentes, a morfologia das mesmas e relacionar com o comportamento frente à corrosão. $\mathrm{Na}$ segunda parte serão apresentados e discutidos os resultados da caracterização eletroquímica em solução PBS e de caracterização microestrutural após os ensaios. Serão discutidos sequencialmente os resultados das curvas de potencial de corrosão versus tempo, espectroscopia de impedância eletroquímica, polarizações potenciodinâmicas. Posteriormente, também em seções separadas, serão apresentados os resultados dos ensaios com o magneto protegido com os diversos tratamentos, os quais se constituíram de ensaios eletroquímicos e de observações por microscopia eletrônica de varredura. Finalmente os resultados da avaliação da biocompatibilidade/citotoxicidade do magneto serão discutidos visando uma avaliação preliminar de seu emprego como biomaterial.

\subsection{CARACTERIZAÇÃO MICROESTRUTURAL E ELETROQUÍMICA DO MAGNETO EM IMERSÃO EM SOLUÇÃO DE PBS}

\subsubsection{CARACTERIZAÇÃO MICROESTRUTURAL DA AMOSTRA POLIDA}

A microestrutura do magneto foi observada por microscopia eletrônica de varredura (MEV) após lixamento com lixas de carbeto de silício até granulometria 1200. A Figura 3, mostra a micrografia obtida por MEV e o espectro de EDS é mostrado na Figura 4. Os ímãs de Nd-Fe-B apresentam duas fases principais possíveis de serem distinguidas pelos diferentes contrastes, observa-se também a presença de porosidades originadas do processo de fabricação e o destacamento em algumas regiões devido ao lixamento. 


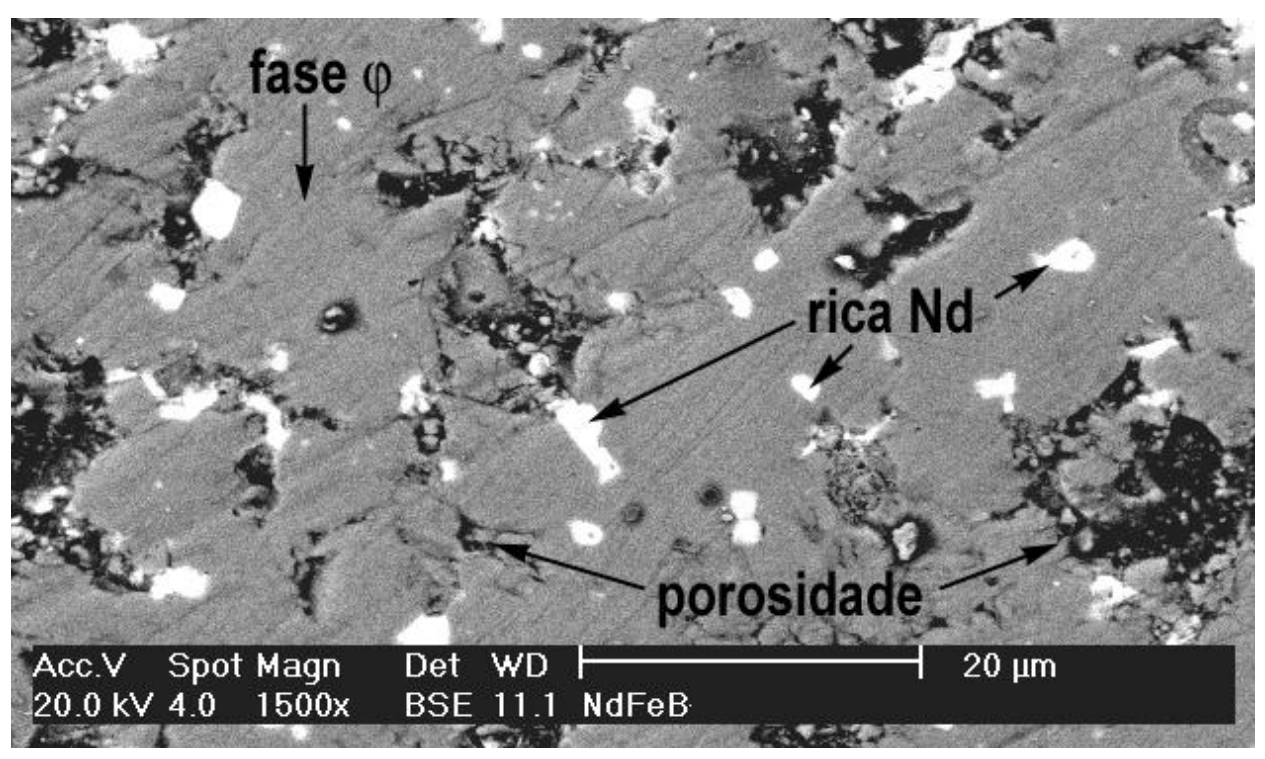

Figura 3 - Micrografia por MEV da superfície do magneto de Nd-Fe-B após lixamento com lixa de SiC até granulometria 1200. (Figura gentilmente cedida pelo Dr Adonis Marcelo SalibaSilva). ${ }^{38}$

Na Figura 3 é possível observar duas fases bem distintas: a área cinza corresponde à fase $\varphi$, $\left(\mathrm{Nd}_{2} \mathrm{Fe}_{14} \mathrm{~B}\right)$ que é a fase magnética do material utilizado. $A$ área branca é a fase rica em $\mathrm{Nd}$. As áreas escuras são porosidades originadas do processo de fabricação e/ou provocadas pelo destacamento do material, provavelmente durante o lixamento.

Cada uma das fases foi analisada por EDS (análise por energia dispersiva) e os resultados semi-quantitativos são mostrados na Tabela 5. A Figura 4 mostra um espectro de EDS da fase rica em $\mathrm{Nd}$.

Tabela 5. Resultados de análise semi-quantitativa por EDS (em porcentagem atômica) do ímã de $\mathrm{Nd}-\mathrm{Fe}-\mathrm{B}$ como recebido, nas regiões de fase rica em $\mathrm{Nd}$ (branca) e fase magnética $(\varphi)$.

\begin{tabular}{|c|l|l|l|}
\hline FASE & ÁREA & Nd & Fe \\
\hline$\varphi$ & Cinza & 12,9 & 81,4 \\
\hline Rica em Nd & Branca & 78,4 & 21,6 \\
\hline
\end{tabular}




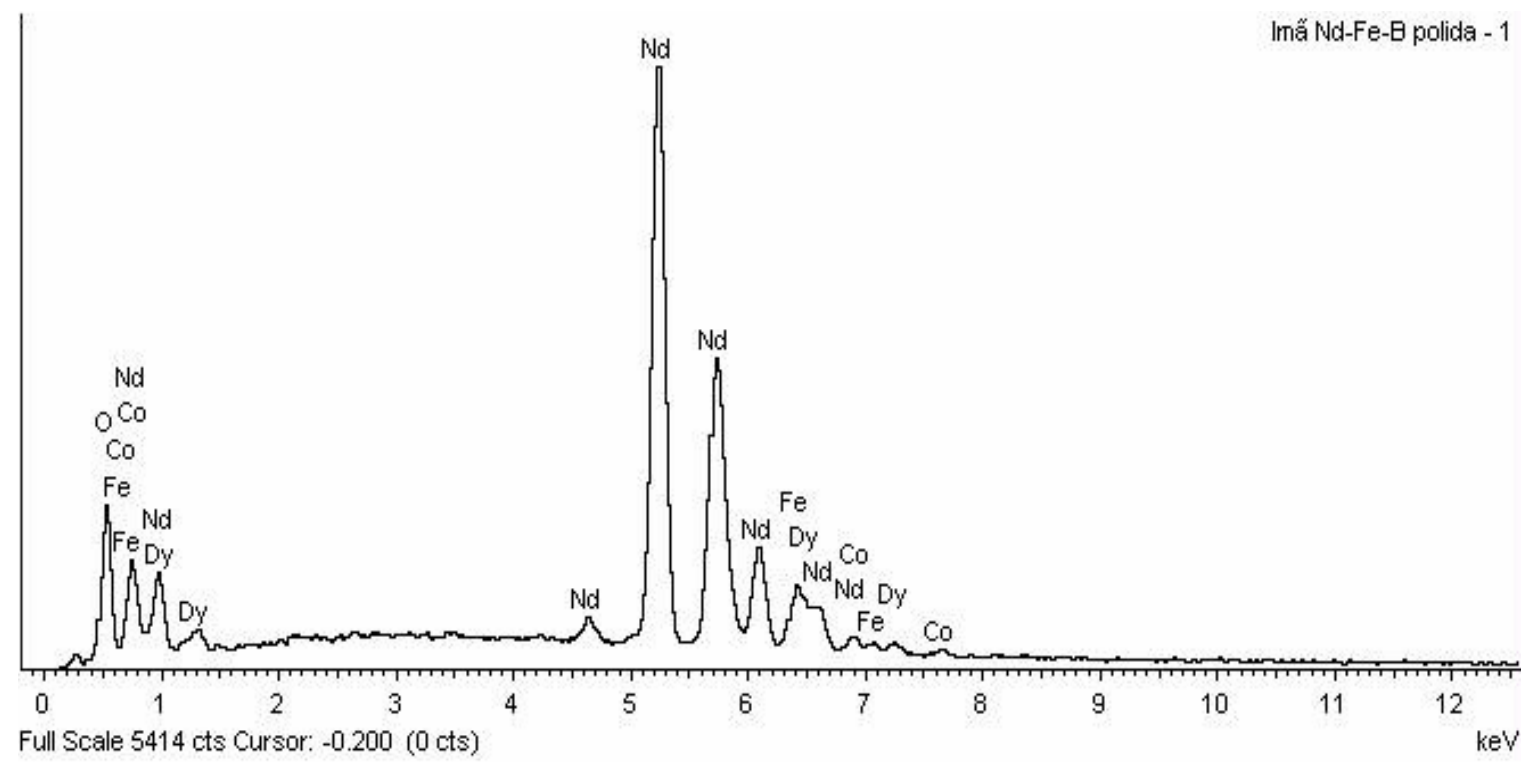

Figura 4 . EDS da área branca (rica em Nd) do magneto de Nd-Fe-B. Amostra lixada com SiC \# 1200.

Os resultados da Tabela 5 comprovam que as áreas cinza constituem a fase $\varphi$, e a composição média nesta região é 12,9 at\% de $\mathrm{Nd}$ e 81,4 at\% de $\mathrm{Fe}$, com composição aproximada de $1(\mathrm{Nd})$ para $7(\mathrm{Fe})$; e para a fase branca é de aproximadamente 78,4 at\% $\mathrm{Nd}$ e 21,6 at\% de $\mathrm{Fe}$, o que corresponde aproximadamente à relação (4 Nd para 1 $\mathrm{Fe})^{34}$.

\subsubsection{CURVAS DE POTENCIAL DE CORROSÃO VERSUS TEMPO}

A variação do potencial de corrosão com o tempo para os magnetos em solução de PBS durante 4 h de imersão é mostrada na Figura 5. O objetivo deste ensaio foi avaliar a estabilidade do potencial antes do início dos ensaios eletroquímicos. 


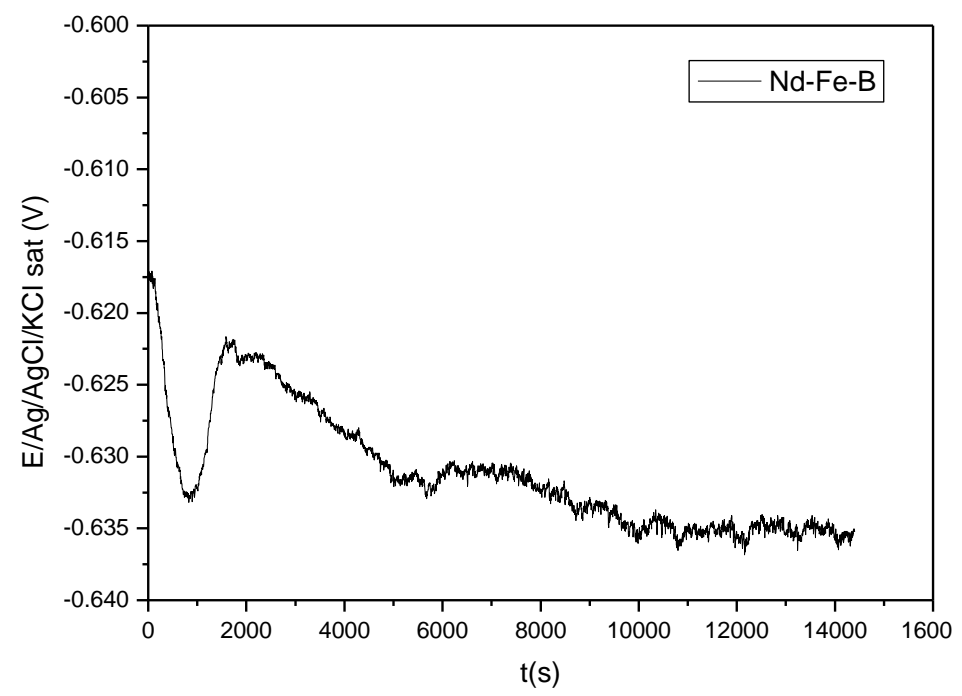

Figura 5 - Variação do potencial de corrosão com o tempo de ensaio para amostra do imã NdFe-B polida (SiC \# 1200) e imersa em solução PBS por 4h.

Nota-se pela Figura 5 que o potencial de corrosão da amostra torna-se estável após um período relativamente curto de imersão (aproximadamente 30 minutos) sendo mantido praticamente inalterado para tempos mais longos de ensaio (até 4 horas). As Figuras 6 e 7 apresentam, respectivamente, micrografias da superfície do magneto antes e depois da imersão por 4 horas no eletrólito teste.

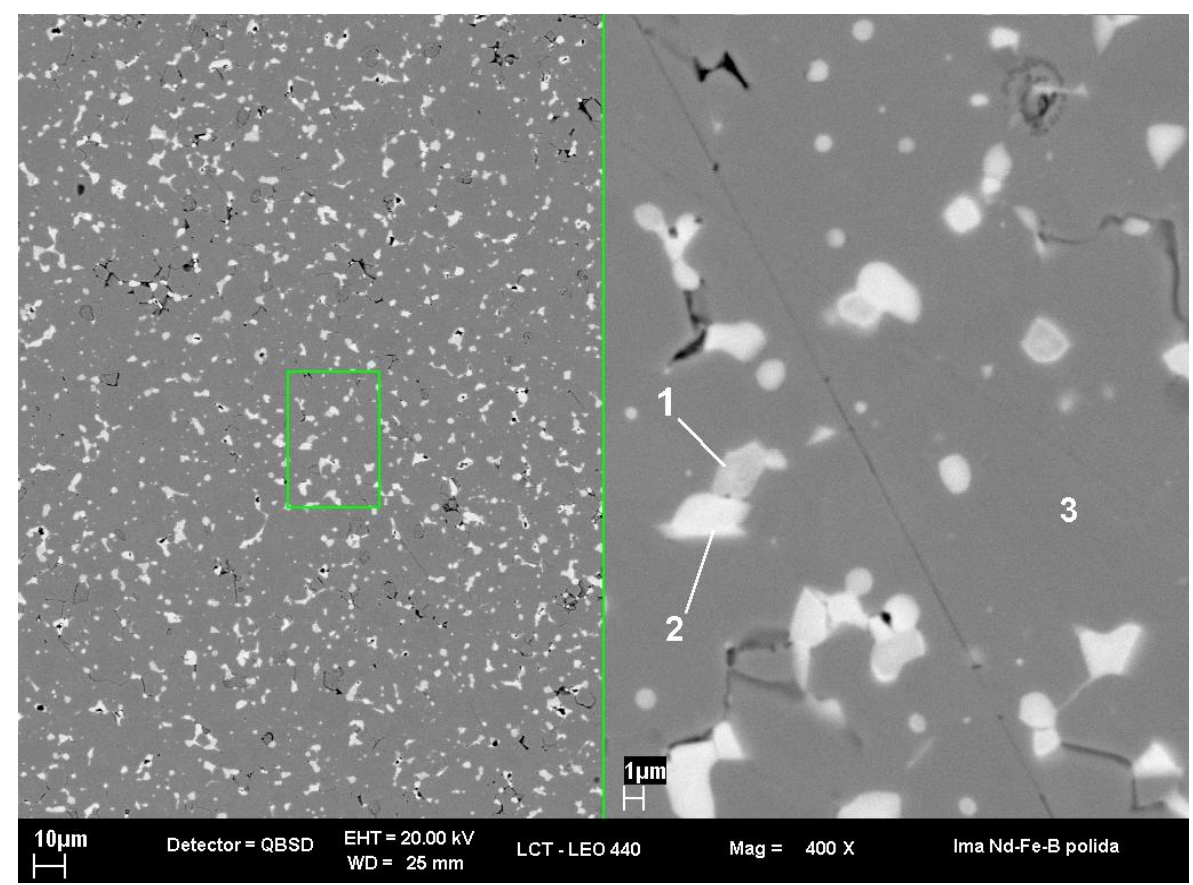

Figura 6 - Micrografia obtida por MEV da amostra polida. Regiões 1 e 2, fases ricas em Nd, e região 3 , fase magnética. 
As imagens de elétrons secundários e retroespalhados da amostra polida e em seguida imersa por 4 horas em solução de PBS, (Figura 7) mostram uma intensa corrosão intergranular, assim como uma dissolução preferencial ao redor das partículas ricas em $\mathrm{Nd}$. Além disso, em algumas regiões da amostra observou-se a ocorrência de ataque mais intenso, provavelmente devido a variações localizadas na composição da solução e que promoveram a continuação e aprofundamento do ataque nestes locais.

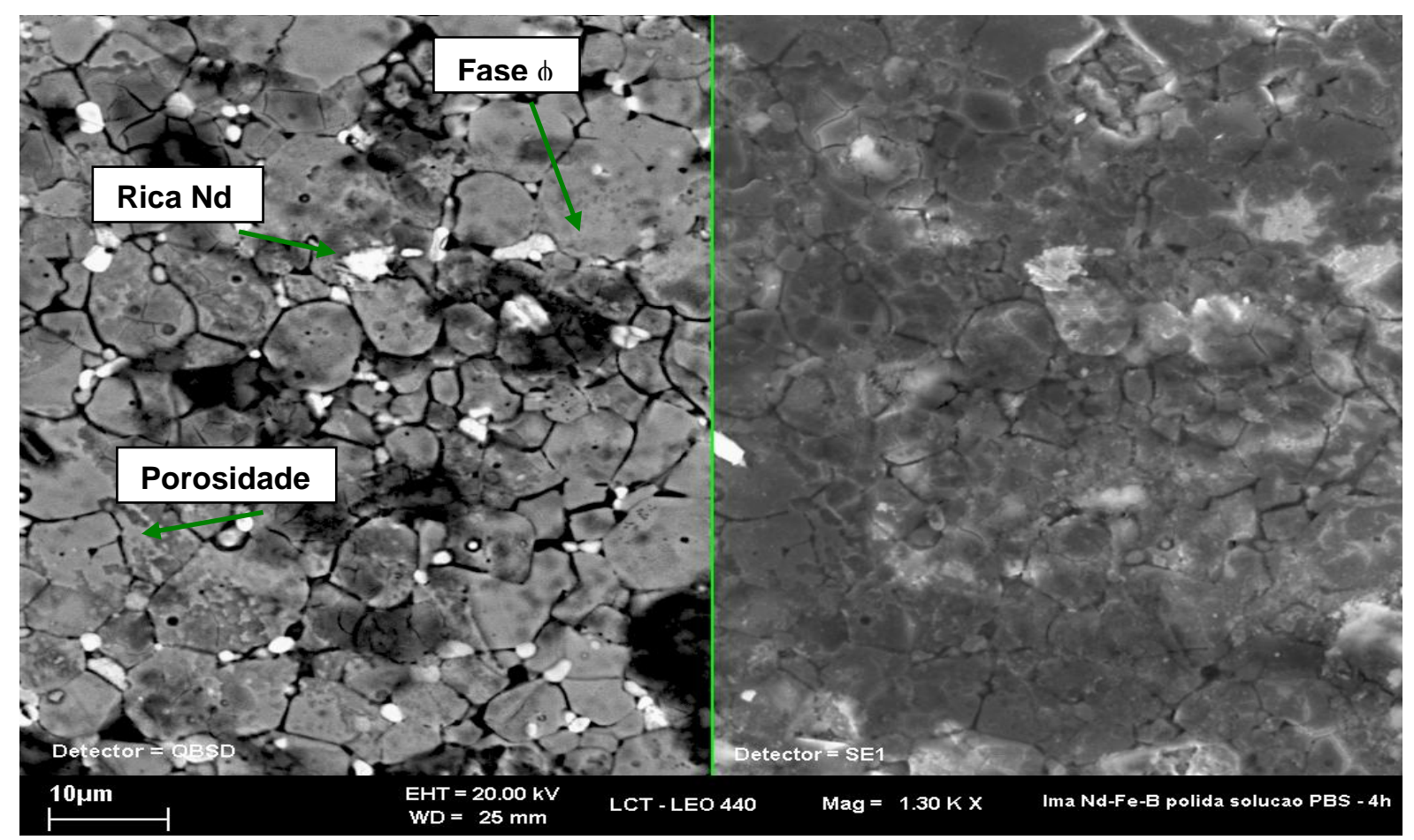

Figura 7 - Micrografias obtidas por MEV da superfície da amostra de Nd-Fe-B imersa por 4 horas em solução de PBS.

Os resultados das medidas de impedância eletroquímica para o magneto de $\mathrm{Nd}-\mathrm{Fe}-\mathrm{B}$ imerso na solução PBS por $30 \mathrm{~min}$, 1h e 4h são apresentados na Figura 8. Os diagramas mostram que nenhuma mudança relevante ocorreu durante o período de imersão. Dois diferentes fenômenos de relaxação podem ser facilmente distinguidos nos diagramas de Nyquist e de ângulo de fase de Bode, sendo que os primeiros são constituídos de dois arcos bastante achatados. 


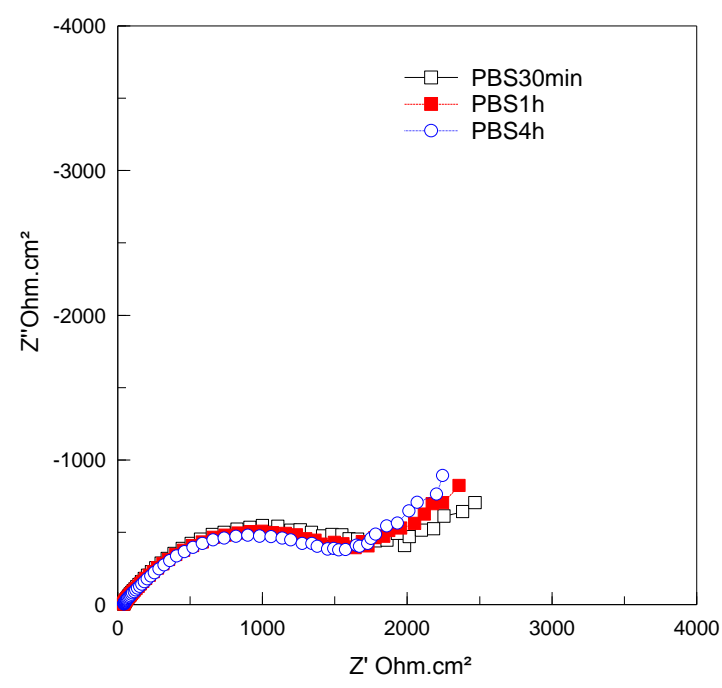

(a)

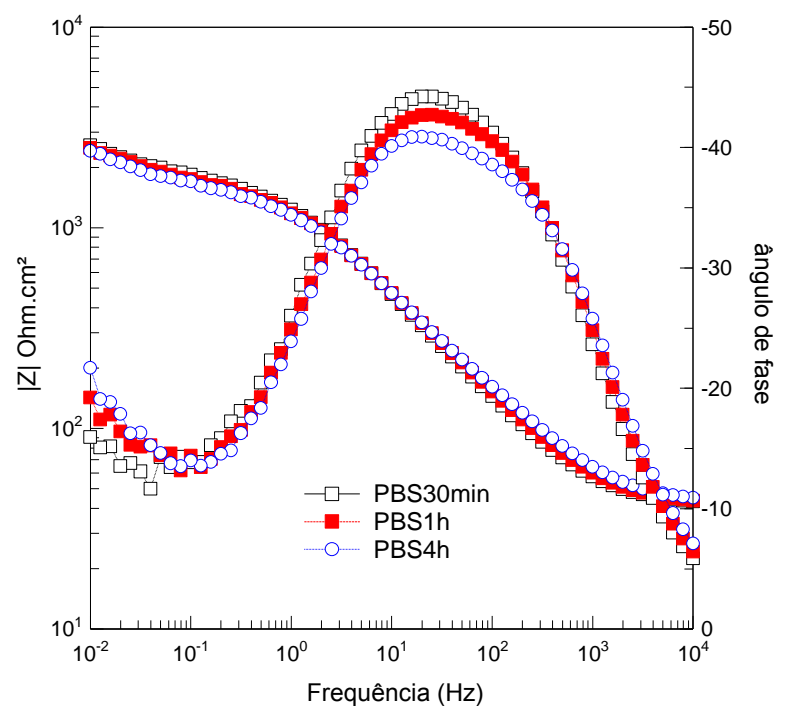

(b)

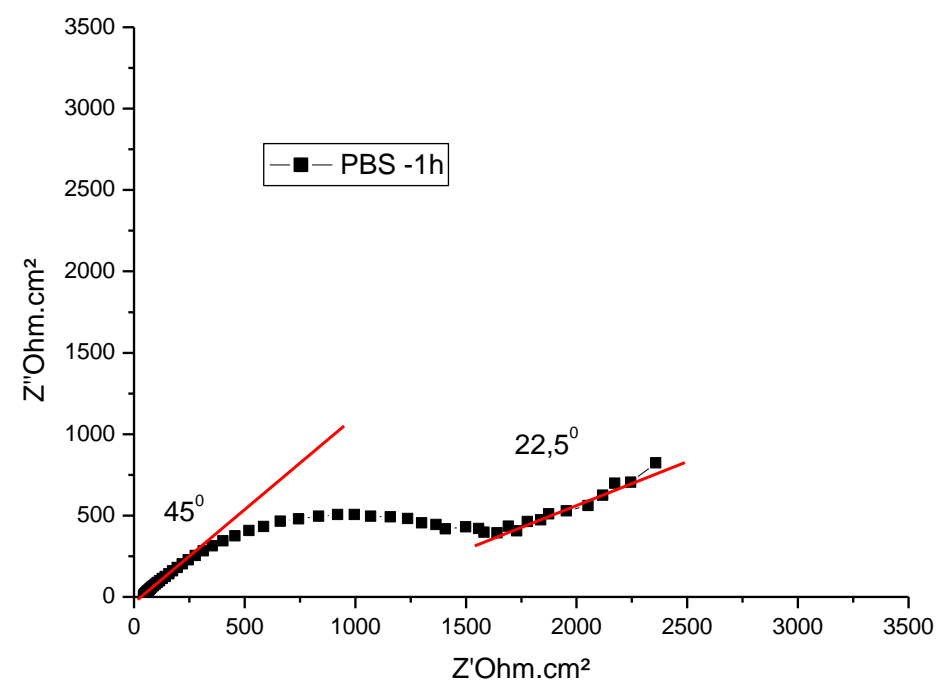

(c)

Figura 8 Diagramas de (a) Nyquist, (b) ângulo de fases e módulo da impedância para o magneto de Nd-Fe-B após 30 min, 1 hora e 4 horas de imersão em solução de PBS e (c) diagrama obtido após uma hora de ensaio evidenciando ângulos entre os arcos capacitivo e o eixo real do diagrama de Nyquist.

A Figura 8 (c) apresenta o diagrama de Nyquist obtido após 1 hora de imersão. $\mathrm{Na}$ mesma verifica-se que o arco capacitivo em altas frequências (AF) apresenta ângulo próximo a 45ำ com relação ao eixo real, e que o arco em baixas frequências apresenta 
um ângulo de 22,5․ Este tipo de resposta está relacionado à porosidade intrínseca do eletrodo, e mostra que o magneto se comporta como um eletrodo poroso com profundidade de poro semi-infinita, de acordo com a teoria de de Levie $^{96}$.

$\mathrm{O}$ arco capacitivo AF na Figura 8 (c) está relacionado às reações de transferência de cargas e carregamento da dupla camada elétrica, que ocorrem nas paredes dos poros, que possuem área geométrica bem superior à superfície plana do magneto. De acordo com demonstração matemática e procedimentos experimentais especiais apresentados por de Levie para verificar o comportamento de impedância de eletrodos porosos $^{96}$, quando as reações eletroquímicas ocorrem no interior dos poros de um eletrodo poroso com profundidade de poros semi-infinita, todos os ângulos de fase são reduzidos à metade com relação à resposta de um eletrodo plano. Assim uma resposta capacitiva relacionada ao carregamento da dupla camada elétrica, que apresenta um ângulo de $90^{\circ}$ em relação ao eixo real em um eletrodo plano, apresenta um ângulo de $45^{\circ}$ em um eletrodo poroso.

Por sua vez, o arco capacitivo BF apresenta um ângulo de 22,5ำ em relação ao eixo real. Segundo de Levie $^{96}$, para eletrodos porosos com profundidade de poro semiinfinita, este tipo de resposta está relacionado à ocorrência de fenômenos controlados por difusão no interior dos poros do eletrodo. Em um eletrodo plano este tipo de resposta apresentaria um ângulo de $45^{\circ}$ com relação ao eixo real, e é conhecida como impedância de Warburg.

A ausência de evolução significativa na resposta de impedância com o aumento do tempo de imersão demonstra uma rápida estabilização do eletrodo na solução teste. Desta maneira o tempo de imersão mais curto (30 minutos) foi utilizado como referência para estudar o comportamento eletroquímico do eletrodo quando imerso na solução de PBS.

\subsection{TRATAMENTO DE PROTEÇÃO COM SILANO}

Com a finalidade de melhorar a resistência à corrosão, o magneto foi primeiramente pré-tratado com Silano BTSE e os resultados de impedância após imersão durante 30 minutos em solução de PBS são apresentados na Figura 9. Como já discutido na revisão de literatura os silanos, que são agentes acopladores, têm sido avaliado com sucesso para a proteção de diferentes metais contra processos corrosivos. Observa-se nos dois diagramas apresentados na Figura 9, que, mesmo na presença do BTSE o 
magneto continua a apresentar o comportamento de eletrodo poroso com comprimento de poro semi-infinito, caracterizado pelo ângulo de fases de $45^{\circ}$ na região AF do diagrama de Nyquist, mostrando que o BTSE não consegue bloquear os poros do substrato. O diagrama de Nyquist é constituído por apenas um arco bastante achatado, e, na região $B F$, o comportamento controlado por difusão não é mais evidenciado. $O$ fato de este arco encontrar o eixo real no limite BF do experimento mostra uma resistência de transferência de cargas bem definida. Isto pode ser consequência do deslocamento dos fenômenos interfaciais para freqüências mais baixas devido à presença da camada de silano, embora a mesma seja imperfeita. Esta hipótese é corroborada pela análise dos diagramas de ângulo de fases onde se nota um deslocamento para frequências mais baixas da constante de tempo principal do diagrama, e um ombro em altas frequências, que pode estar associado à presença da camada de BTSE.
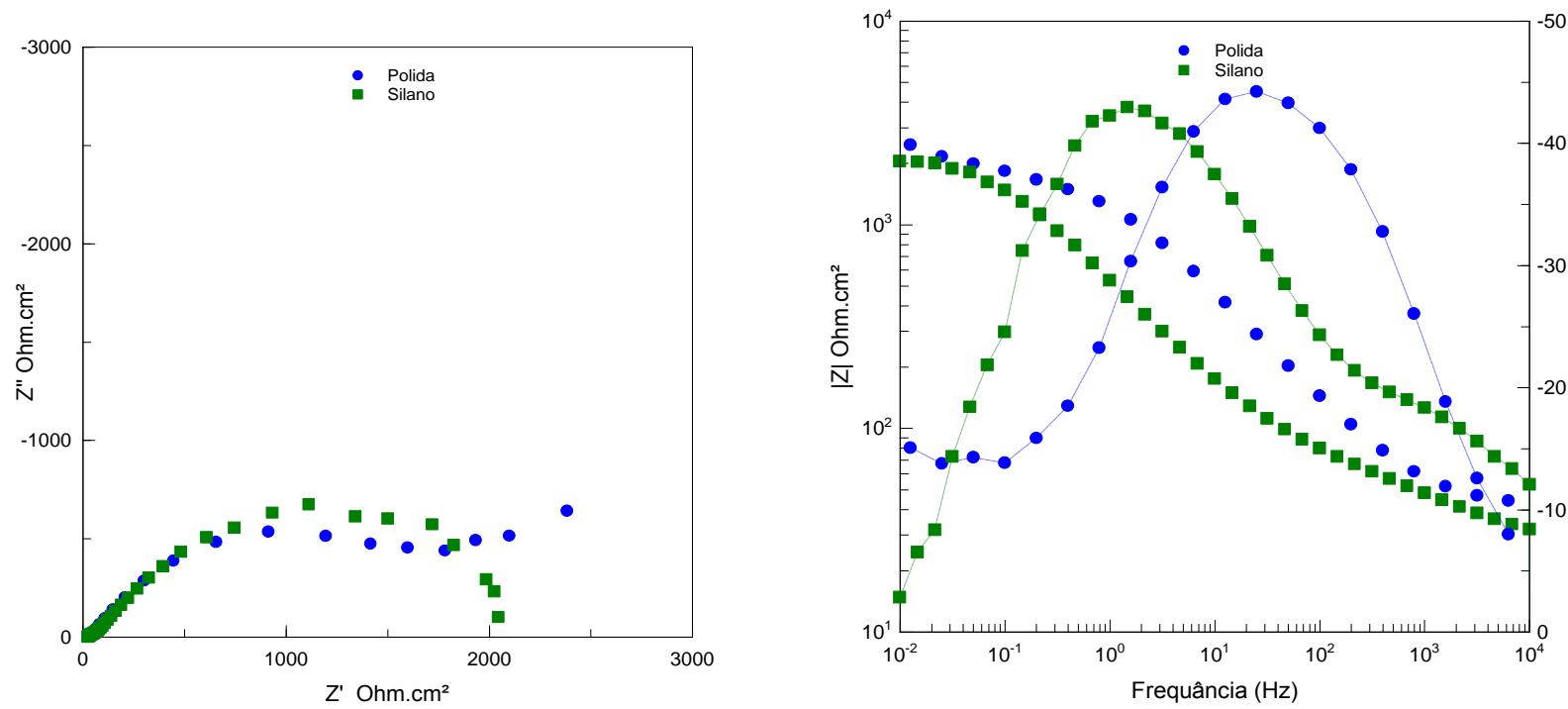

Figura 9- Diagramas de impedância (a) Nyquist (b) ângulo de fase e módulo de impedância das amostras com revestimento de silano e sem revestimento (polida) após 30 minutos de imersão na solução de PBS.

A amostra revestida com silano apresentou valores de impedância muito baixos, praticamente iguais ao da amostra polida. Para esta amostra, o pequeno ombro AF no 
diagrama de Bode indica a formação de uma camada de silano bastante imperfeita e pouco protetora.

A Figura 10 apresenta uma micrografia da superfície do magneto de $\mathrm{Nd}$-Fe-B tratado com BTSE. Pode-se observar através da mesma que o revestimento de silano recobriu heterogeneamente a amostra, deixando áreas cobertas (as áreas escuras) e áreas descobertas, representadas pelas áreas claras. Conclui-se então que o tratamento com silano não foi eficiente, pois não recobriu a totalidade da amostra, o que pode favorecer à corrosão nas áreas não expostas. As diferenças de contraste indicam também diferenças nas espessuras da camada entre as diferentes regiões nas quais a mesma foi formada.

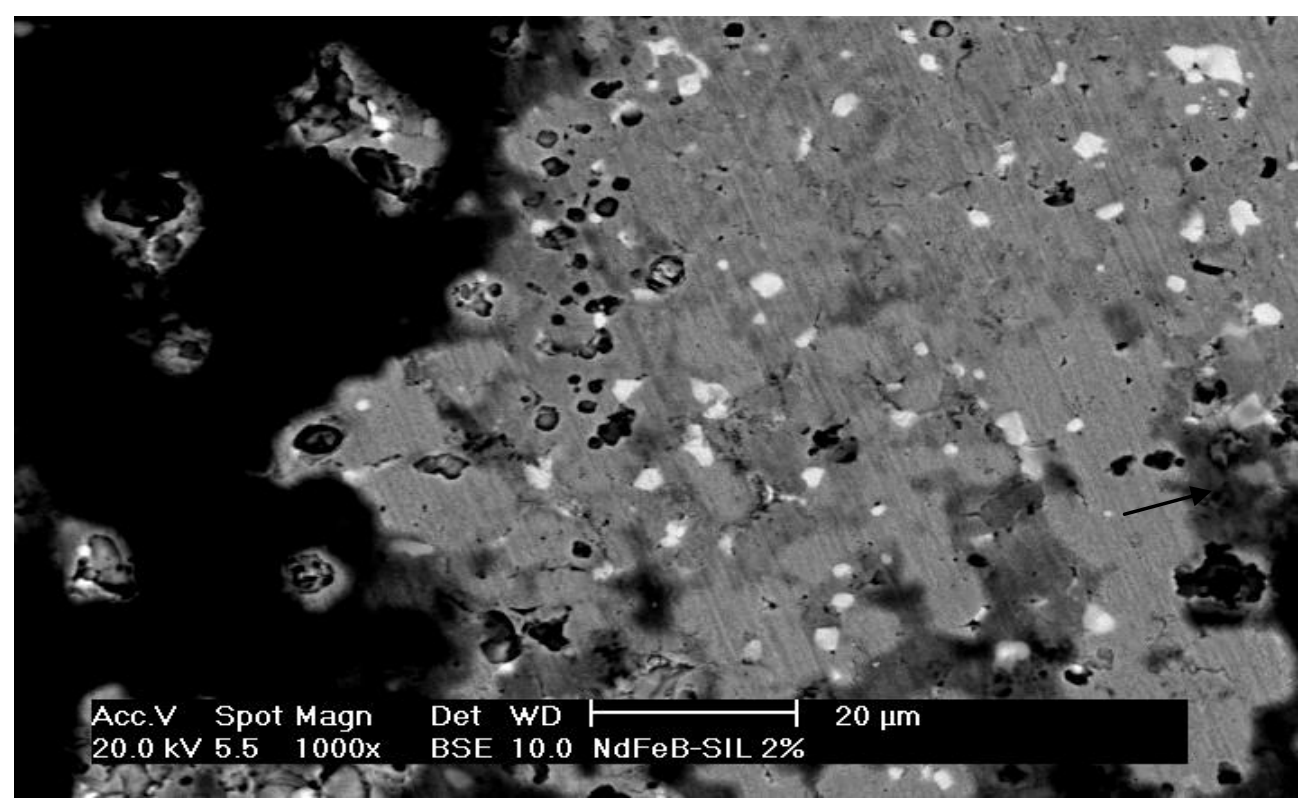

Figura 10 - Micrografia obtida por MEV da superfície do magneto de Nd-Fe-B com revestimento de silano.

A Figura 11 apresenta o espectro EDS da região escurecida da amostra revestida com BTSE, no mesmo é possível verificar um pico intenso associado ao Si indicando a efetiva deposição da camada nesta região. 


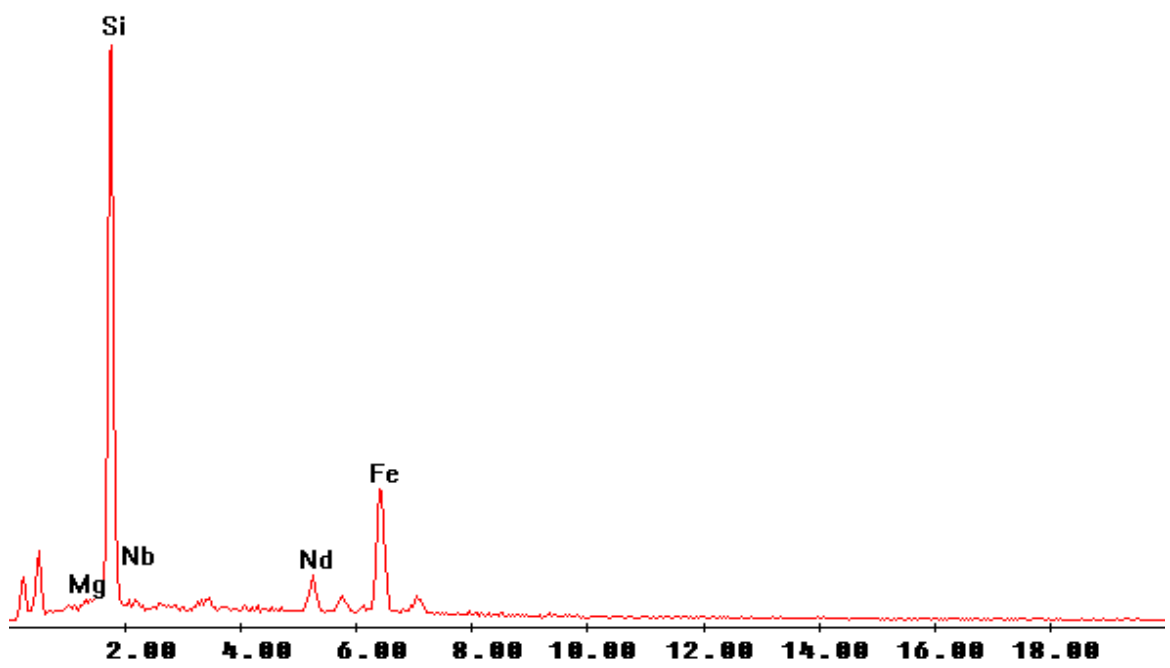

Figura 11. EDS da amostra revestida com BTSE.

A Figura 12 apresenta a comparação entre as curvas de polarização anódica de amostras sem revestimento (polida) e tratada com silano após imersão durante 30 minutos em solução de PBS. A amostra revestida com BTSE apresenta valores de corrente maiores em potenciais mais positivos (curvas mais despolarizadas) indicando menor resistência à corrosão quando comparada com a amostra só polida.

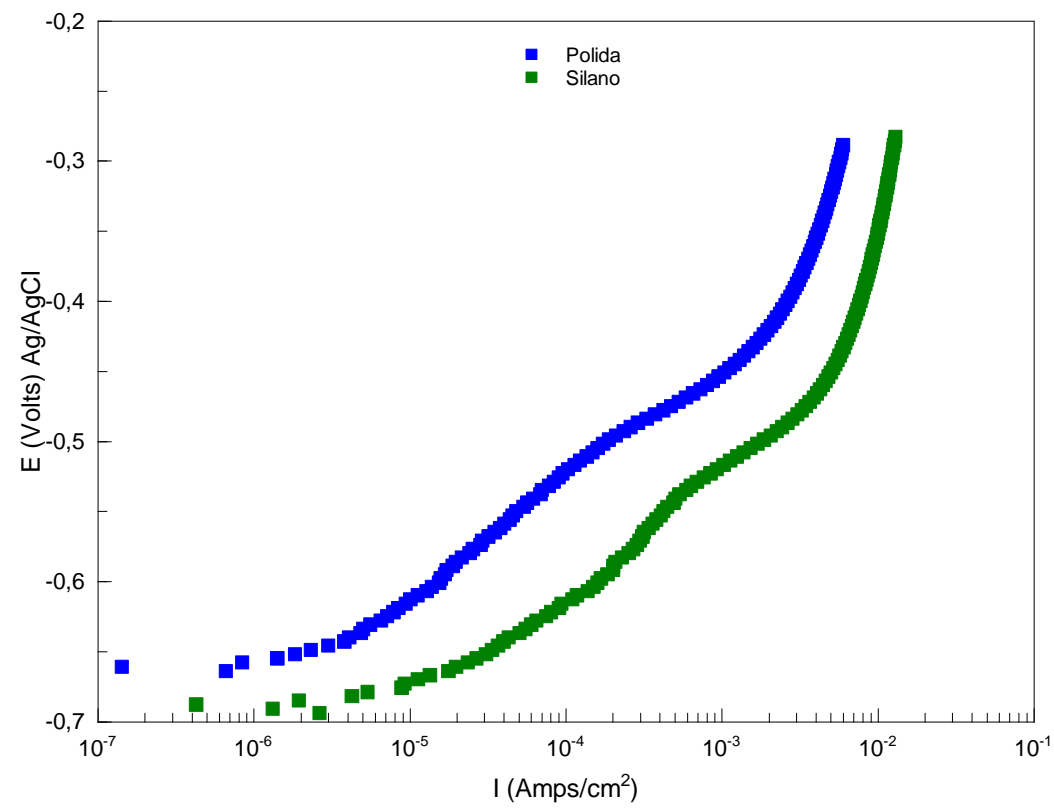

Figura 12 - Curvas de polarização anódica obtidas em solução de PBS para amostras de magnetos Nd-Fe-B polida e revestida com BTSE. Tempo de imersão de 30 minutos. 


\subsection{PROTEÇÃO POR CAMADA DE CONVERSÃO DE CÉRIO}

Para averiguar outra possibilidade de melhoria nas características de resistência à corrosão do magneto, testou-se também um tratamento de conversão à base de Cério. Dois tempos de imersão do magneto na solução de conversão foram adotados: 10 e 30 minutos. A Figura 13 apresenta os diagramas de impedância para amostras tratadas com Cério por 10 minutos e 30 minutos e para a amostra sem revestimento após imersão durante 30 minutos no eletrólito teste de PBS.

Observa-se apenas uma pequena melhora na resistência à corrosão dos magnetos revestidos com as camadas de conversão de Cério quando comparadas com a amostra sem revestimento. Observa-se também que a amostra imersa na solução de Cério por 10 minutos apresentou valores de impedância maiores do que a amostra imersa por 30 minutos, o que indica que a solução de conversão foi corrosiva para o magneto estudado, o que pode estar relacionado ao baixo $\mathrm{pH}$ do banho e também a algumas propriedades do revestimento formado, como discutido nos itens que se seguem. A ausência da constante de tempo da região de altas frequências mostra que a imersão no banho de conversão não proporcionou a formação de uma camada protetora na superfície do magneto.
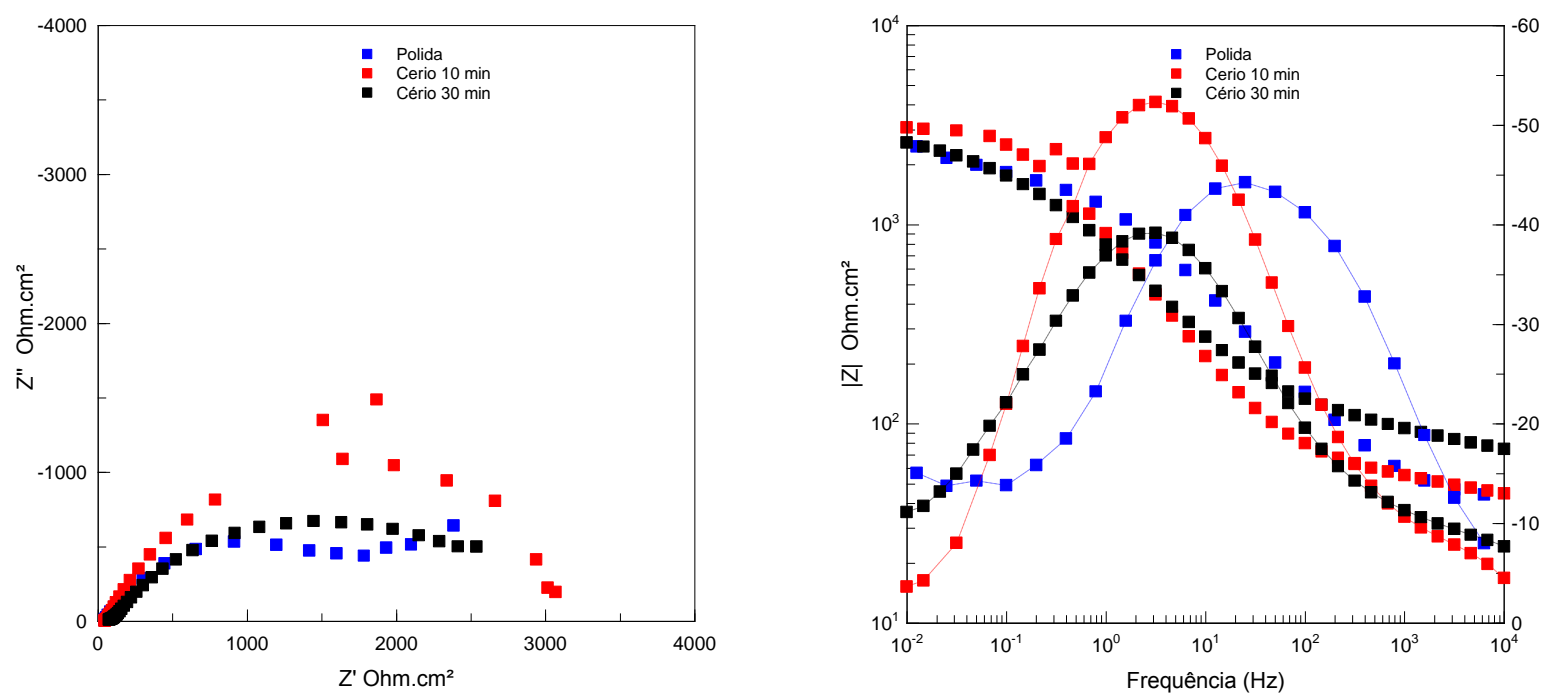

Figura 13 Diagramas de impedância (a) Nyquist (b) ângulo de fase e módulo de impedância das amostras com camada de conversão e sem revestimento (polida) após 30 minutos de imersão na solução de PBS. 
As Figuras 14 (a) e (b) apresentam, respectivamente, as micrografias das superfícies de magnetos tratados com revestimento de conversão de cério por 10 minutos e 30 minutos. As imagens mostram características diferentes conforme aumenta o tempo de imersão. A amostra tratada por 30 minutos apresenta uma área craqueada maior quando comparada com a amostra tratada com cério por apenas 10 minutos. A área craqueada é referente à deposição da camada de conversão sendo esta aparência típica das camadas de conversão de cério ${ }^{97}$.

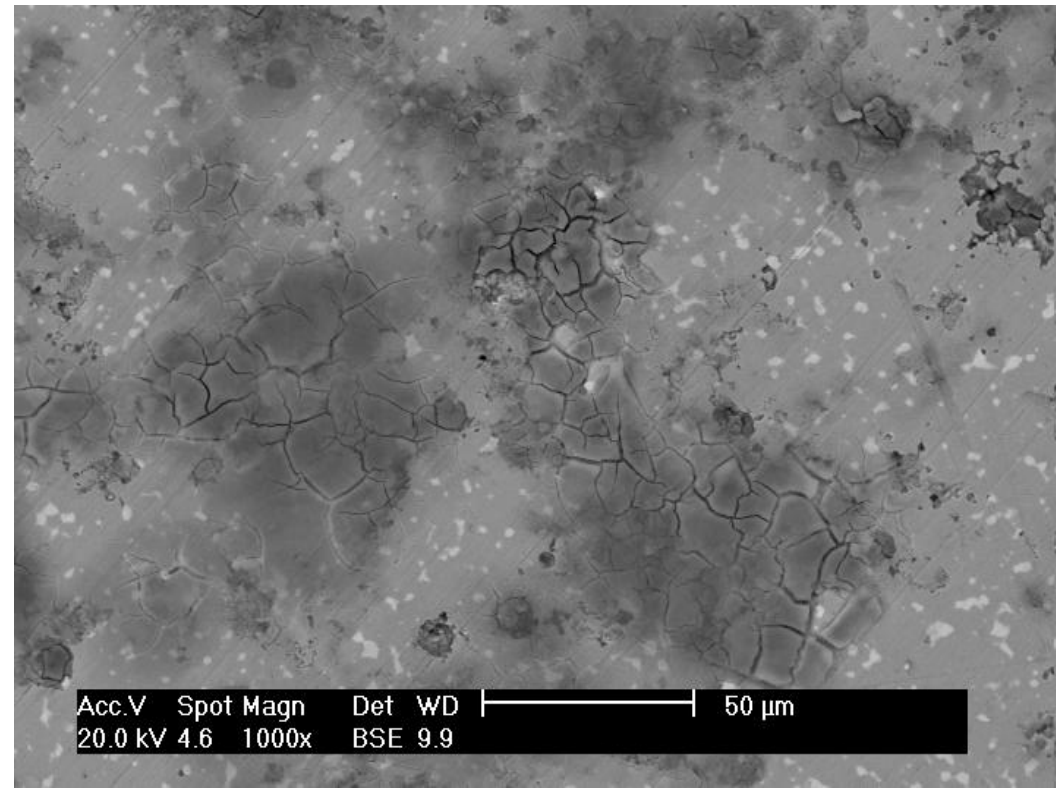

(a)

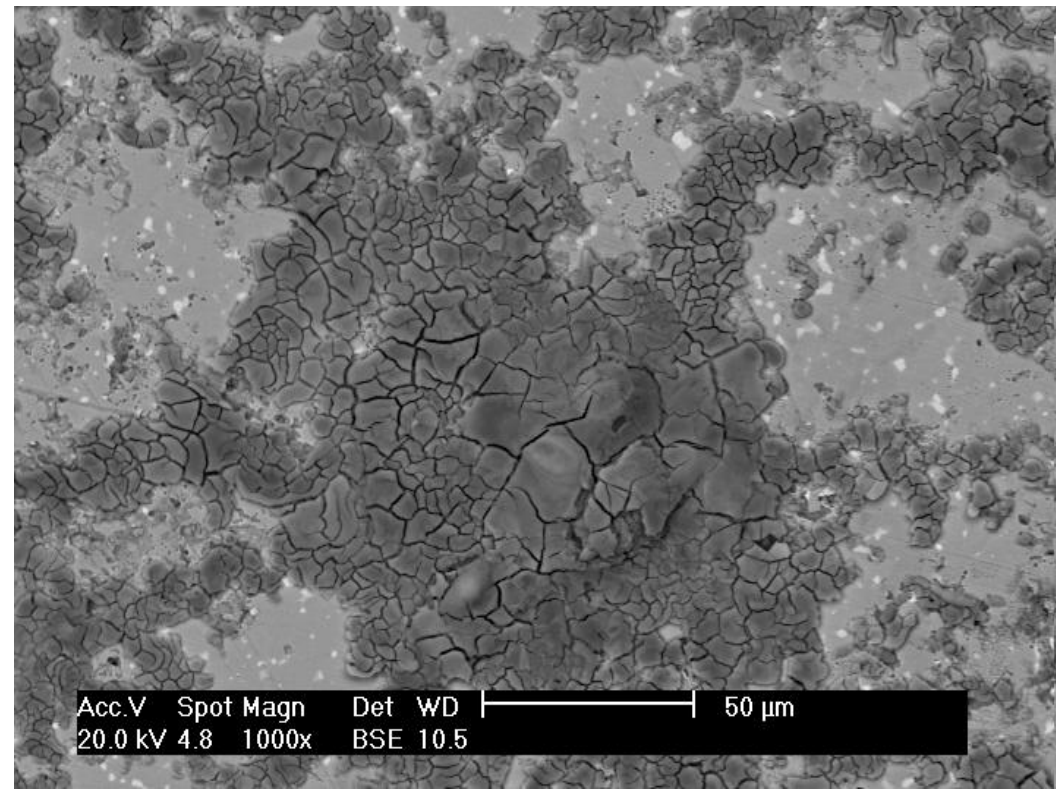

(b)

Figura 14 - Micrografia obtida por MEV da superfície da amostra do ímã Nd-Fe-B tratada com Cério por 10 minutos (a) e por 30 minutos (b). 
As Figuras 15 e 16 apresentam, respectivamente, espectros EDS das amostras tratadas no banho de conversão de cério (obtidos com apenas 50 vezes de aumento) onde se verifica picos intensos relativamente a este elemento.

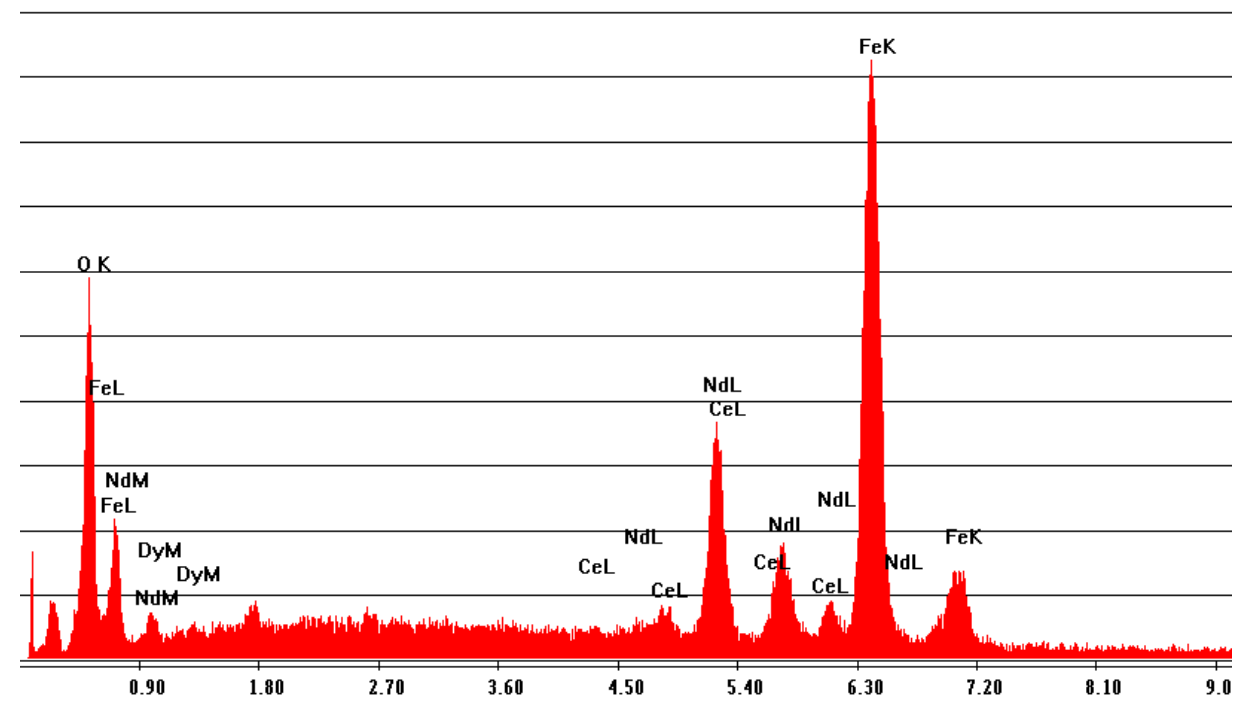

Figura 15- Espectro EDS da amostra de Nd-Fe-B imersa em banho de conversão de cério por 10 minutos.

C:\{ProfessoresłłHercilioł̣Emerson_EDSł̧Ce_30_Geral_B_5000X.spc

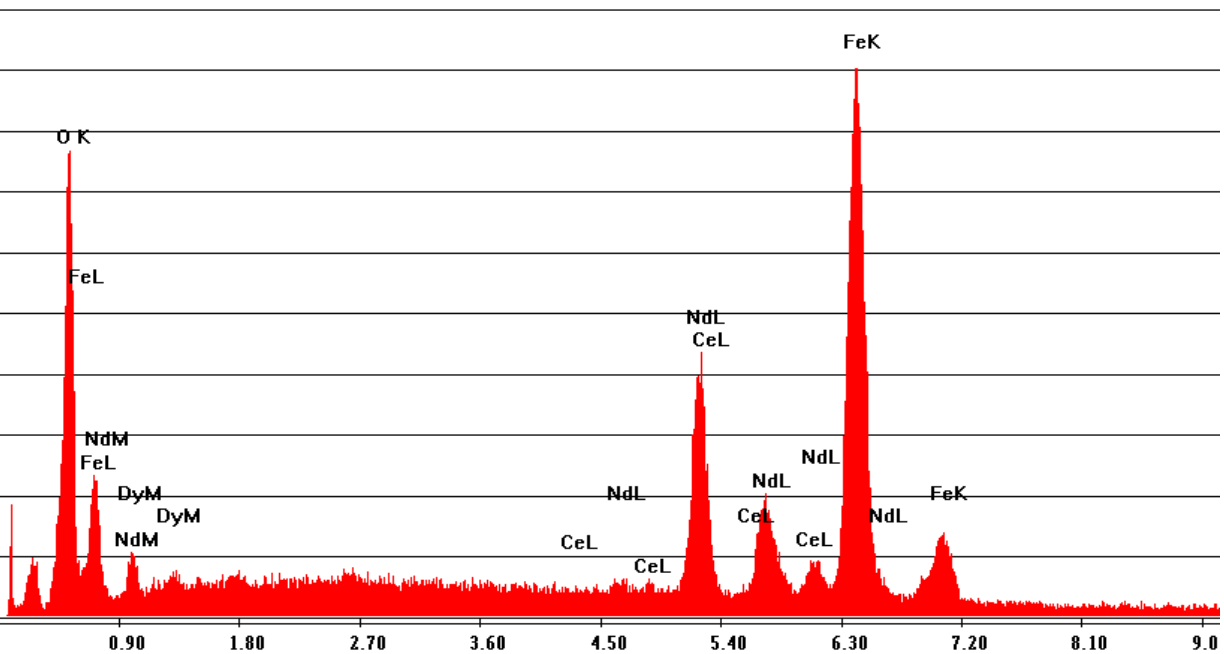

Figura 16 Espectro EDS da amostra de Nd-Fe-B imersa em banho de conversão de cério por 30 minutos. 
A análise por EDS das regiões craqueadas detectou a presença de teores relativamente elevados de Cério (lembrar que a profundidade de penetração do feixe na análise por EDS é de aproximadamente $1 \mu \mathrm{m}$, logo os teores detectados representam elevadas quantidades superficiais). Entretanto, detectou-se também, nestas mesmas regiões, teores de $\mathrm{Nd}$ ligeiramente superiores aos encontrados na composição da liga. Isto indica que, durante a imersão no banho de conversão de $\mathrm{Ce}$, o Nd dissolvido, que também é um terra-rara, precipita sobre a superfície do magneto sob a forma de óxido-hidróxido, formando uma camada de conversão mista, que, no entanto, não apresenta características protetoras. A Tabela 6 apresenta as médias dos teores de $\mathrm{Nd}$ e de $\mathrm{Ce}$ (em porcentagem atômica) obtidas em várias análises realizadas em regiões craqueadas. Na última coluna da tabela é apresentado o teor médio de $\mathrm{Nd}$ na liga. Observam-se menores teores de Ce na amostra imersa por mais tempo na solução de conversão, a qual apresenta menor resistência à corrosão. Entretanto, as micrografias apresentadas nas Figuras 14 (a) e (b) mostram que a superfície do magneto revestida com a camada de conversão (com aspecto craqueado) é mais importante na amostra imersa por mais tempo na solução de conversão. Estes resultados indicam que o enriquecimento em $\mathrm{Nd}$ da camada de conversão seria $\mathrm{O}$ responsável pela diminuição da resistência à corrosão com o aumento do tempo de imersão na solução de conversão.

Tabela 6 - Teores médios de $\mathrm{Ce}$ e $\mathrm{Nd}$ (em porcentagem atômica) determinados nas regiões craqueadas de amostras do magneto Nd-Fe-B imersas durante 10 ou 30 minutos em banho de conversão de Ce. Na última coluna é apresentado o teor médio de Nd encontrado na liga (porcentagens em massa).

\begin{tabular}{|l|c|c|c|}
\cline { 2 - 3 } \multicolumn{1}{c|}{} & Médias Ce & Médias Nd & $\%$ Nd na LIGA \\
\hline CÉRIO 10 & 4,42 & 30,01 & \multirow{2}{*}{28,31} \\
\hline CÉRIO 30 & 2,21 & 29,08 & \\
\hline
\end{tabular}

A Figura 17 apresenta as curvas de polarização anódica, obtidas após 30 minutos de imersão em solução de PBS, para uma amostra revestida com cério por 10 minutos e uma amostra polida, observa-se que a curva para a amostra apenas polida é mais polarizada, indicando melhor resistência à corrosão. 


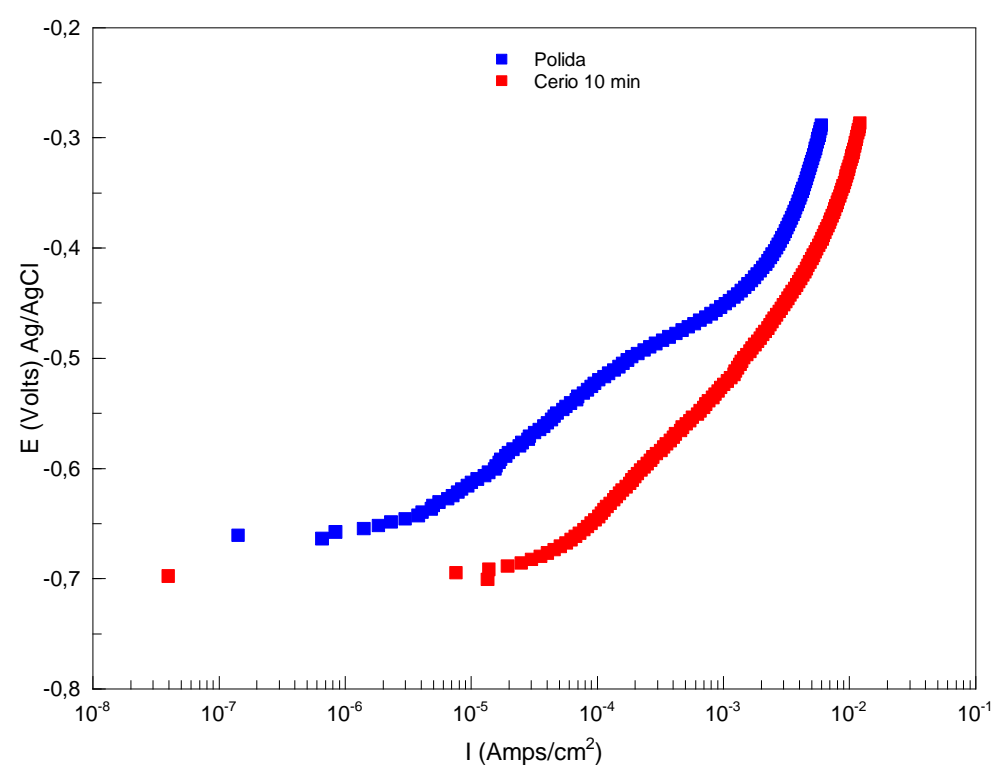

Figura 17 - Curvas de polarização anódica para amostras do magneto Nd-Fe-B apenas polida e polida e revestida com camada de conversão de cério (10 minutos de tratamento) após imersão durante 30 minutos na solução de PBS.

\subsection{PROTEÇÃO POR TRATAMENTO COM SAM}

Buscando-se outras alternativas com a finalidade de proteger o magneto de $\mathrm{Nd}-\mathrm{Fe}-\mathrm{B}$ contra corrosão, também foi testado o tratamento à base de SAM (moléculas autoorganizáveis). O diagrama de impedância obtido após 30 minutos de imersão no eletrólito teste está apresentado na Figura 18, sendo o mesmo comparado com aquele obtido com a amostra polida.

Assim como nos resultados apresentados com os tratamentos precedentes notam-se valores muito baixos de impedância associados à amostra com revestimento de SAM, sendo estes praticamente iguais aos valores do magneto apenas polido. Neste sentido, tanto os diagramas de Nyquist como os de Bode foram muito semelhantes. 

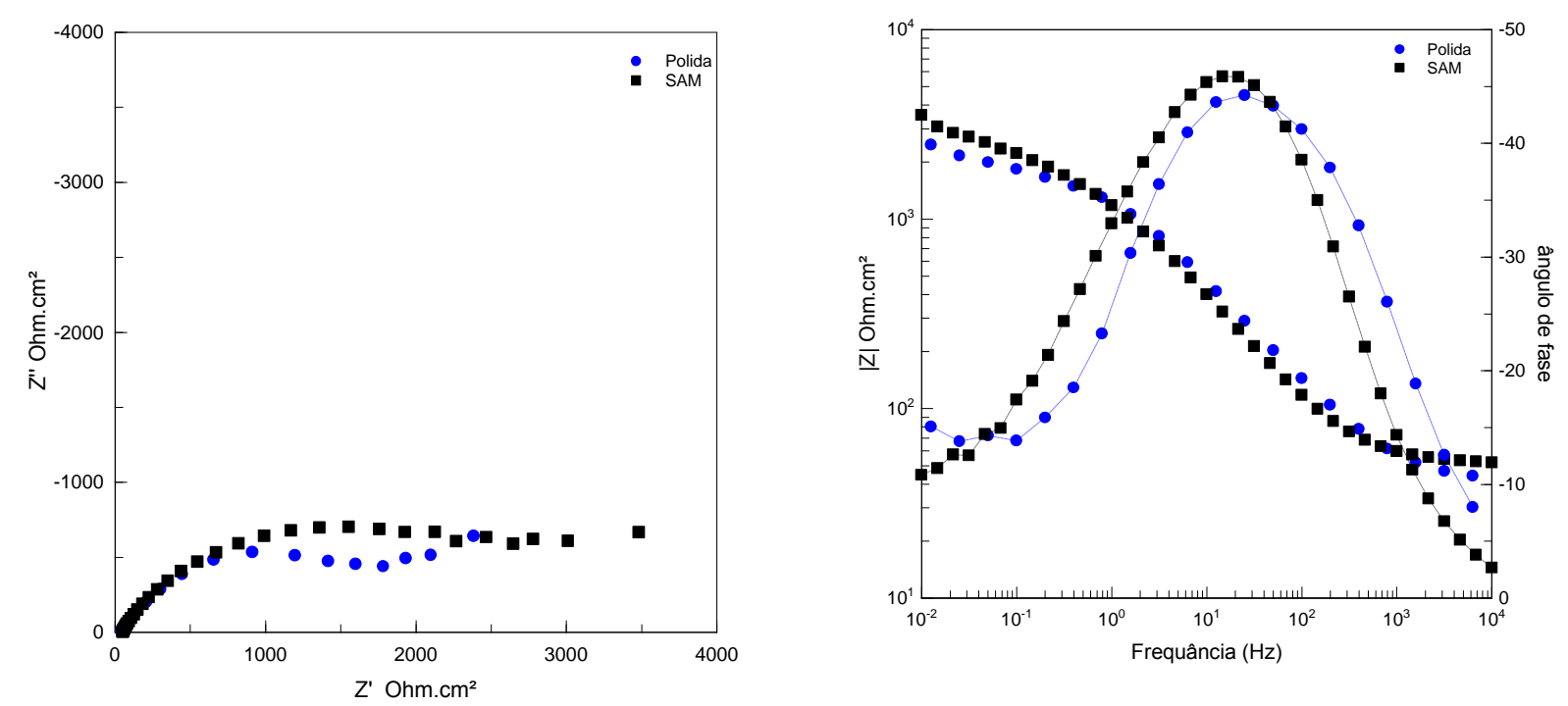

Figura 18. Diagramas de (a) Nyquist e (b) ângulo de fase e módulo de impedância para amostras do magneto de $\mathrm{Nd}-\mathrm{Fe}-\mathrm{B}$ com revestimento de SAM e amostra sem revestimento (polida) na solução de ensaio (PBS). Diagramas obtidos após 30 minutos de imersão.

As Figuras 19(a) e 19(b) apresentam micrografias da amostra revestida com SAM. Observa-se que a proteção obtida não é uniforme, o que deve ser responsável pela baixa resistência à corrosão apresentada pelas amostras tratadas, uma vez que pilhas galvânicas podem ser formadas entre as regiões protegidas e não protegidas. A região apresentada na Figura 19(a) apresenta-se bastante danificada indicando um forte ataque da superfície do magneto pela solução de pré-tratamento.
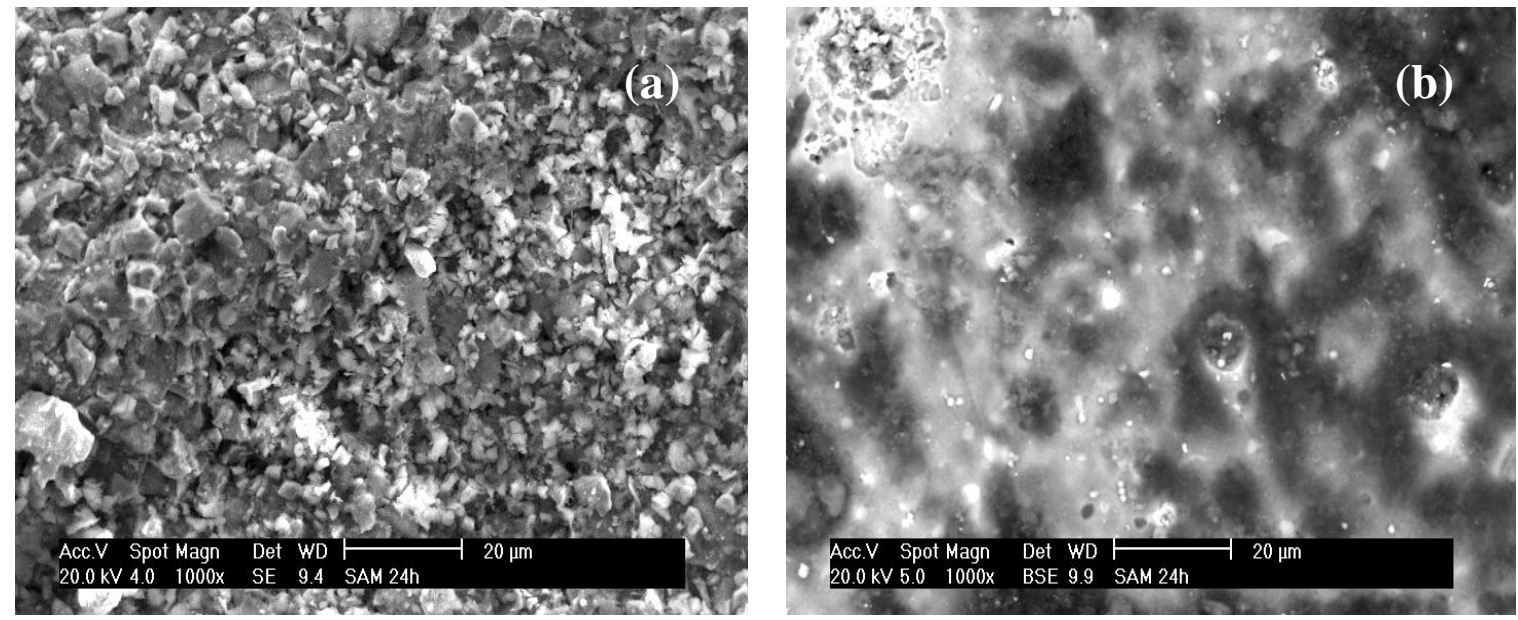

Figura 19. (a) e (b) Micrografia obtida por MEV do magneto de Nd-Fe-B após imersão durante 5 minutos em solução de SAM. 
A Figura 20 apresenta o espectro EDS da amostra tratada com SAM. A presença do pico relativo ao fósforo indica a adsorção das moléculas sobre a superfície do magneto, embora isto tenha ocorrido de modo não homogêneo.

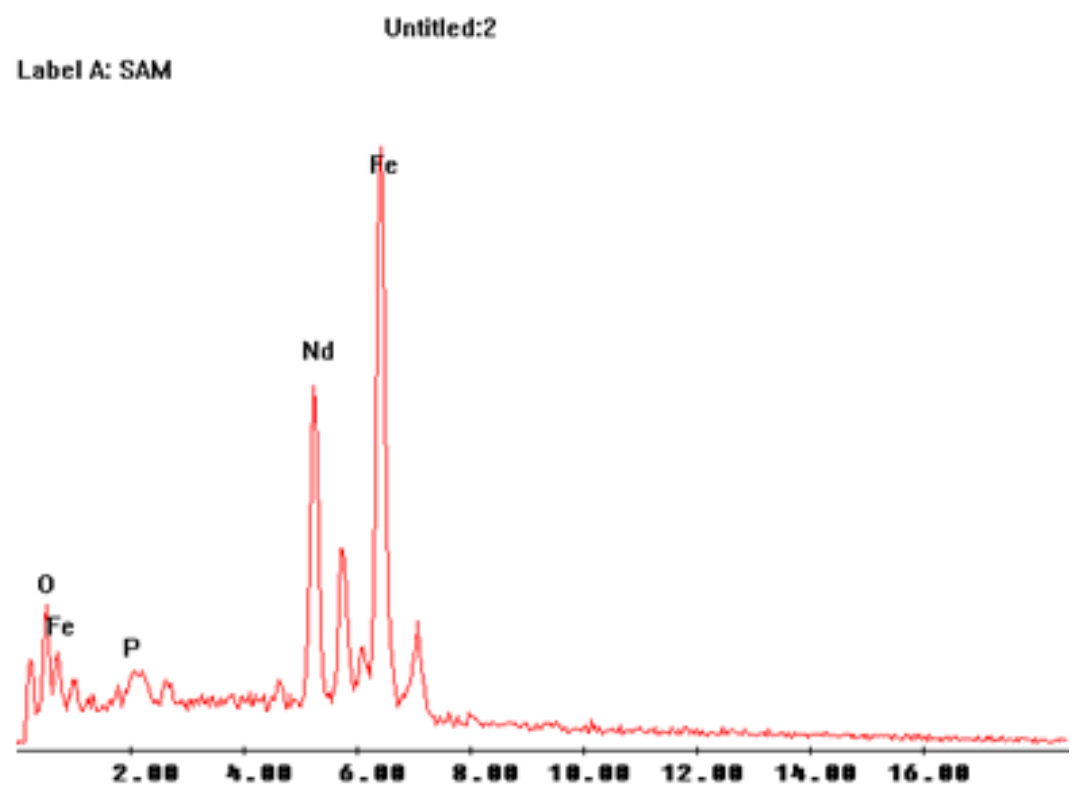

Figura 20. Espectro EDS da superfície do magneto de Nd-Fe-B tratado com SAM durante 5 minutos.

A Figura 21 apresenta as curvas de polarização anódica para a amostra tratada com SAM e polida. Mais uma vez a resposta da amostra polida apresentou-se mais polarizada, indicando melhor resistência à corrosão.

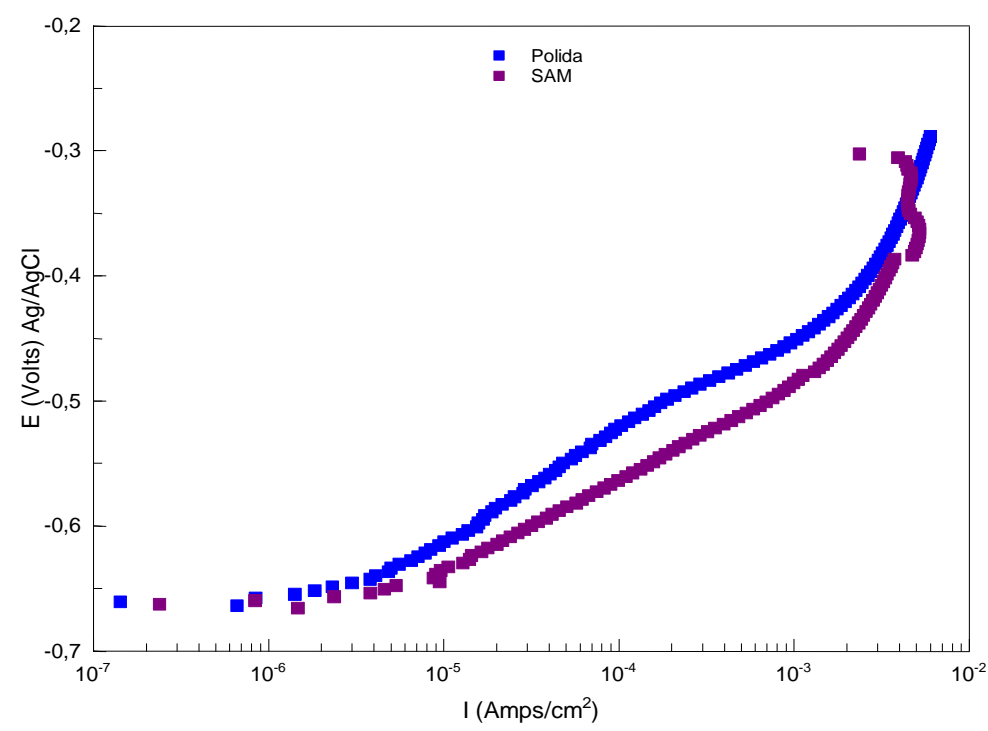

Figura 21. Curvas de polarização anódica para amostras do magneto $\mathrm{Nd}-\mathrm{Fe}-\mathrm{B}$ polida e revestida com SAM após imersão durante 1 hora na solução de PBS. 


\subsection{TRATAMENTO COM CROMO TRIVALENTE E HEXAVALENTE}

Como o tratamento com SAM também não foi efetivo para a proteção contra a corrosão do magneto de $\mathrm{Nd}-\mathrm{Fe}-\mathrm{B}$, foram investigados, como alternativas, prétratamentos com cromo trivalente e cromo hexavalente.

A Figura 22 apresenta os diagramas de impedância, Nyquist (a) e de ângulo de fase e módulo de impedância (b) para amostras do magneto de Nd-Fe-B com revestimentos de $\mathrm{Cr}^{3+}, \mathrm{Cr}^{6+}$ e amostra sem revestimento (polida) após 30 minutos de imersão na solução de ensaio (PBS).
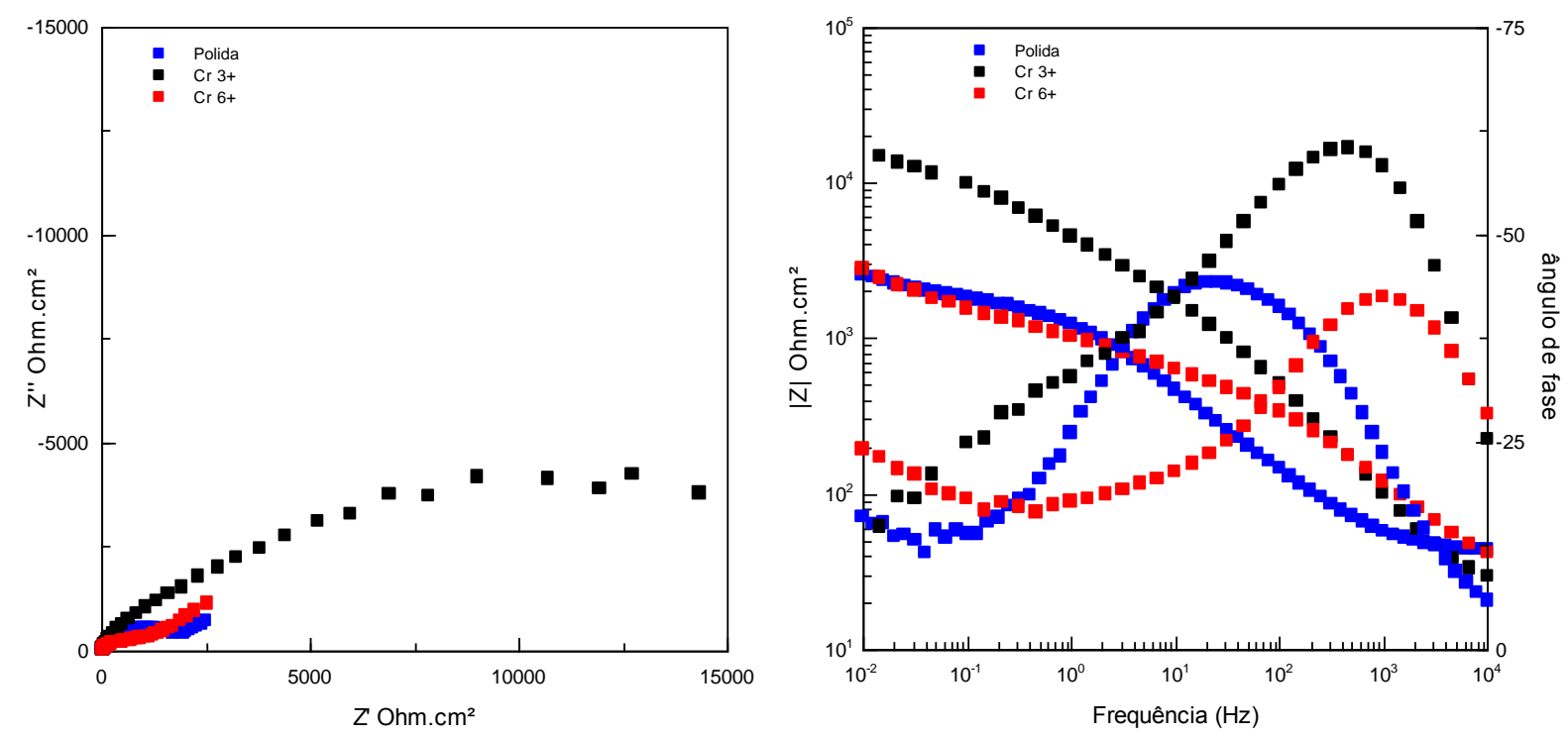

Figura 22. Diagramas de (a) Nyquist, (b) ângulo de fase e módulo de impedância para amostras do magneto de Nd-Fe-B com revestimentos de $\mathrm{Cr}^{3+}, \mathrm{Cr}^{6+}$ e amostra sem revestimento (polida) após imersão durante 30 minutos na solução de ensaio (PBS).

Os diagramas de Nyquist mostram impedâncias significativamente maiores para o magneto após tratamento com $\mathrm{Cr}^{3+}$ em comparação com as amostras com revestimento de $\mathrm{Cr}^{6+}$ e polida. Estes resultados sugerem que o primeiro tratamento é uma alternativa viável a ser considerada para substituição do $\mathrm{Cr}^{6+}$ uma vez que aumenta significativamente a impedância da amostra. Os diagramas de Nyquist também mostram um arco capacitivo achatado para todas as amostras tratadas, indicativo de interação de mais de uma constante de tempo. Os diagramas de ângulo de fase de Bode correspondentes mostram uma constante de tempo em altas 


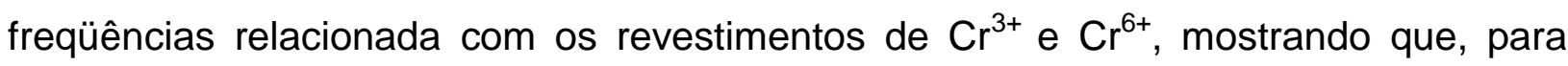
estes revestimentos, ocorre a formação de uma camada sobre a superfície da amostra. Entretanto, pelos valores de impedância, a camada formada na solução de $\mathrm{Cr}^{6+}$ não é protetora. Para a amostra tratada em solução de cromo trivalente, o comportamento de eletrodo poroso em altas freqüências (no diagrama de Nyquist ângulo de $45^{\circ} \mathrm{com}$ o eixo real) não pode ser mais distinguido, indicando bloqueio dos poros pela camada formada. Por sua vez, no diagrama obtido com a amostra tratada na solução de cromo hexavalente a resposta de eletrodo poroso ainda é claramente evidente. As Figuras 23 (a) e (b) apresentam as micrografias das superfícies de amostras tratadas com cromo trivalente e hexavalente, respectivamente. Para esta últma amostra, o comportamento de eletrodo poroso na região altas frequências não pode ser mais distinguido, indicando o bloqueio dos poros pela camada formada. Por sua vez, no diagrama obtido com a amostra tratada na solução de $\mathrm{Cr}^{6+}$ a resposta de eletrodo poroso ainda é claramente evidente. $O$ revestimento com cromo trivalente mostrou-se um potencial candidato para proteção dos magnetos de Nd-Fe-B. As micrografias mostram claramente que o tratamento do magneto por cromatização em solução com $\mathrm{Cr}^{6+}$ resultou em ataque mais intenso da superfície em relação ao tratamento em solução de $\mathrm{Cr}^{3+}$. A amostra tratada com $\mathrm{Cr}^{6+}$ apresenta pequenas crateras em sua superfície e as mesmas apresentam dimensões bem maiores do que as observadas na amostra tratada por $\mathrm{Cr}^{3+}$. Em concordância com os resultados obtidos nos ensaios de impedância, observa-se nitidamente a presença de microporosidades na superfície da amostra tratada com cromo hexavalente, o que não é evidenciado na amostra prétratada com o cromo trivalente.

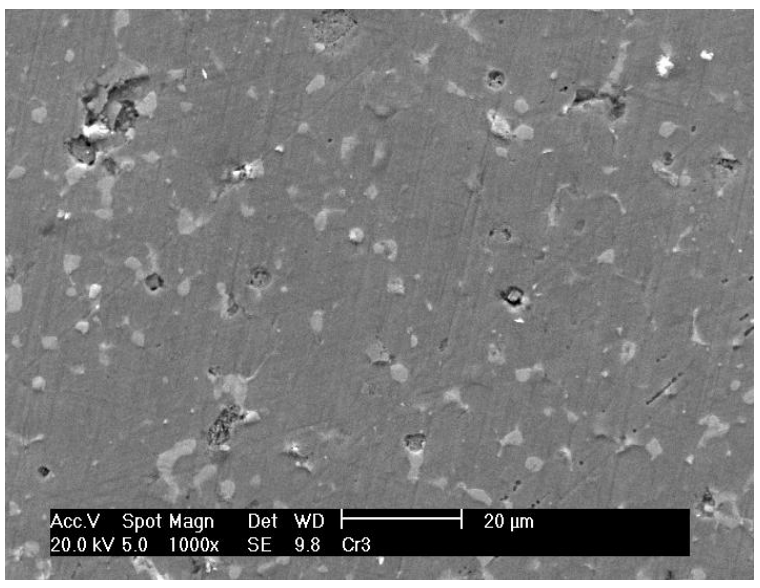

(a)

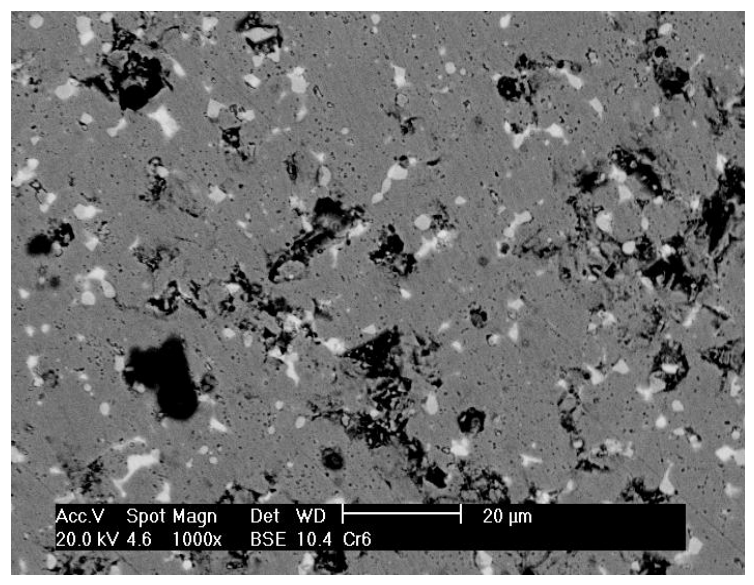

(b)

Figura 23. Micrografias das amostras do magneto de Nd-Fe-B tratadas com (a) $\mathrm{Cr}^{3+}$ e (b) $\mathrm{Cr}^{6+}$. 
A Figura 24 apresenta as curvas de polarização anódica de amostras polidas e revestidas com $\mathrm{Cr}^{3+}$ ou $\mathrm{Cr}^{6+}$ após imersão durante 30 minutos na solução de PBS. Na região de baixas polarizações, a curva obtida para a amostra revestida com $\mathrm{Cr}^{6+}$ apresenta-se ligeiramente mais despolarizada que as demais, o que está de acordo com o a menor resistência à corrosão exibida por esta amostra.

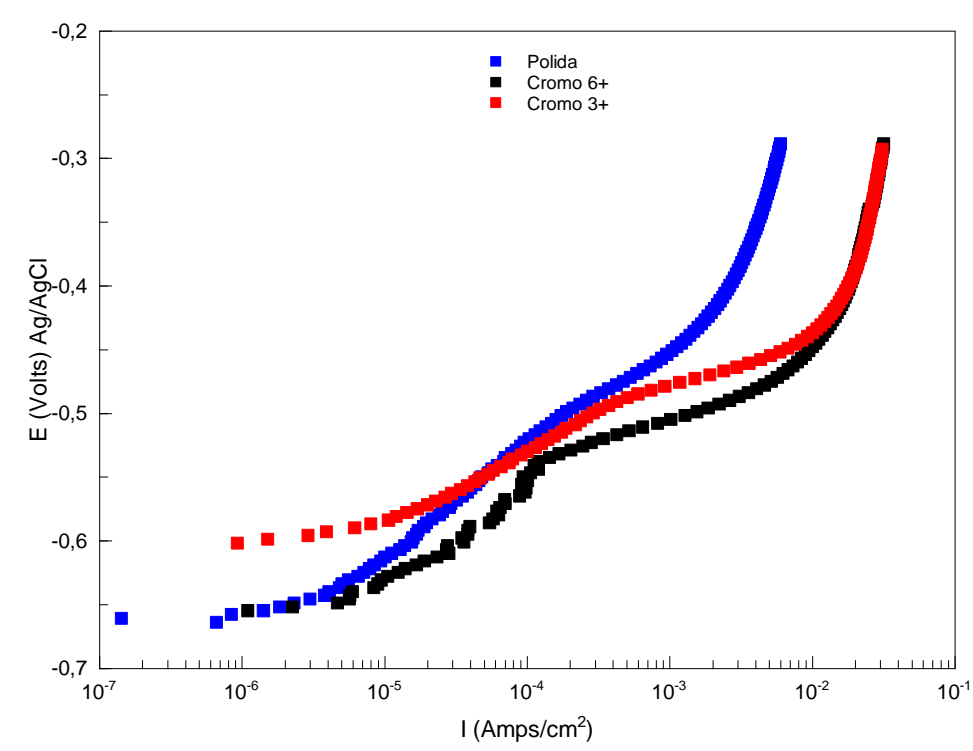

Figura 24. Curvas de polarização anódica para amostras de Nd-Fe-B polidas ou tratadas com $\mathrm{Cr}^{3+}$ ou $\mathrm{Cr}^{6+}$ após 30 minutos da imersão em solução de PBS.

As Figuras 25 e 26 apresentam os espectros EDS das superfícies das amostras tratadas com $\mathrm{Cr}^{3+}$ e $\mathrm{Cr}^{6+}$.É possível observar que a intensidade do pico associado ao $\mathrm{Cr}$ é maior na amostra submetida ao tratamento com $\mathrm{Cr}^{3+}$ indicando a formação de uma camada ou mais espessa ou então mais uniforme de revestimento, o que está coerente com o melhor comportamento eletroquímico exibido por esta amostra. 


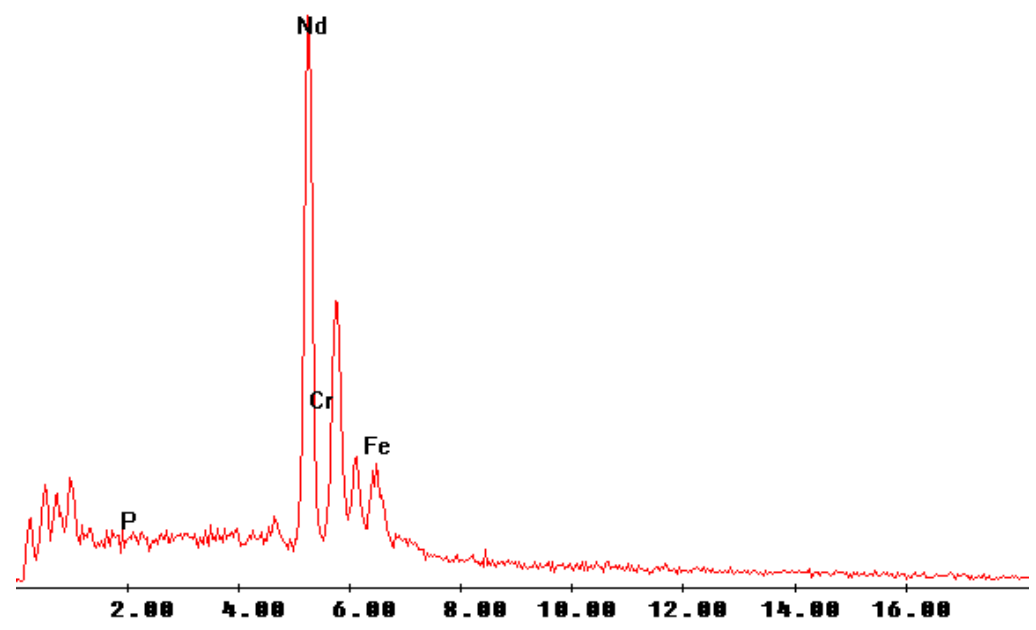

Figura 25. Espectro EDS da amostra de magneto $\mathrm{Nd}-\mathrm{Fe}-\mathrm{B}$ revestida por $\mathrm{Cr}^{3+}$.

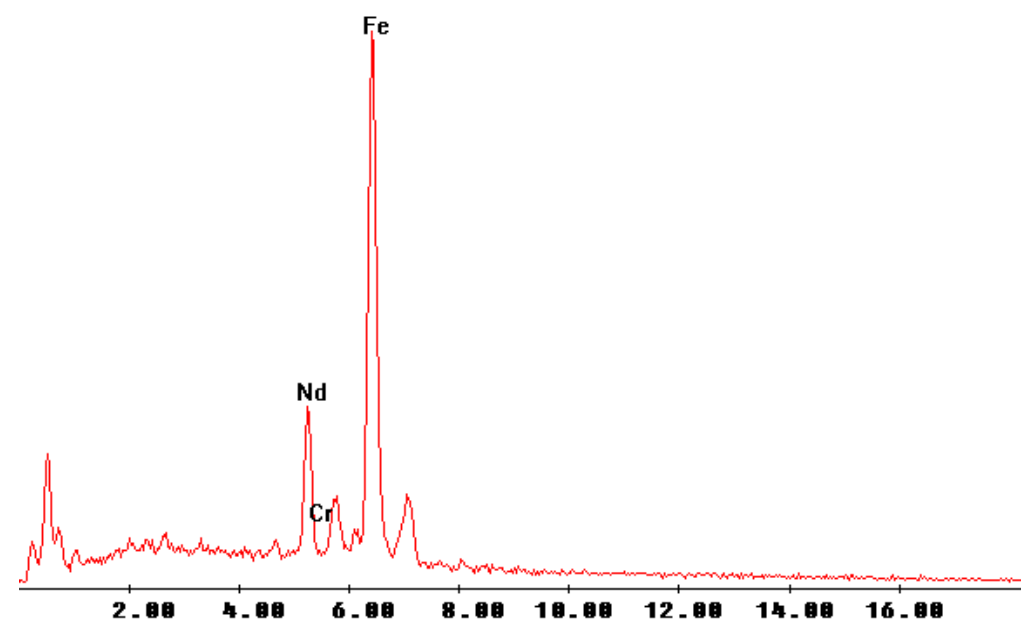

Figura 26 - Espectro EDS da amostra do magneto Nd-Fe-B revestida por $\mathrm{Cr}^{6+}$.

\subsection{TRATAMENTO COM FOSFATO TRICATÔNICO}

Outra alternativa testada para proteção do magneto contra a corrosão foi o tratamento com fosfato tricatiônico. Os resultados de impedância para as amostras fosfatizadas após 30 minutos da imersão na solução PBS são mostrados na Figura 27. 

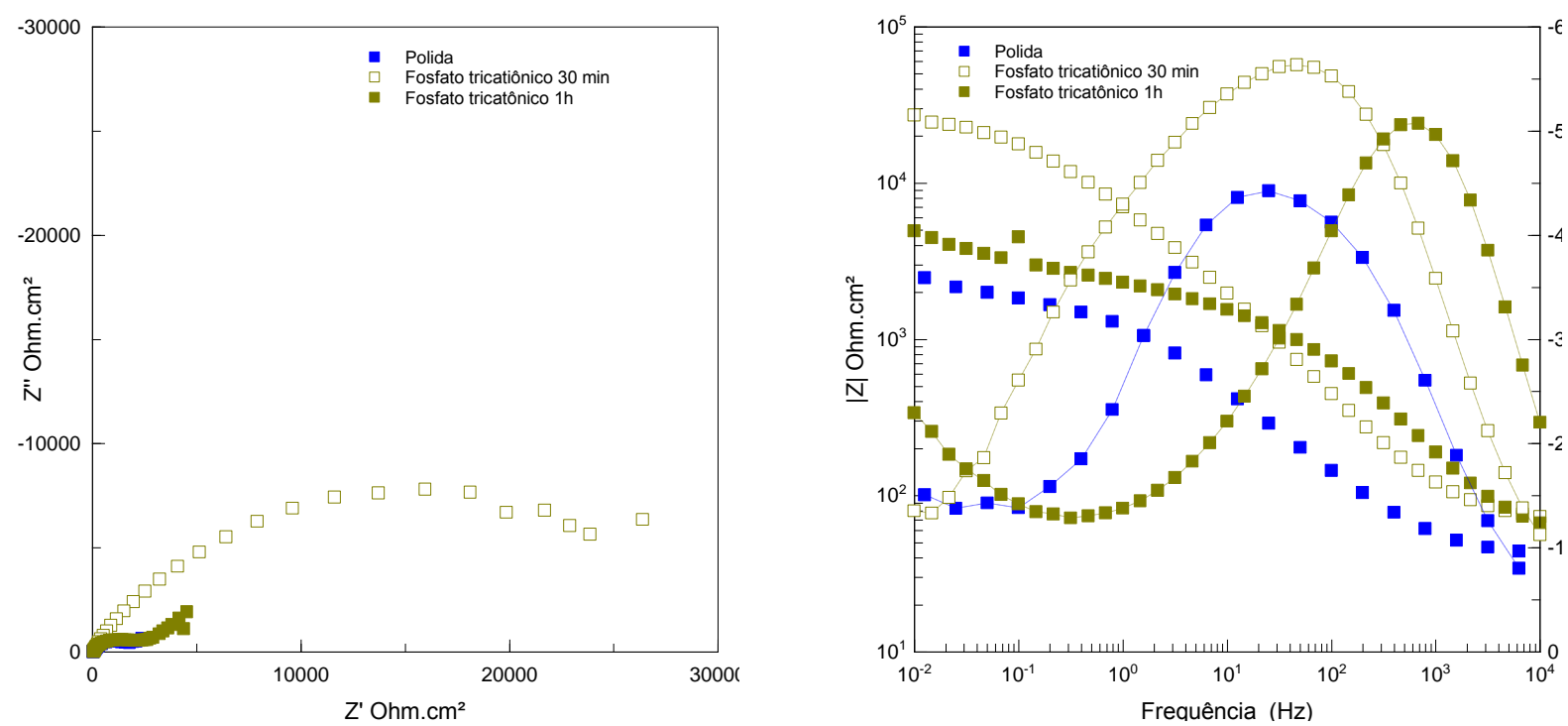

Figura 27 Diagramas de (a) Nyquist, (b) ângulo de fase e módulo de impedância para Nd-Fe-B com fosfato tricatiônico (30 min e 1h) e amostra sem revestimento (polida). Diagramas obtidos após 30 minutos de imersão na solução de ensaio (PBS).

Os diagramas de Nyquist apresentam valores de impedância maiores para a amostra tratada com fosfato tricatiônico por 30 minutos quando a comparamos com a amostra tratada por 1 hora e com a amostra sem revestimento. Maiores ângulos de fase e em frequências mais elevadas foram obtidos para a amostra tratada com fosfato tricatiônico por 30 minutos, sugerindo que este tratamento oferece proteção contra a corrosão do magneto devido à formação de uma camada protetora. Observa-se que com o aumento no tempo de tratamento na solução de fosfato ocorre uma degradação das propriedades de resistência à corrosão.

A comparação do diagrama de impedância obtido com o tratamento por 1 hora na solução de fosfato tricatiônico com aquele da amostra polida (mais facilmente visível nos ensaios realizados com a amostra polida), mostra que a resposta do eletrodo tratado também pode ser explicada como sendo resultante de um eletrodo poroso com profundidade de poro semi-infinita. Este tipo de resposta não é evidenciado no eletrodo tratado por 30 minutos, indicando um bloqueio dos poros pelo revestimento.

A Figura 28 apresenta a micrografia por MEV da amostra do magneto de $\mathrm{Nd}-\mathrm{Fe}-\mathrm{B}$ tratada com fosfato tricatiônico por 30 minutos. Observa-se a presença de buracos na superfície da liga, que parecem estar associados à dissolução de regiões situadas em 
contornos de grão. O agravamento deste processo pode estar relacionado à deterioração das propriedades de proteção da camada com o aumento do tempo de imersão na solução de fosfato tricatiônico.

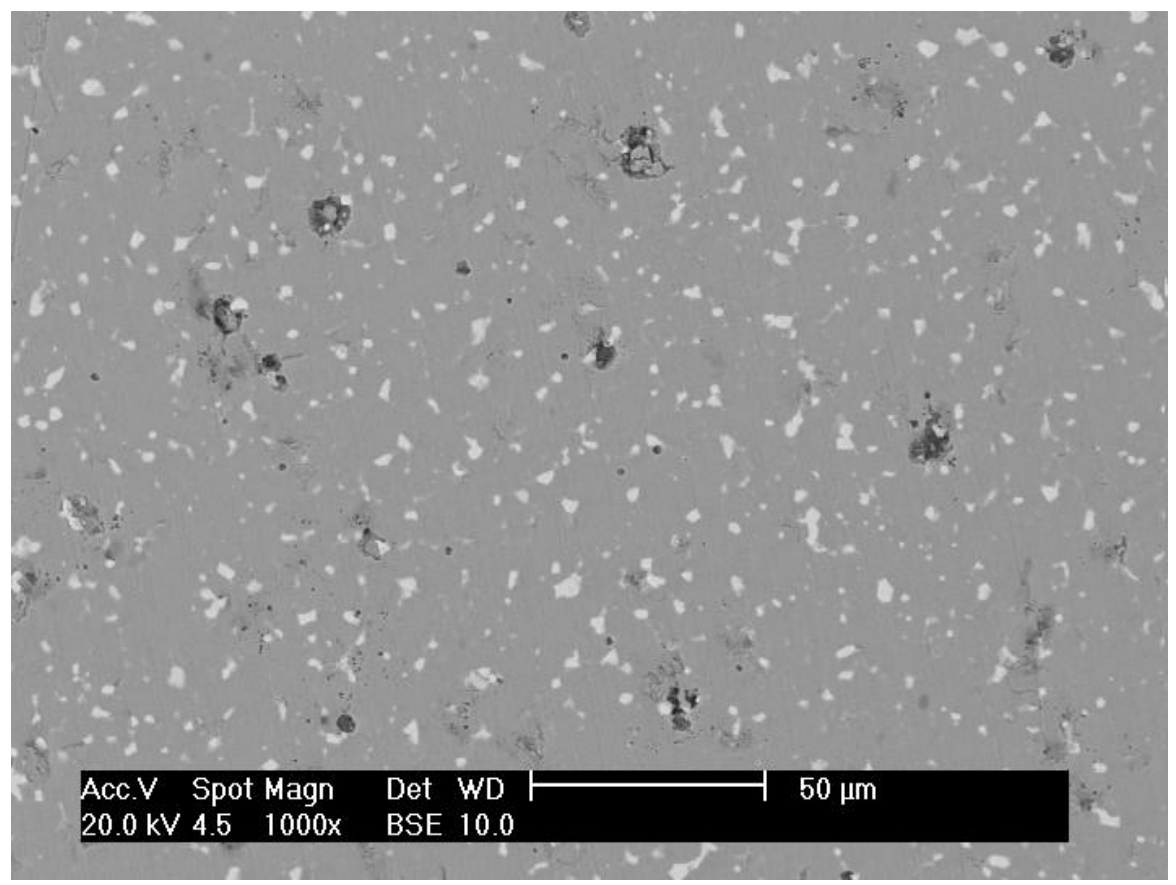

Figura 28 Micrografia obtida por MEV da amostra do magneto de Nd-Fe-B tratada com fosfato tricatiônico por 30 minutos.

A Figura 29 apresenta o espectro EDS da amostra do magneto de $\mathrm{Nd}-\mathrm{Fe}-\mathrm{B}$ tratado com fosfato tricatiônico. A presença de um pequeno pico associado ao fósforo indica a existência de uma fina camada de fosfato sobre a superfície da amostra. 


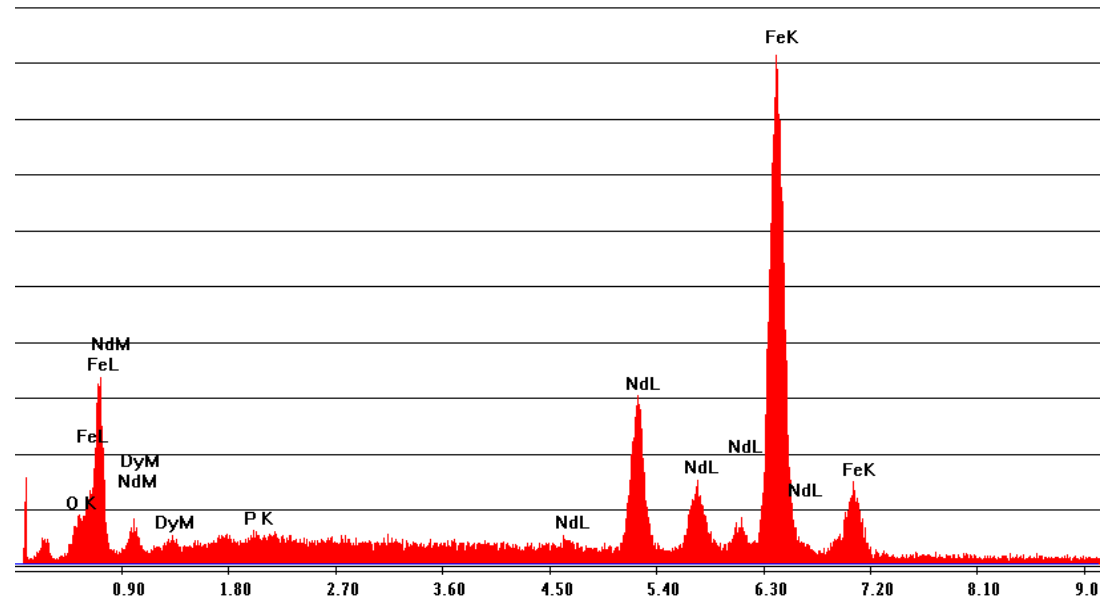

Figura 29. Espectro EDS da superfície da amostra do magneto de Nd-Fe-B tratado com fosfato tricatiônico.

A Figura 30 apresenta as curvas de polarização anódica para amostras polida e tratada com fosfato tricatiônico por 30 minutos, após 30 minutos de imersão na solução de PBS. Observa-se que a amostra tratada com fosfato tricatiônico apresenta uma região passiva caracterizada por correntes muito baixas. Além do mais, após a quebra da passividade, a corrente anódica permanece menor para a amostra revestida com fosfato por certo intervalo de potencial, o que confirma a proteção conferida pelo prétratamento. 


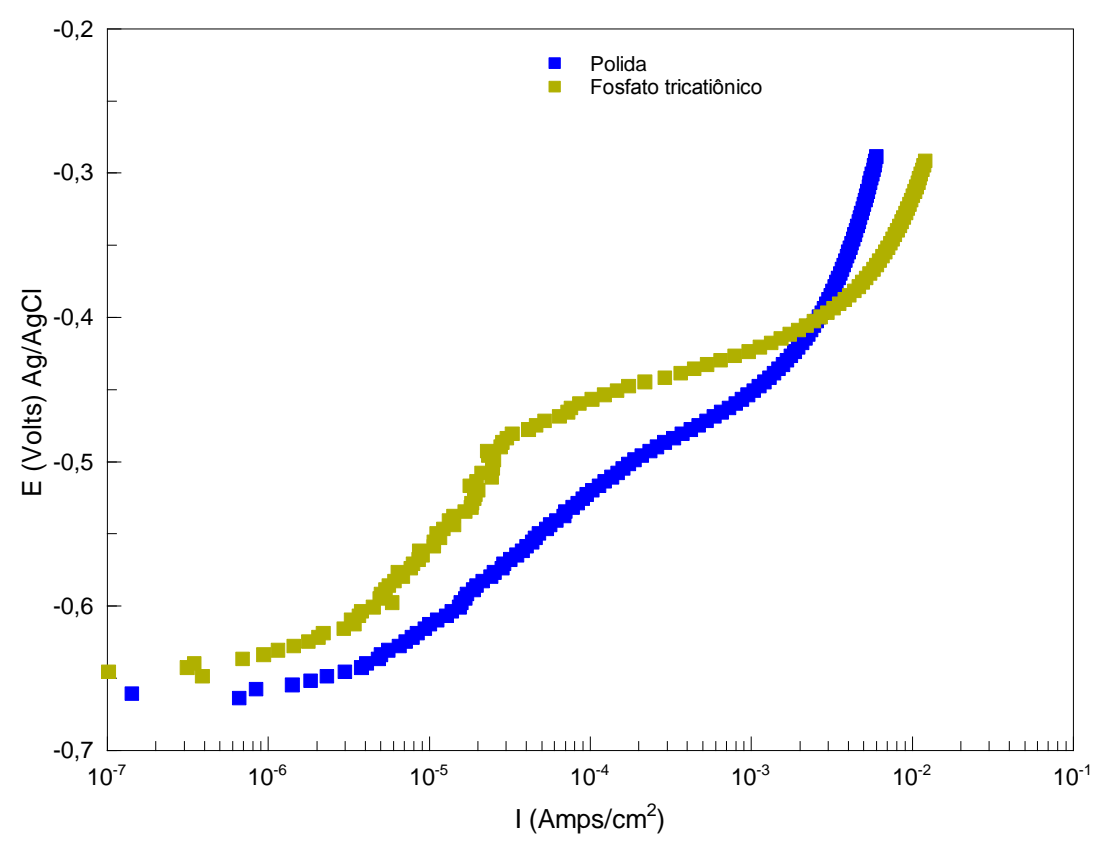

Figura 30 - Curvas de polarização anódica de amostras do magneto Nd-Fe-B polida e polida e tratada com fosfato tricatiônico por 30 minutos. Curvas obtidas após 30 minutos de imersão na solução de PBS.

Como o tratamento com fosfato tricatiônico por 30 minutos ofereceu proteção considerável contra a corrosão do magneto, testou-se também este tratamento acrescido por um banho passivante de trióxido de cromo, variando-se o tempo de imersão no banho entre 30 minutos e 1 hora.A Figura 31 apresenta os resultados de impedância para as amostras submetidas a esta sequência de tratamento. Os resultados mostram que o tratamento da amostra previamente tratada com fosfato tricatiônico com a solução de trióxido de cromo causa uma diminução da impedância, mostrando que os dois tratamentos não podem ser utilizados em conjunto. Para as amostras tratadas com os dois banhos o comportamento de eletrodo poroso com processo controlado por difusão (já discutido na apresentação dos resultados para o eletrodo polido) volta a ser evidenciado indicando que a segunda etapa do prétratamento causa grandes danos à camada de proteção de fosfato tricatiônico. 

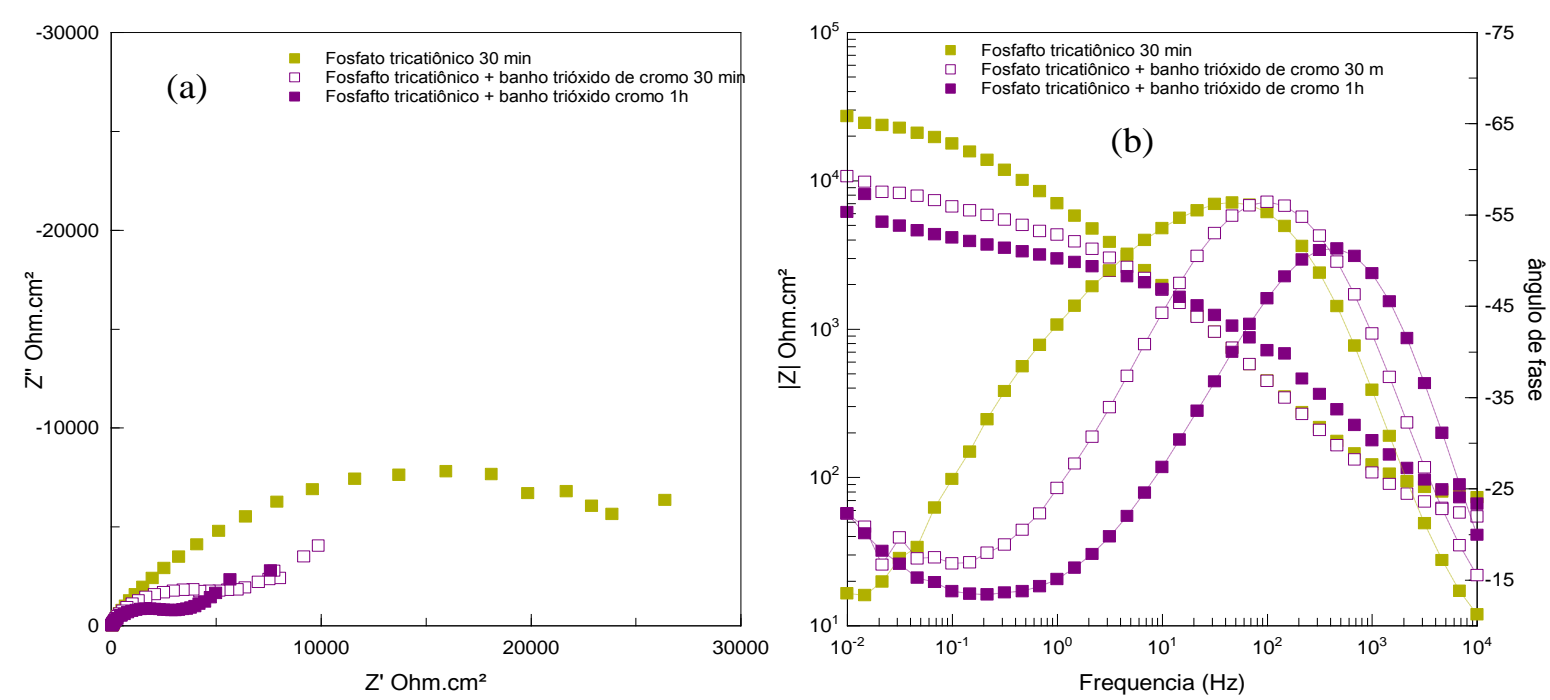

Figura 31 - Diagramas de (a) Nyquist, (b) ângulo de fase e módulo de impedância para amostras do magneto de Nd-Fe-B com pré-tratamento de fosfato tricationico por 30 minutos, e amostras com o mesmo tratamento seguido de imersão no banho passivante de trióxido de cromo por 30 minutos e 1 hora. Resultados obtidos na solução de ensaio (PBS) após 30 minutos de imersão.

\subsection{TRATAMENTO DE FOSFATIZAÇÃo POR IMERSÃo EM SOLUÇÃO DE $\mathrm{NaH}_{2} \mathrm{PO}_{4}$}

Mais uma vez, para averiguar a possibilidade de melhoria nas características de resistência à corrosão do magneto, foi testado outro tipo de tratamento de fosfatização, desta vez com fosfato ácido de sódio. Este tratamento já havia sido anteriormente testado no Laboratório de Corrosão do IPEN para este tipo de magneto, tendo apresentado bons resultados de proteção ${ }^{37,38}$. O tratamento consistiu da imersão em solução $\mathrm{NaH}_{2} \mathrm{PO}_{4}, 10 \mathrm{~g} \mathrm{~L}^{-1}$ com pH ajustado em 3,8, variando-se os tempos de imersão em 1h, 4h, $8 \mathrm{~h}$ e 24h. Os resultados dos ensaios de impedância são mostrados na Figura 32. 

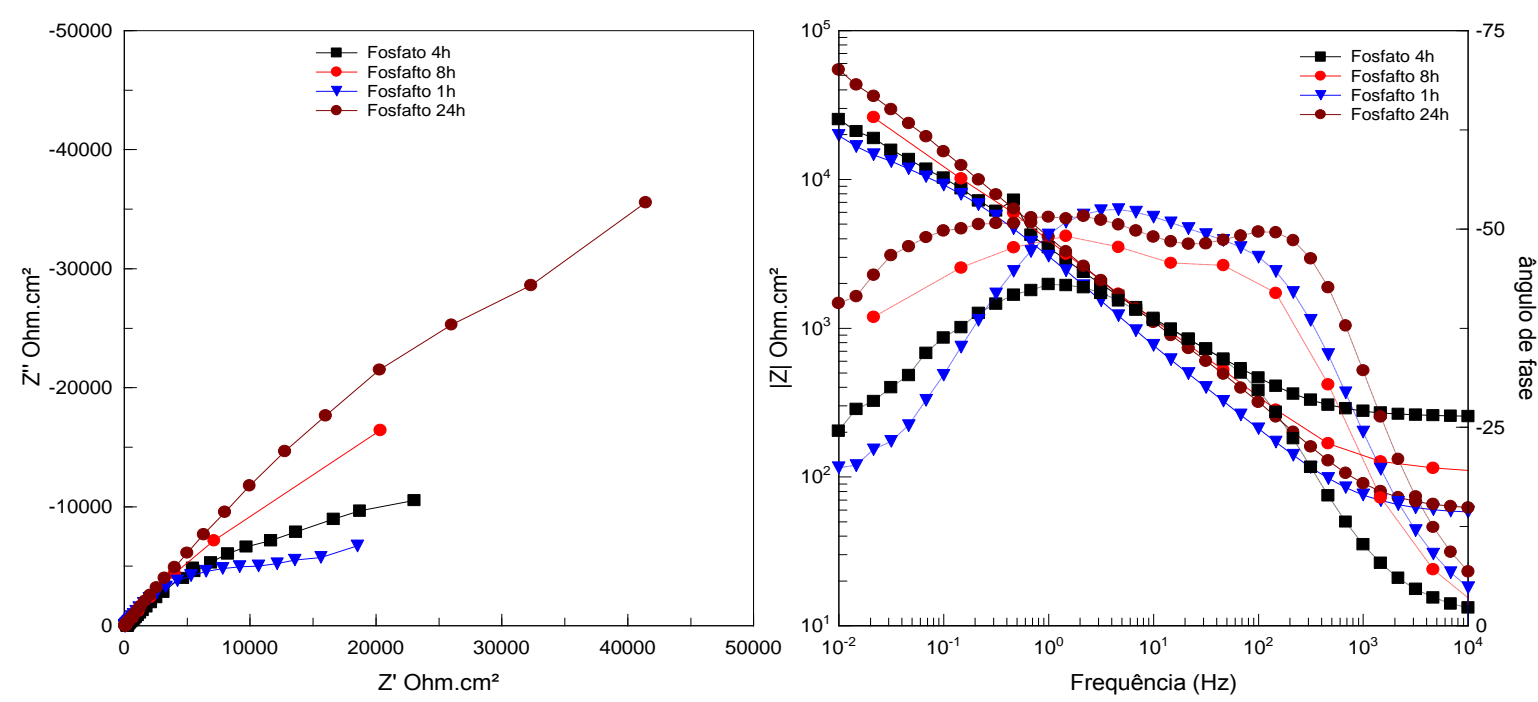

Figura 32. Diagramas de (a) Nyquist e (b) ângulo de fase e módulo de impedância para amostras do magneto de Nd-Fe-B imersas na solução de $\mathrm{NaH}_{2} \mathrm{PO}_{4}$, por $1 \mathrm{~h}$, 4h, $8 \mathrm{~h}$ e $24 \mathrm{~h}$. Resultados obtidos após 30 minutos de imersão em solução PBS.

Os magnetos fosfatizados apresentaram valores de impedâncias que aumentaram de acordo com o aumento do tempo de imersão, o que fica evidenciado tanto no diagrama de Nyquist como no de Bode. Já o diagrama de Bode, sugere a presença de pelo menos 2 constantes de tempo para as amostras, independente do tempo de imersão. A primeira constante de tempo, em altas freqüências, parece estar relacionada com a resposta aos processos de transferência de cargas (em paralelo com o carregamento da dupla camada elétrica) para um eletrodo poroso com profundidade de poro semiinfinita, uma vez que ângulos de $45^{\circ}$ são claramente evidenciados entre os diagramas de Nyquist e o eixo real. A segunda, em baixas frequências deve-se provavelmente aos fenômenos de difusão detectados nos ensaios com a amostra polida. $O$ aumento da impedância verificado com o tratamento na solução de fosfato deve-se, provavelmente, à diminuição da superfície ativa do eletrodo devido à presença da camada de fosfato, que deve-se formar também nas paredes dos poros.

As Figuras 33 a 36 apresentam as micrografias obtidas por MEV das amostras fosfatizadas por diferentes tempos de imersão: $1 \mathrm{~h}, 4 \mathrm{~h}$, $8 \mathrm{~h}$ e $24 \mathrm{~h}$, respectivamente. 


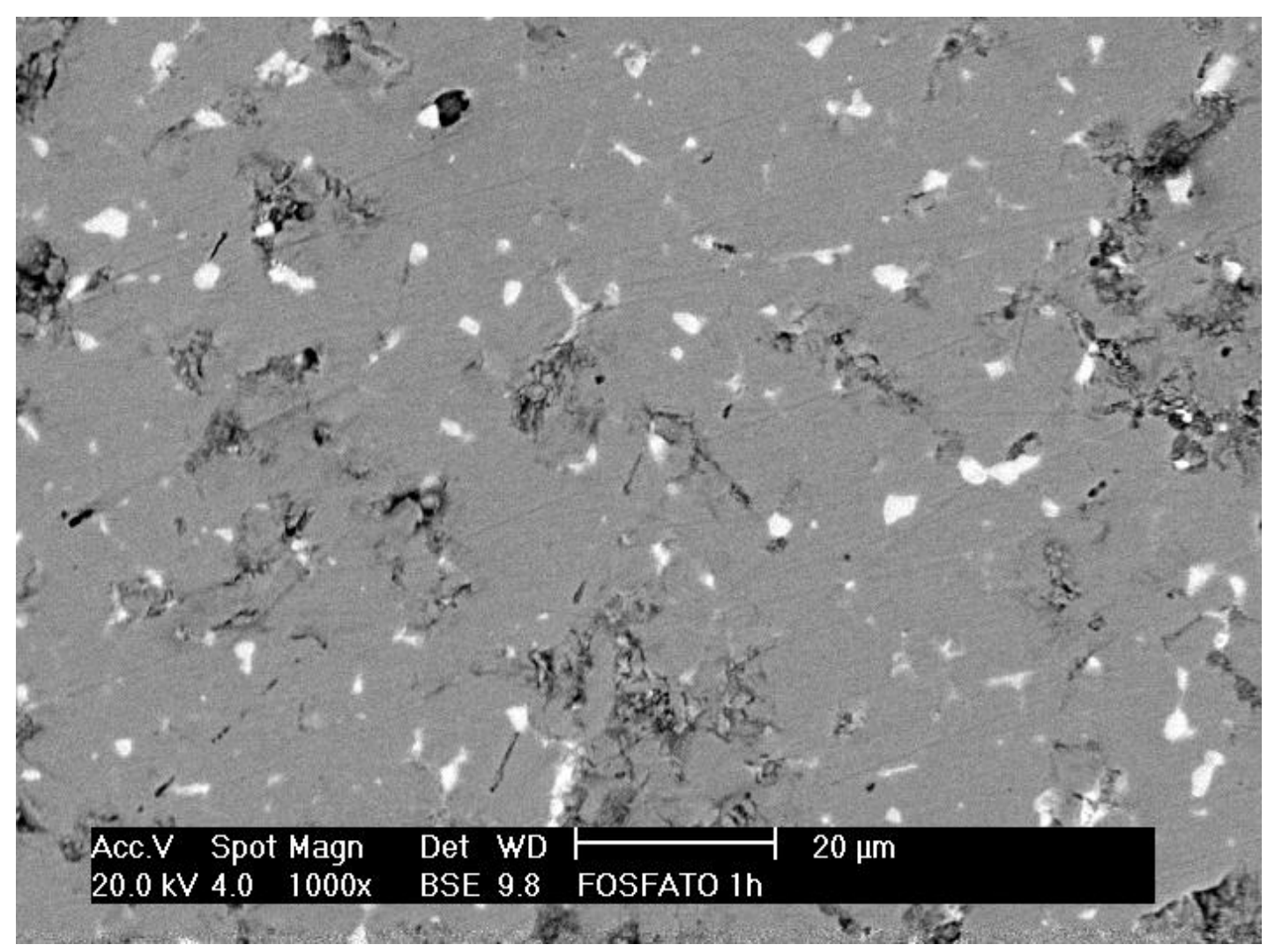

Figura 33 - Micrografia obtida por MEV da amostra fosfatizada por 1hora .

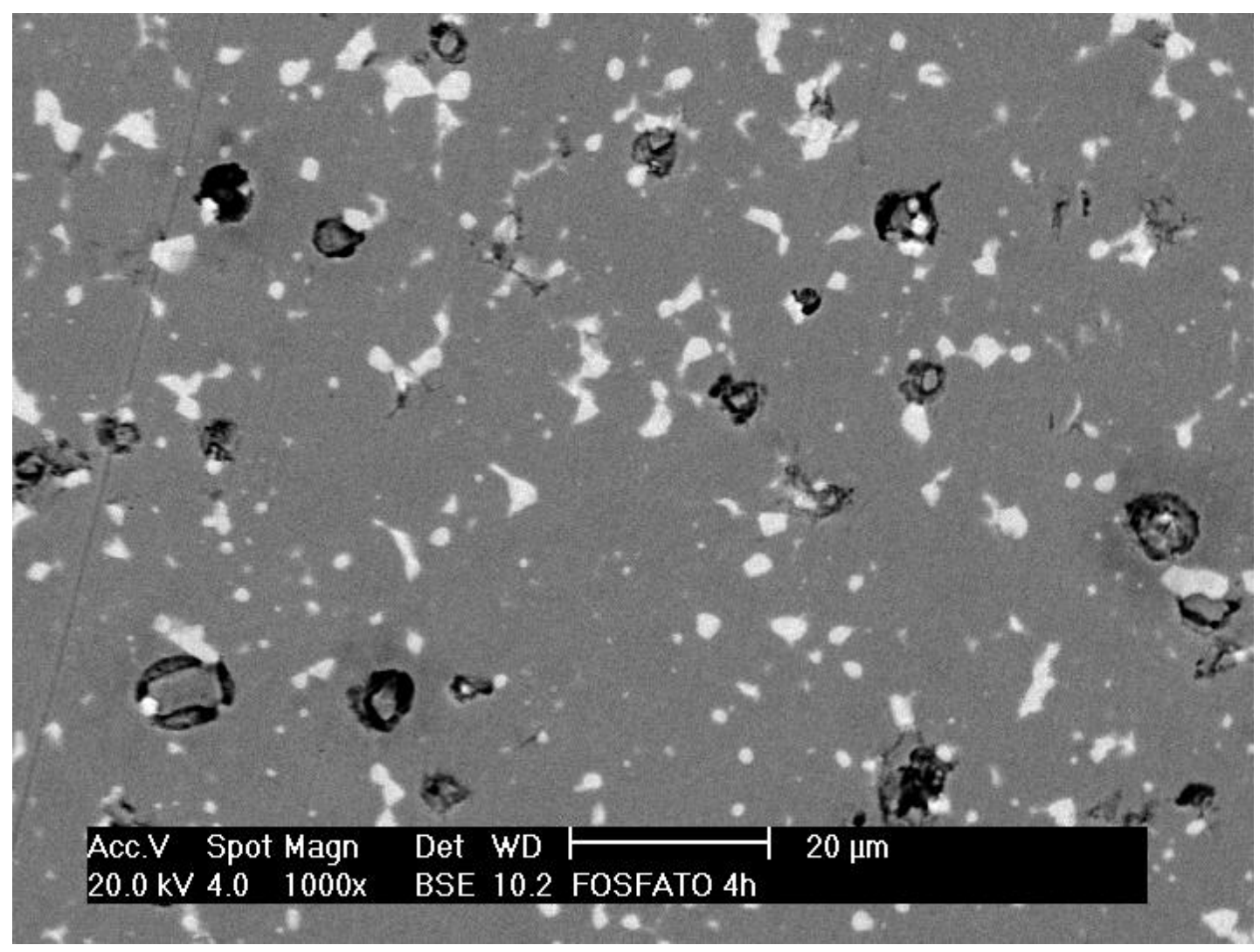

Figura 34 - Micrografia obtida por MEV da amostra fosfatizada por 4 horas . 


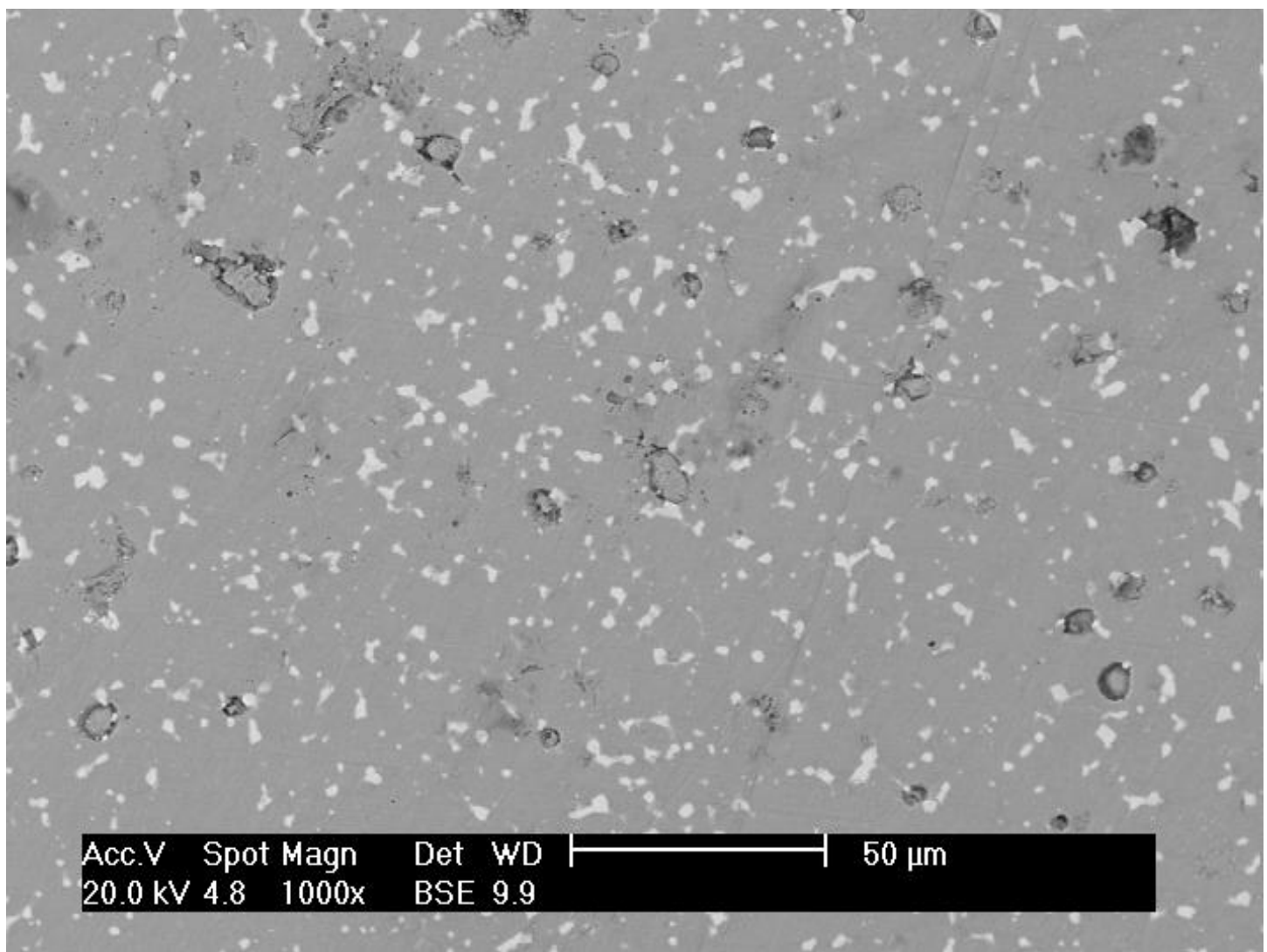

Figura 35 - Micrografia obtida por MEV da amostra fosfatizada por 8 horas .

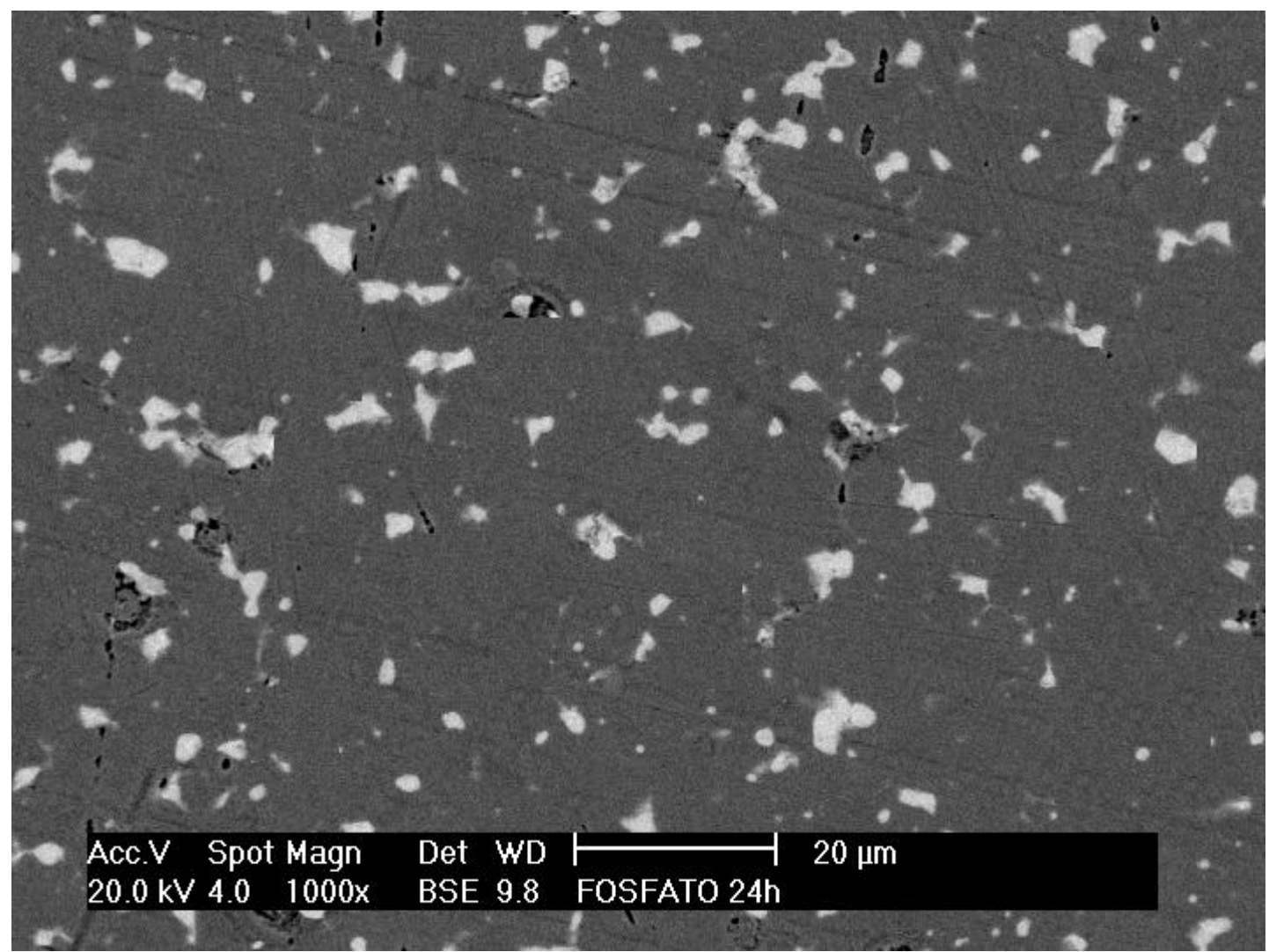

Figura 36 - Micrografia obtida por MEV da amostra fosfatizada por 24 horas. 
As micrografias apresentadas nas Figuras 33 a 36 mostram o ataque da matriz do magneto em redor das partículas ricas em $\mathrm{Nd}$, o que contraria as expectativas com relação à polaridade das fases, uma vez que a fase rica em $\mathrm{Nd}$ é mais ativa eletroquimicamente do que a fase matriz. Estes resultados sugerem que durante a fosfatização ocorre a formação de um filme protetor sobre a fase rica em $\mathrm{Nd}$. Este resultado é apoiado pela solubilidade extremamente baixa do fosfato de $\mathrm{Nd}$, o que foi comprovado experimentalmente no laboratório de Corrosão do IPEN ${ }^{37,38}$. A formação de um filme fino e protetor sobre a fase rica em $\mathrm{Nd}$ é a causa da inversão da polaridade deixando a fase matriz anódica em relação à fase rica em $\mathrm{Nd}$. Um filme fino e protetor com cores de interferência é também formado sobre a fase magnética, sendo visível à vista desarmada, o que também resulta no aumento da resistência à corrosão do magneto. $O$ aumento da resistência à corrosão com o aumento do tempo de tratamento deve estar relacionado à formação deste filme de fosfato sobre as paredes dos poros. O aumento a resistência à corrosão foi confirmada pelos resultados de polarização anódica apresentados na Figura 37.

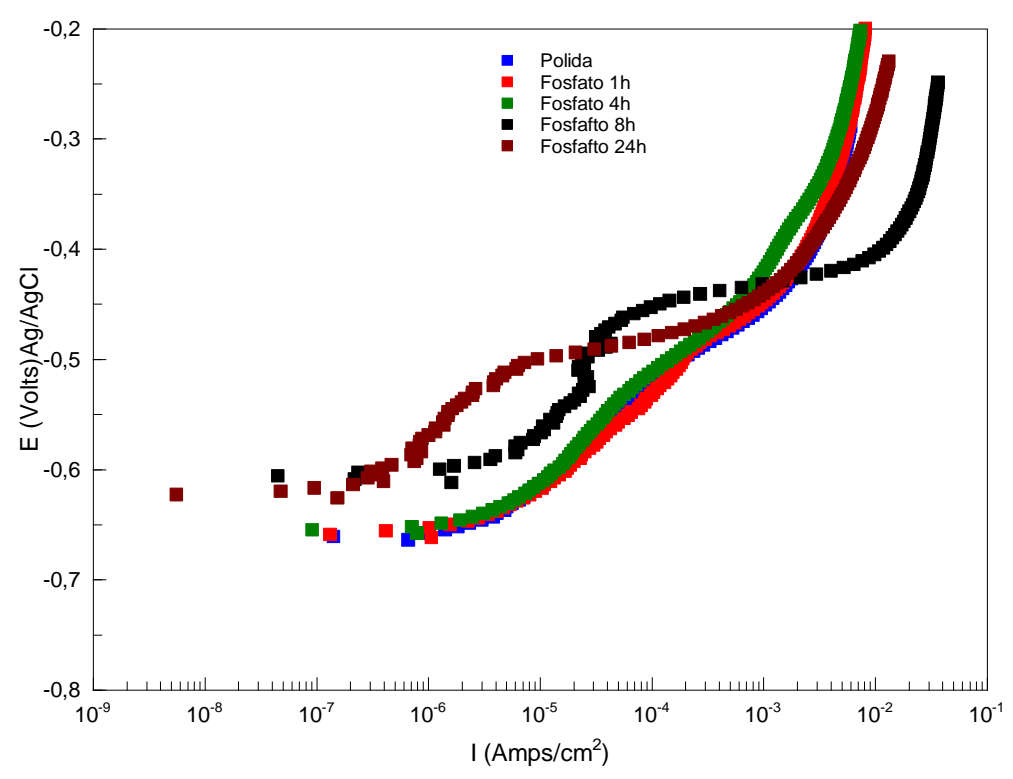

Figura 37. Curvas de polarização anódica das amostras do magneto de $\mathrm{Nd}-\mathrm{Fe}-\mathrm{B}$ tratadas na solução de $10 \mathrm{~g} \mathrm{~L}^{-1} \mathrm{NaH}_{2} \mathrm{PO}_{4}$ por 1h, 4h, 8h e 24h. Curvas obtidas após 30 minutos de imersão na solução de ensaio (PBS). 
A Figura 38 apresenta o espectro EDS da amostra tratada por imersão durante $24 \mathrm{~h}$ na solução com fosfato $24 \mathrm{~h}$. Observa-se o pico associado ao fósforo, confirmando a formação da camada.

A: $P 04$

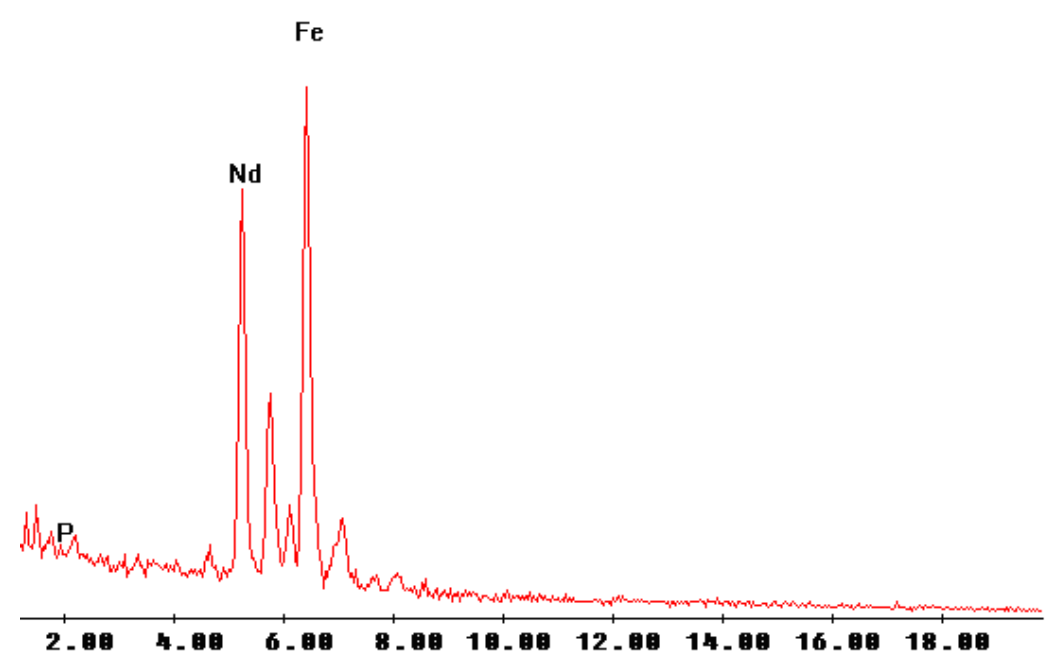

Figura 38- Espectro EDS da amostra tratada na solução de $\mathrm{NaH}_{2} \mathrm{PO}_{4}$ por 24 horas

A Figura 39 apresenta os resultados dos ensaios de impedância onde são comparadas as amostras fosfatada por 24 horas e a polida. Um grande aumento da impedância pode ser verificado.
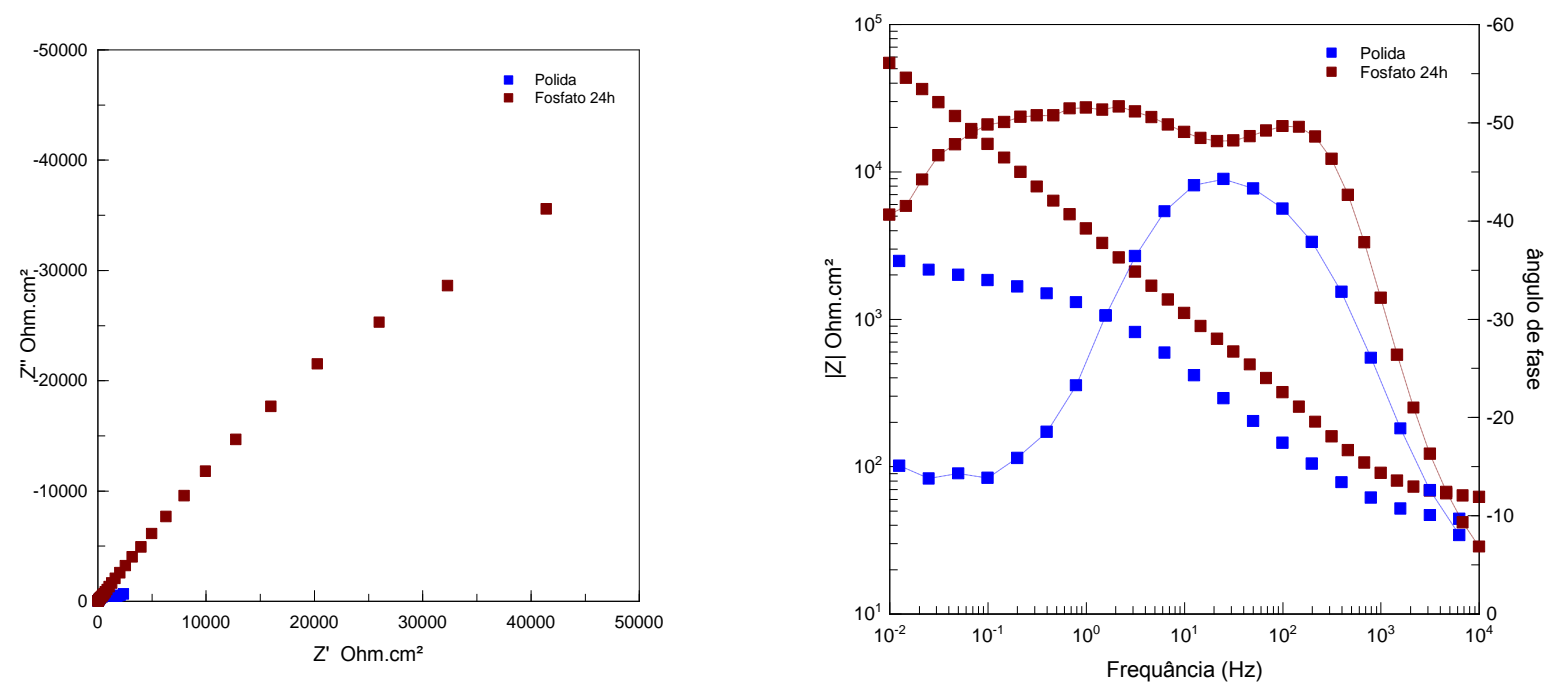

Figura 39 Diagramas de (a) Nyquist, (b) ângulo de fase e módulo de impedância para amostras de $\mathrm{Nd}-\mathrm{Fe}-\mathrm{B}$ com tratamento de imersão por 24horas em soluçao $\mathrm{NaH}_{2} \mathrm{PO}_{4}$ e amostra polida. Diagramas obtidos após 30 minutos de imersão na solução de PBS. 
A Figura 40 apresenta as curvas de polarização anódicas para a amostra polida e fosfatizada por 24h. Verifica-se que a curva da amostra fosfatada é mais polarizada, confirmando a melhor resistência à corrosão.

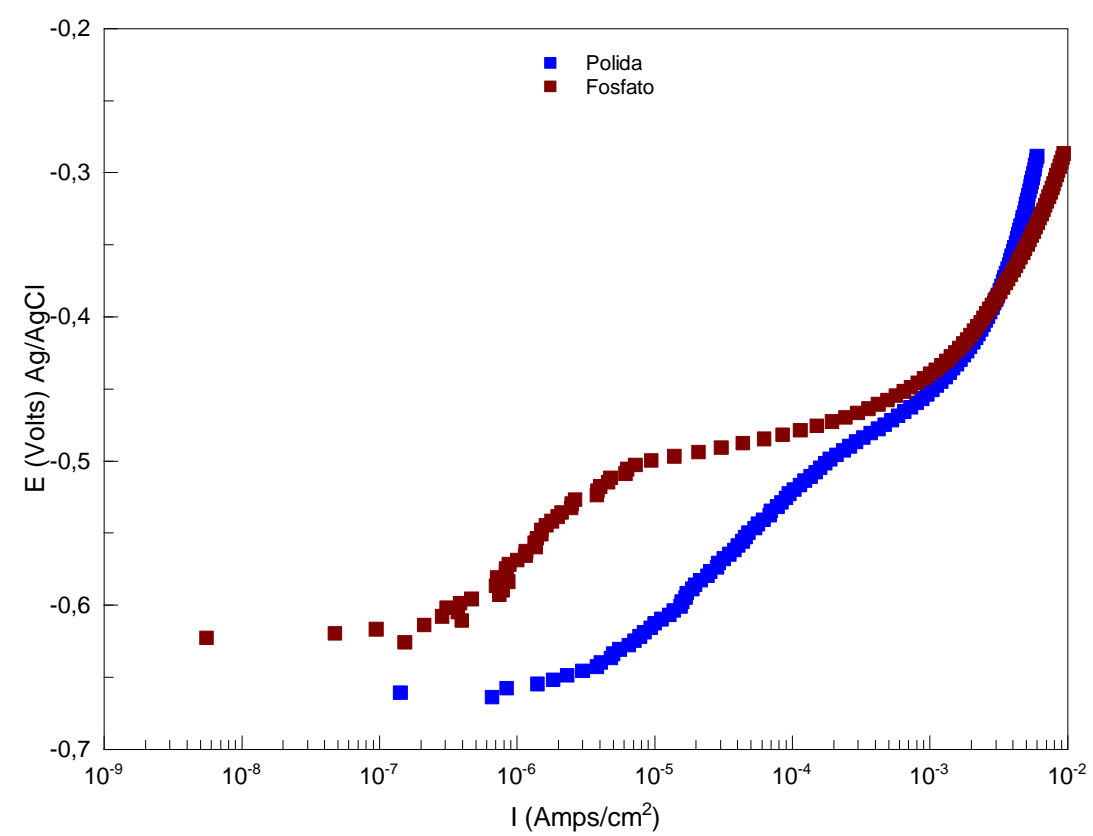

Figura 40. Curvas de polarização anódica para amostra polida ou tratada por imersão durante 24h em solução de $\mathrm{NaH}_{2} \mathrm{PO}_{4}$. Diagramas obtidos após 30 minutos de imersão na solução de PBS.

\subsection{TRATAMENTO COM FOSFATO + SULFATO DE ZINCO}

Esta outra alternativa para proteção do magneto contra a corrosão consistiu no tratamento de fosfatização por imersão por 24 horas seguido de imersão em solução de sulfato de zinco. Os resultados dos ensaios de impedância da amostra tratada por imersão durante 24 horas em solução de $\mathrm{NaH}_{2} \mathrm{PO}_{4}$ seguida de imersão em sulfato de zinco com são apresentados na Figura 41. Os resultados mostraram que o tratamento por imersão em solução de solução de zinco foi prejudicial na resistência à corrosão das amostras pré-tratadas em $\mathrm{NaH}_{2} \mathrm{PO}_{4}$, indicando que a segunda etapa do tratamento deteriora a camada de fosfato formada previamente. 

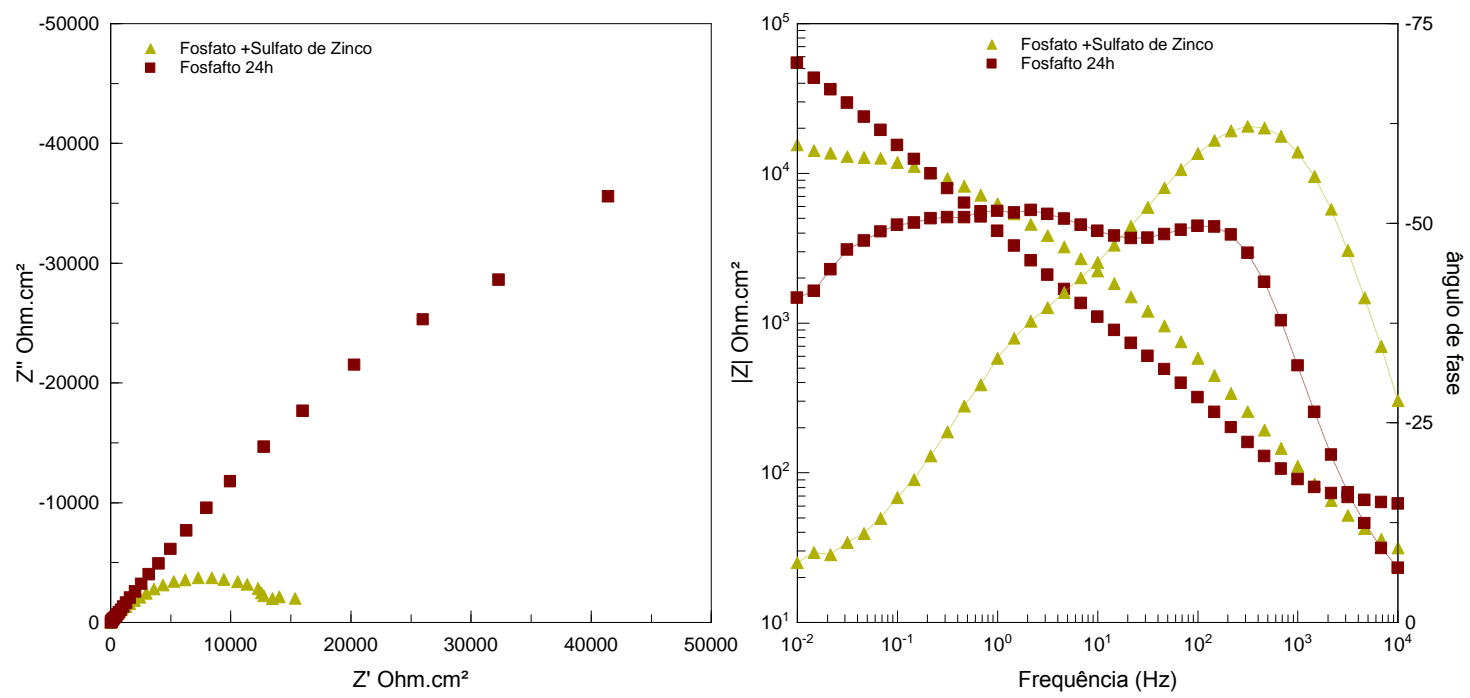

Figura 41. Diagramas de (a) Nyquist, (b) ângulo de fase e módulo de impedância para amostras do magneto de $\mathrm{Nd}-\mathrm{Fe}-\mathrm{B}$ tratadas em solução de $\mathrm{NaH}_{2} \mathrm{PO}_{4}$ por 24 horas e seguido por imersão em solução de sulfato de zinco e apenas por fosfatização por 24 horas.Resultados obtidos na solução de ensaio (PBS) após 30 minutos de imersão.

A Figura 42 apresenta as curvas de polarização para amostra fosfatizada por $24 \mathrm{~h}$ e amostra fosfatizada por $24 \mathrm{~h}$ e em seguida imersa em solução de sulfato de zinco. Os resultados da amostra polida são também apresentados para efeito de comparação.

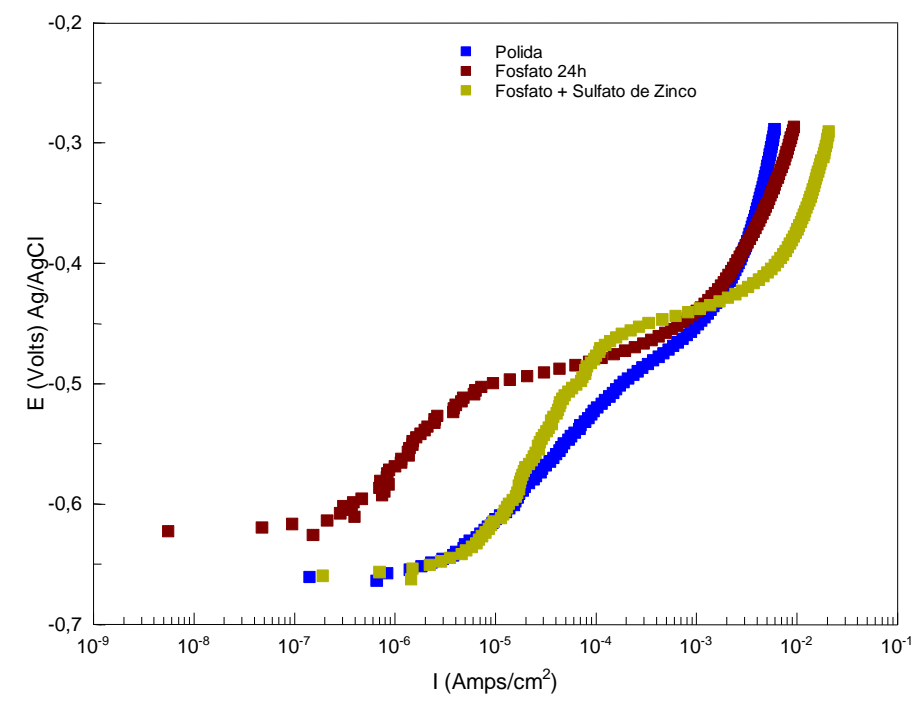

Figura 42 - Curvas de polarização anódica em solução de PBS para amostras do magneto de Nd-Fe-B polida,fosfatizada por $24 \mathrm{~h}$ e fosfatizada por $24 \mathrm{~h}$ seguida por imersão em solução de sulfato de zinco. 


\subsection{COMPARAÇÃO DOS RESULTADOS DE TRATAMENTOS AUMENTAM A RESISTÊNCIA À CORROSÃO DO MAGNETO DE Nd-Fe-B}

Os magnetos tratados com $\mathrm{Cr}^{3+}$ e fosfato 24 horas foram os que ofereceram melhor resistência à corrosão ao maneto de $\mathrm{Nd}-\mathrm{Fe}-\mathrm{B}$ dentre os tratamentos investigados. $\mathrm{A}$ Figura 43 apresenta a comparação dos ensaios de impedância com estes dois prétratamentos.
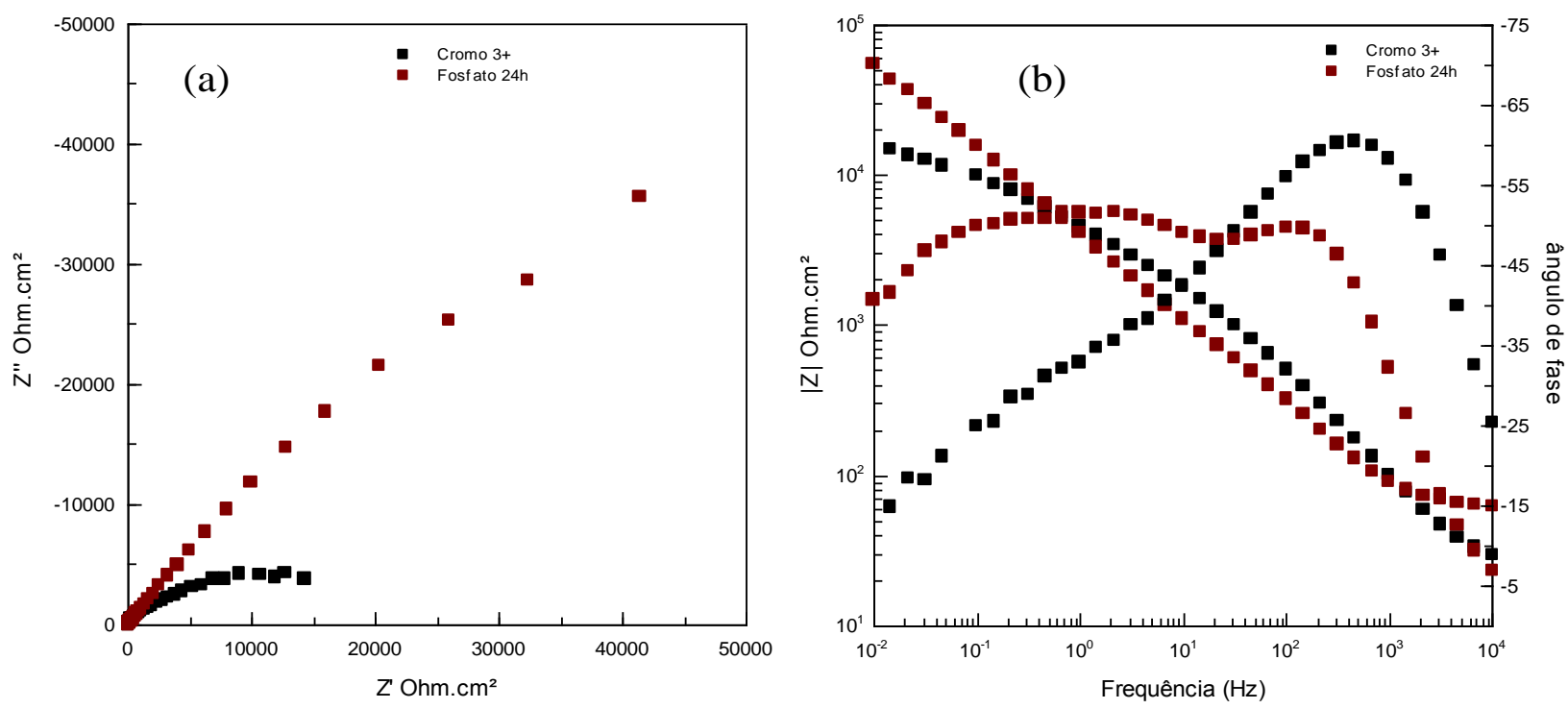

Figura 43 Diagramas de (a) Nyquist, (b) ângulo de fase e módulo de impedância para amostras do magneto de $\mathrm{Nd}-\mathrm{Fe}-\mathrm{B}$ tratados com fosfato 24 horas e $\mathrm{Cr}^{3+}$ na solução de ensaio (PBS). Diagramas obtidos após 30 minutos de imersão na solução de PBS.

Os diagramas mostram impedâncias muito maiores para o ímã fosfatizado por $24 \mathrm{~h}$ em comparação ao revestido com $\mathrm{Cr}^{3+}$. O diagrama de ângulo de fase de Bode para a amostra fosfatizada sugere a presença de duas constantes de tempo. A primeira constante de tempo, em altas freqüências, parece estar relacionada com a resposta aos processos de transferência de cargas (em paralelo com o carregamento da dupla camada elétrica) para um eletrodo poroso com profundidade de poro semi-infinita, uma vez que ângulos de 45ㅇa sa claramente evidenciados entre os diagramas de Nyquist e o eixo real. Para esta amostra, os processos difusionais não são observados, indicando que os mesmos devem ter sido deslocados para frequências mais baixas 
que as investigadas neste trabalho. As altas impedâncias para o magneto fosfatizado indicam que o revestimento oferece elevada proteção contra a corrosão do magneto.

Comparando-se os resultados da fosfatização por 24 horas com os do revestimento de $\mathrm{Cr}^{3+}$, observa-se claramente que o primeiro tratamento mostrou-se ser o mais indicado entre os testados para proteção frente aos processos corrosivos no magneto estudado. A figura 44 apresenta as curvas de polarização anódica para as amostras polida, tratada com $\mathrm{Cr}^{3+}$ e fosfatizada por $24 \mathrm{~h}$.

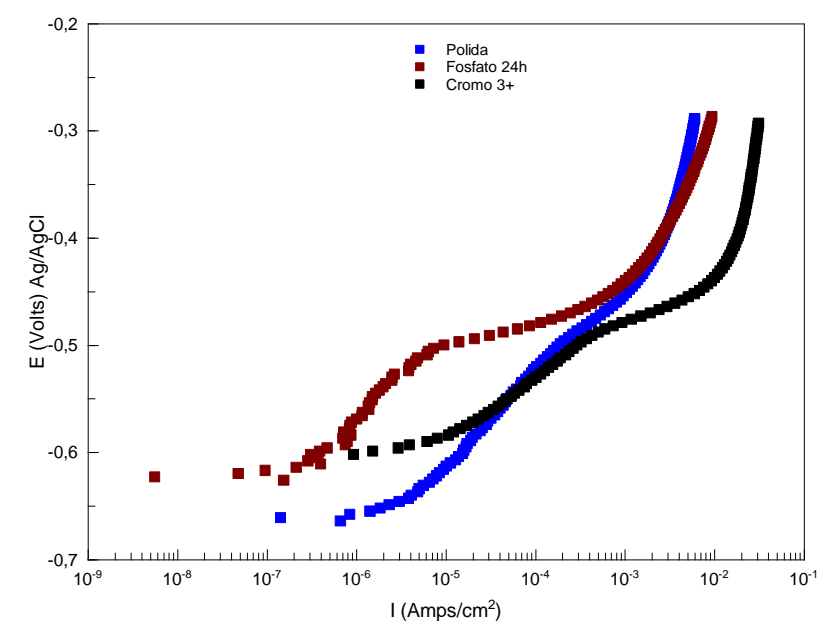

Figura 44 Curvas de polarização anódicas para as amostras polida, tratada com $\mathrm{Cr}^{3+}$ e fosfatizada por $24 \mathrm{~h}$. Curvas obtidas em solução de PBS após a realização dos ensaios de impedância.

As curvas de polarização confirmam os resultados obtidos por espectroscopia de impedância. Densidades de corrente (i) cerca de 10 vezes menores foram associadas ao magneto fosfatizado em comparação com o revestimento de $\mathrm{Cr}^{3+}$. Nota-se também que no potencial de corrosão, a amostra fosfatizada apresenta valores de $i_{\text {corr }}$ da ordem de $10^{-7} \mathrm{~A} / \mathrm{cm}^{2}$, típicas de materiais passivos. Um aumento de densidade de corrente, sugestivo de quebra do filme passivo, ocorre em potenciais de $-0,47 \mathrm{~V}$ obtendo-se valores de corrente próximos para ambas amostras, previamente tratada ou polida. A amostra com revestimento de $\mathrm{Cr}^{+3}$ apresentou-se mais ativa que a fosfatizada, apesar deste revestimento ter produzido aumento na resistência à corrosão do magneto e não apresentar toxicidade. 


\section{BIOCOMPATIBILIDADE E CITOTOXICIDADE}

O índice de citotoxicidade (IC ${ }_{50 \%}$ ) foi estimado por interpolação, como a concentração do extrato que resulta em $50 \%$ de inibição da absorção de MTS, após a construção de um gráfico com a média de porcentagem de células vivas contra a concentração do extrato (\%).

As amostras de Nd-Fe-B e Nd-Fe-B fosfatada por 24 horas mostraram comportamentos semelhantes ao controle negativo, apresentando curvas de viabilidade celular acima da linha do índice de citotoxicidade $\mathrm{IC}_{50 \%}$, indicando ser não citotóxicos. O controle positivo, látex de borracha natural, comprovadamente tóxico, apresentou $\mathrm{IC}_{50 \%}$ de 40 .

A Tabela 7 apresenta os resultados da porcentagem de viabilidade celular no ensaio de citotoxicidade pelo método de incorporação de um corante vital.

Tabela 7 Resultados da porcentagem de viabilidade celular pelo método de incorporação de corante vital.

\begin{tabular}{|c|c|c|c|c|}
\hline \multirow{2}{*}{$\begin{array}{c}\text { Concentração } \\
\text { Extrato (\%) }\end{array}$} & \multicolumn{4}{|c|}{ \% Viabilidade celular $\pm \mathrm{dp}$} \\
\cline { 2 - 5 } & $\begin{array}{c}\text { Controle } \\
\text { negativo }\end{array}$ & $\begin{array}{c}\text { Controle } \\
\text { positivo }\end{array}$ & $\mathrm{NdFeB}$ & $\begin{array}{c}\text { NdFeB } \\
\text { fosfatado }\end{array}$ \\
\hline 100 & $91 \pm 10$ & $8 \pm 11$ & $112 \pm 5$ & $121 \pm 11$ \\
\hline 50 & $109 \pm 4$ & $9 \pm 5$ & $118 \pm 6$ & $119 \pm 0$ \\
\hline 25 & $84 \pm 7$ & $108 \pm 12$ & $113 \pm 0$ & $108 \pm 4$ \\
\hline 12,5 & $71 \pm 9$ & $88 \pm 12$ & $113 \pm 0$ & $108 \pm 17$ \\
\hline 6,25 & $100 \pm 3$ & $98 \pm 12$ & $90 \pm 19$ & $101 \pm 10$ \\
\hline
\end{tabular}

A Figura 45 apresenta as curvas de viabilidade celular do ensaio de citotoxicidade de amostras de $\mathrm{NdFeB}$ e NdFeB fosfatado por 24 horas. 


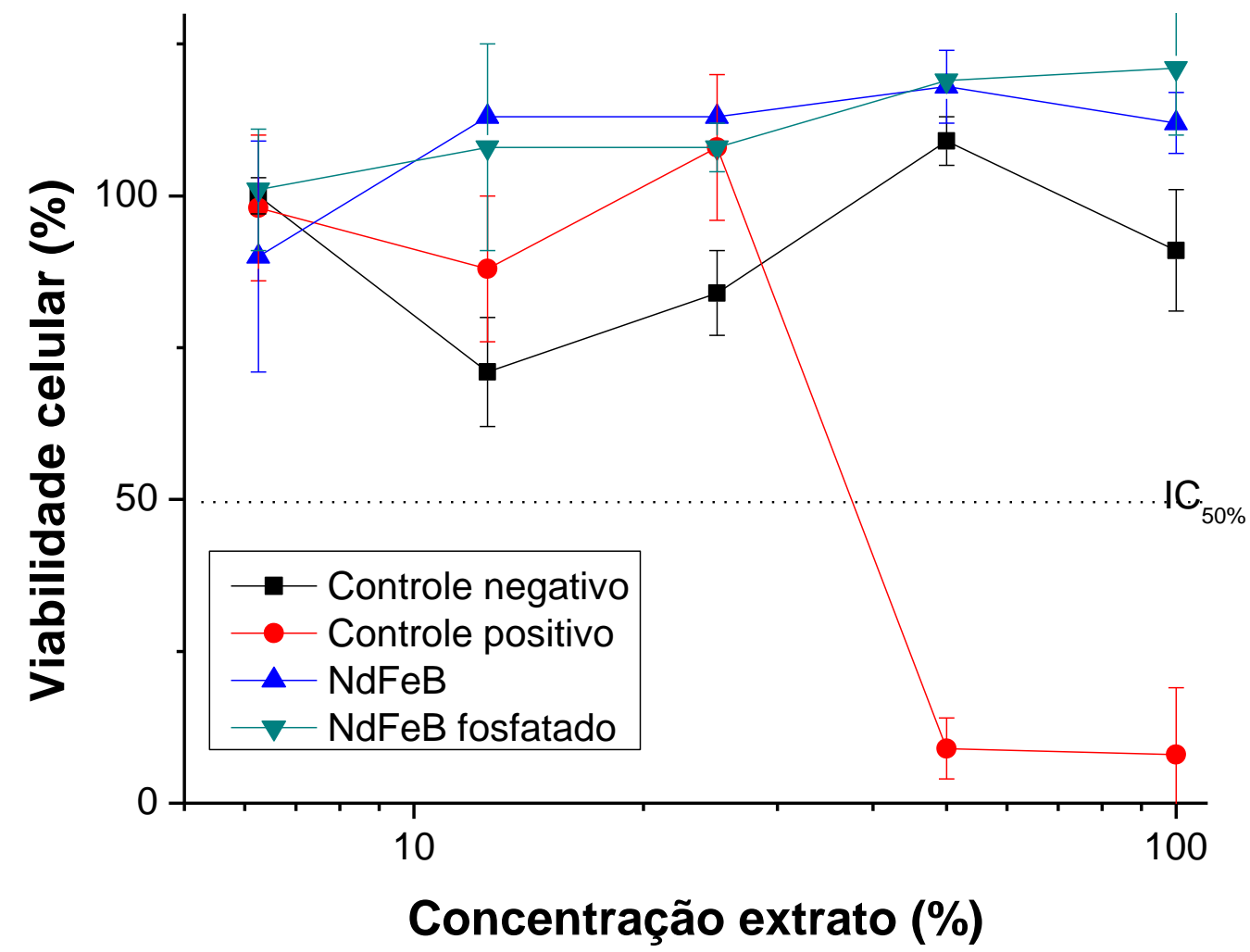

Figura 45. Curvas de viabilidade celular do ensaio de citotoxicidade de amostras de Nd-Fe-B e Nd-Fe-B fosfatado por 24 horas. 


\section{EFEITO DO TEMPO DE IMERSÃO NA SOLUÇÃO DE FOSFATIZAÇÃO $\left(\mathrm{NaH}_{2} \mathrm{PO}\right)$}

Após avaliar os diversos tipos de tratamentos já apresentados neste trabalho, foi monitorado o comportamento eletroquímico em função do tempo de imersão na própria solução de fosfatização (10 $\left.\mathrm{g} \mathrm{L}^{-1} \mathrm{NaH}_{2} \mathrm{PO}_{4}\right)$ por ensaios de espectroscopia de impedância.(EIS)

As medidas de impedância foram obtidas para tempos de imersão correspondentes a $1 \mathrm{~h}, 4 \mathrm{~h}, 8 \mathrm{~h}, 16 \mathrm{~h}$ e $24 \mathrm{~h}$.

Os resultados mostram aumento contínuo da impedância com o tempo de imersão confirmando os testes realizados com amostras tratadas por diferentes tempos e em seguida imersas na solução de ensaio (PBS).

As medidas de potencial de corrosão em função do tempo de imersão na soluão de fosfatização (Figura 46) também confirmam os resultados de (EIS) mostrando aumento do potencial entre 10 min e 1 h de imersão na solução de fosfatização.

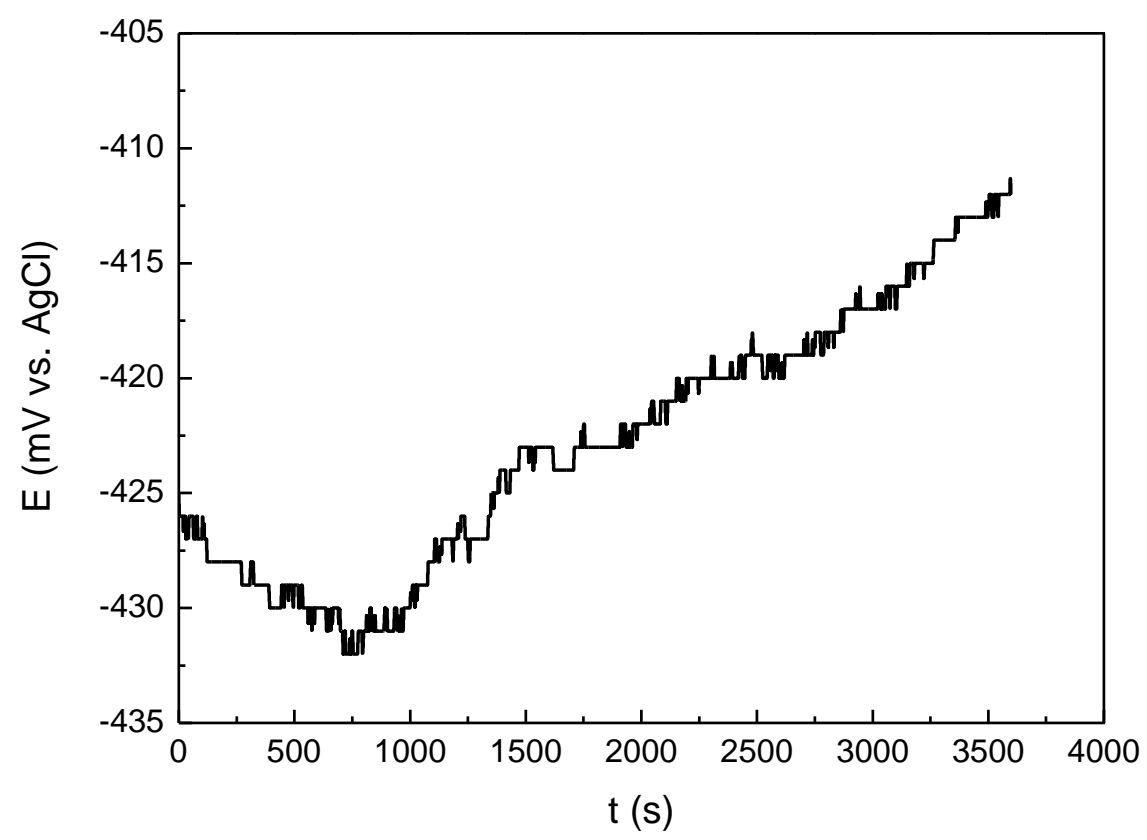

Figura 46. Variação do potencial de corrosão em função do tempo de imersão em solução $10 \mathrm{~g}$ $\mathrm{L}^{-1} \mathrm{NaH}_{2} \mathrm{PO}_{4}$. 
A Figura 47 apresenta os diagramas de impedância (a) Nyquist (b) ângulo de fase de Bode e módulo de impedância de amostra de magneto de $\mathrm{Nd}-\mathrm{Fe}-\mathrm{B}$ para vários períodos de imersão na solução de fosfatização.
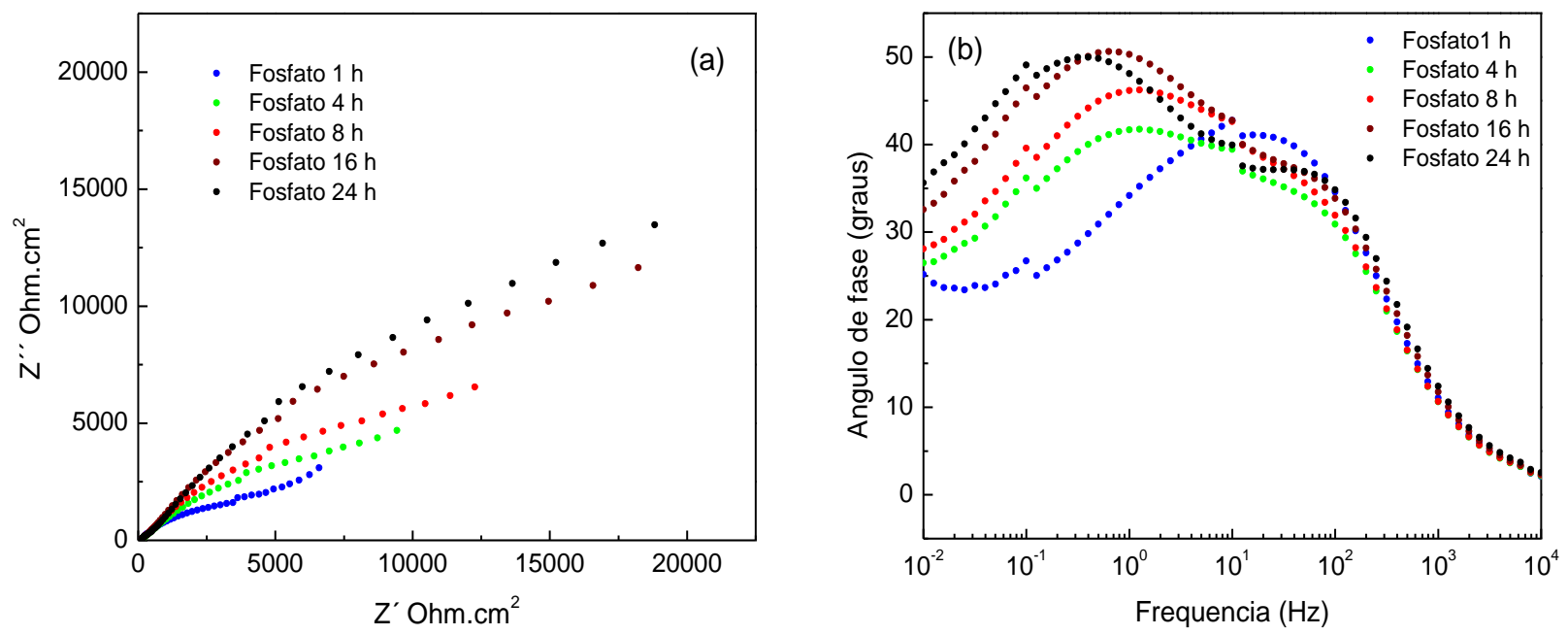

Figura 47- Diagramas de Nyquist e ângulo de fase de Bode obtidos para magneto de Nd-Fe-B em solução de $\mathrm{NaH}_{2} \mathrm{PO}_{4}$.

Os diagramas de Nyquist mostram aumento contínuo da impedância com o tempo de imersão na solução de fosfatização, enquanto que os diagramas de ângulo de fase de Bode indicam a presença de pelo menos duas constantes de tempo para tempos de imersão superiores a $1 \mathrm{~h}$. A constante de tempo em freqüências da ordem de $100 \mathrm{~Hz}$, ou seja, em médias freqüências (MF) foi associada a processos de transferência de cargas e carregamento da dupla camada elétrica. Nota-se entre $1 \mathrm{~h}$ e $4 \mathrm{~h}$ a diminuição do ângulo de fase e o deslocamento do pico associado a esta constante de tempo para mais altas freqüências, sugerindo a aceleração dos processos de transferência de carga neste período. Este resultado poderia ser explicado pela maior atividade superficial do magneto nos períodos iniciais de imersão na solução de fosfatização. Para tempos de imersão maiores que $4 \mathrm{~h}$, nota-se pequeno aumento nos ângulos de fase na MF e leve deslocamento para freqüências mais altas, indicando ainda um pequeno aumento na cinética dos processos de transferência de carga mas que tende a atingir uma certa estabilidade. A constante de tempo em baixas freqüências (BF) por sua vez mostra grande variação ao longo de todo o período de tempo monitorado; os 
ângulos de fase aumentam significativamente e se deslocam para mais baixas freqüências. Esta constante de tempo, foi associada anteriormente aos fenômenos de difusão nos poros do magneto. O aumento da impedância e dos ângulos de fase, bem como seu deslocamento para menores freqüências, com o tempo na solução de fosfato deve-se, provavelmente, à diminuição da superfície ativa do eletrodo devido à contínua formação da camada de fosfato nas paredes dos poros, conforme já proposto. 


\section{CONCLUSÕES}

- A microestrutura complexa dos magnetos de Nd-Fe-B e a porosidade inerente ao processo de fabricação resultam em alta susceptibilidade à corrosão dos mesmos.

- A corrosão é usualmente mais severa na fase rica em $\mathrm{Nd}$, mais ativa e localizada nos contornos da fase magnética $(\varphi)$, observando-se a tendência à corrosão intergranular no magneto sem revestimento (polido) e imerso na solução de ensaio de corrosão (PBS).

- Os tratamentos com moléculas auto-organizáveis (SAM), revestimento de silano, revestimento de conversão de cério, revestimento de conversão com cromo hexavalente, fosfatização por imersão por $24 \mathrm{~h}$ em solução de $\mathrm{NaH}_{2} \mathrm{PO}_{4}$ seguido de imersão em sulfato de zinco e tratamento com fosfato tricatiônico seguido de passivação com trióxido de cromo não ofereceram reistência contra a corrosão nos magnetos de $\mathrm{Nd}-\mathrm{Fe}-\mathrm{B}$.

- Tratamentos de fosfatização por imersão em solução de $\mathrm{NaH}_{2} \mathrm{PO}_{4}$ em tempos variados, revestimento de conversão em solução de cromo trivalente e por imersão em solução com fosfato tricatiônico por 30 minutos, ofereceram proteção contra corrosão para o magneto estudado.

- O tratamento de fosfatização por imersão em solução de $\mathrm{NaH}_{2} \mathrm{PO}_{4}$ sugere que há formação de um filme fino e protetor, preferencialmetne sobre a fase rica em $\mathrm{Nd}$, que a causa da inversão da polaridade entre as fases rica em $\mathrm{Nd}$ (inicialmente mais ativa) e a fase magnética e rica em $\mathrm{Fe}$, fazendo com que esta se tornasse anódica em relação à fase rica em $\mathrm{Nd}$.

- Os resultados indicaram que o tratamento na solução de fosfato resulta na diminuição da superfície ativa do eletrodo devido à presença da camada de fosfato que provavelmente se forma também nas paredes dos poros. 


\section{SUGESTÕES PARA TRABALHOS FUTUROS}

- Investigar o efeito do $\mathrm{pH}$ da solução de fosfatização $\left(\mathrm{NaH}_{2} \mathrm{PO}_{4}\right)$ na resistência à corrosão do magneto de Nd-Fe-B para tentar obter uma melhor proteção contra a corrosão.

- Avançar em pesquisas laboratoriais e clínicas a fim de buscar novos materiais com propriedades magnéticas formados por matrizes poliméricas, principalmente para uso como biomaterial.

- Investigar recobrimentos biocompatíveis e hidrofóbicos.

- Estudar o efeito do campo magnético e sua relação com a osteogênese quando os magnetos forem utilizados em aplicações em Odontologia.

- Realizar testes de Genotoxicidade . 


\section{REFERÊNCIAS BIBLIOGRÁFICAS}

1. MATSUURA,Y.;HIROSHWA, S.;YAMAMOTO,H.;FUJIMURA,S.;, SAGAWA, M.;OSAMURA,K. Japanese Journal of Applyed Physics, part 2,p.635,1985.

2. WALMSLEY, A.D. Magnets in restaurative dentistry. Birmingham, 2001.School of Dentistry, University of Birmingham.

3. CALLISTER, Jr.W.D. Ciência e Engenharia de Materiais: Uma Introdução. Rio de Janeiro, Ed LTC, 247, 2002.

4. ARAÚJO, R.C. Tese de Doutorado - IFGW-UNICAMP-2000.

5. CULLITY, B.D. Introduction to magnetic materials .Adisson-Wesley, 1972.

6. RODRIGUES,DANIEL.Disponível em: http://www.nobreconsultoria.com.br/artigos/Materiais\%20Magneticoss $\% 20$ e $\% 20$ Met alurgia\%20do\%20Po.pdf Acesso em 12/01/2009.

7. CLARK, A., E. TOMOGAWA. N Journal Of Applied Physics, 42 n², p.160$162,1972$.

8. FARIA, R.N.; LIMA, L.F.C.P. Introdução ao magnetismo dos materiais. Ed Livraria da Física, 192 p.,2005.

9. SAGAWA,M.; FUJIMURA,S.; TOGAWA,N.; YAMAMOTO,H.; and MATSUURA,Y. Journal of Applied Physics, 55 n.6, p. 2083-2087,1984.

10. KUJI, T.; FUJITA, M. The minerals, Metals \& Materials Society. 95 p.95-101,1998.

11.VARDIMON, D.A.; MUELER, H.J. In vivo and in vitro corrosion of permanent magnets in Orthodontics therapy, J Dent Res. 64:185,1985.

12. GENTIL, V. Corrosão, LTC, 3ª edição, Rio de Janeiro, p. 319-384, 1987.

13. ADELL, R. et al. A 15 year study of osseointegrated implants in the treatment of the edentulous jaw. Int.J.Oral Surg,v.6, p.387-416,1981.

14. RAMIRES, I. Estudo de corrosão em biomateriais. Araraquara, 1988. 83p. Dissertação (Mestrado em Físico-Química) Instituto de Química de Araraquara, Universidade Estadual Paulista.

15. BUNDY, K. J. Corrosion and other electrochemical aspects of biomaterials. Crit . Rev. Biomed. Eng., v.22, n.314, p.139-251, 1994.

16. KLAUBER, C.; LENZ, L.J.; HENRY,P.J. Oxide thickness and surface contamination of six endosseaous dental implants determined by electron spectroscopy for 
chemical analysis; a preliminary report. Int. J. Oral Maxillofacial. Implants,v.5,p. 264-271,1990.

17. OLEJEFORD, I.; HANSSON. S. Surface analysis of four dental implants, v.8, p.3240, 1993.

18. McALARNEY, M.E.; OSHIRO, M.A.; McALARNEY, C.A.Effects of titanium dioxide passive film crystal structure, thickness, and crystallinity on C3 adsorption. Int. J. Oral maxillofac. Implants, v.11, p. 73-80,1996.

19.BRICK, R.M.; GORDON, R.B.; PHILLIPS, A. Reactive and refratory metals for high temperature service. In: Structure and properties of alloys.3.ed.New York: McGraw-Hill,1965.Chap.14, 382-406.

20.DIETER, G.E. Metalurgia mecânica. 2.ed.Rio de Janeiro: Guanabara Koogan, McGraw-Hill Book, 1981.343p.

21.BYRNE, J. E.; LOVASKO, J.H.; LASKIN, D.M. Corrosion of metal fracture fixation appliances .J. Oral. Surg ., v.31, n.8, p.639, 1973.

22. MELETIS, E.; GIBBS, C.; LIAN,K. A new dynamic corrosion test for dental materials. Dent.Mater., v.5, p. 411, 1989.

23. REVISTA BRASILEIRA DE ORTOPEDIA, In: Aços inoxidáveis em implantes ortopédicos : Fundamentos e resistência à corrosão. vol. 37 n 11/12, Nov/Dez 2002.

24. HOUSE, KATE.; SERNETZ,FRIEDERICH.; DYMOC,DAVID.; SANDY, JONATHAN.; IRELAND, ANTHONY. J. Corrosion of orthodontic appliances - should we care? Am Journal Orthod Dentofacial Orthop, 133:584-92,2008.

25. FONTANA, M.G. Corrosion engineeering. $3^{\text {rd }}$ ed. New York: MacGraw-Hill,1986.

26. WEST, J.M. Basic corrosion and oxidation. Ellis Horwood, 1986.

27.ZITTER, H.; PLENK, H. JUNIOR. The electromechanical behaviour of metallic., Journal Dent Res, v.21, p. 881-96,1987.

28.RUCINSKIENE, A.; BICULSIUS, G.; GUDAVICIUT, L.; JUZELIUNA,.E. Electrochemical Commun. 4 p.86-91, 2002.

29. VORKOPIC, L.Z.; KINOUCHI, Y.; SASAKI, H.; SHIOTA. M.; USHITA.T. Journal Dental Res.58, p. 1597-1606,1979.

30. KELLY.E.J. J Electrochemical Society.124, p. 18-22,1999.

31. CHOPARJ, T.; DOUGLADE, J. P.; OLIVIER, A. Electrochemica Acta 36 p.459$463,1991$.

32. LEE, C.C.; CHOUT, T.C. Electrochemica Acta, 40 p. 965-968,1995. 
33. SHINOHARA,K.; AOGAK,R.I. Electrochemistry, 67 p.1261-1263,1999

34.NOZÍERES, J.P.; TAYLOR, D.W.; BALA, H., MALIK,M.; SZYMURA,S. and STOKLOSA, H. Journal of Alloys and compunds,201 p. 23-28,1993.

35. CHIBA, A.; KAWASU, K.; NAKANO, O.; TAMURA, T.; YOSHIHARA, S.; SATO, E. Corrosion Science. 36 p. 539-546,1994.

36. BALA, H.; PAWLOWSKA, G.; SZYMURA, S.; SERGEEV, V.; RABINOVICH, Y.M. Journal of Magnetism and Magnetic Materials. 87,p. L255-L258,1990.

37. COSTA, I.; OLIVEIRA, M.C.L.; DE MELO, H.G.; FARIA, R.N. Key Engineering Materials, 340, p.189-191, 2001.

38.SALIBA-SILVA, A.M. Tese de Doutorado: Desenvolvimento de um processo de fosfatização para proteção anticorrosiva em imãs de Nd-Fe-B. IPEN, Universidade de São Paulo, 139 p., 2001.

39. DABALÀ, MANUELE.; RAMOUS, E.; MAGRINI, MAURIZIO. Corrosion resistance of Cerium-based chemical conversion coatings on AA 5083 aluminium alloy. Materials and Corrosion 55, №. 5, 2004.

40. MANSFELD, F. Corrosion mechanisms. New York: Marcel Dekker Inc,1987.p.99100.

41.UHLIG, H.H.; REVIE, R.W. Corrosion and corrosion control. 3. ed. John Wiley and Sons, 1985.

42.ANSTOTS,T.; GIESA,D.; SPIECKERMANN,K.; WUPERMANN,C.D.:The new annealing and pickling line for widestainless strip in the Krefeld works of thyssen stahl AG. Metallurg Plant Technol Intern 1: 901994.

43. YAMAMOTO, Y.; NISHIAHARA, H.; K.ARAMAKI. H. Journal. Electrochem Acta, 47, 2335, 2002.

44.BREVNOV, D.A.; FINKLEA, H.O.; RYSWYK. H.V. J.Electroanal. Chem, v.500,p.100, 2001.

45. ULMAN, A. J. Mater. Ed. 11 , p. 207. 1989.

46. GALVANUM. São Paulo. Camadas de conversão. Disponível em: www.galvanum.com.br/info.htm. Acesso em 28/08/2003.

47. CAMPESTRINI, P.; TERRYN, H., HOVESTAD, A.; WIT,J.H.W. Formation of a cerium-based conversion coating on AA2024:relationship with the microstructure.Surface and Coatings Technology, v.176, n.3, p.365-381,2004. 
48. AKIYAMA,E.; $\quad$ MARWORTH,A.J.; $\quad$ MCCOY,J.K.; $\quad$ FRANKEL,G.S.; $\quad$ XIA,L.; MCCREERY,R.L. Storage and release os soluble hexavalent chromium from chromate conversion coating on all alloys. Journal of the Electrochemical Society, v.150, n.2, p.83-91, 2005.

49. PALOMINO, L.E.M. Tese Mestrado, EPUSP- Universidade de São Paulo, p.34, 2004.

50.PALOMINO,L.E.M.; PASZTIL,ZOLTAN.; AOKI, I.V.; DE MELO,H.G. Comparative investigation of the adhesion of Ce conversion layers and silane layers to a $A A$ 2024-T3 substrate through mechanical and electrochemical tests. Mat. Res. vol.10 n.4 São Carlos Oct-Dec. 2007.

51. HINTON, B. R.; WILSON,L. A method of forming a corrosion resistant coating. Int Cl.4 C23C 22/48. WO 88/06639. September 7,1998.

52. ARNOT, D.R.; HINTON, B.R.W.; RYAN,N.E. A method of forming a corrosion resistant coating.Int. Cl.4C23C 22/48. WO 88/06639. September, 7, 1988.

53. HIVART, P, B.; HAUW, J.P., BRICOUT, J. OUDIN. Tribology International 8 561$570,1997$.

54.BANCZECK, E. P.; OlIVEIRA, M. F.; CUNHA, M. T.; RODRIGUES, P. R. P. Portugaliae Electrochimica Acta 23 (2005) 379-391.

55.JEGANNATHAN,S.;NARAYANAN,T.S.N.S.;RAVICHANDRAN,K.;RAJESWARI, S. Surface \& Coatings Technology 200, 4117-4126 , 2006.

56. JEGANNATHAN,S.;NARAYANAN,T.S. N. S.;RAVICHANDRAN, K. , RAJESWARI, S. Surface \& Coatings Technology 200, 6014-6021, 2006.OLESEN, P. T. , STEENBERG, T.CHRISTENSEN, E., BJERRUM, N. J. Journal of Materials Science 33, 3059-3063, 1998.

57.NARAYANAN, T.S.N.S.; JEGANNATHAN,S.; RAVICHANDRAN,K. Progress in Organic Coatings,55, p. 355-362,2006.

58. WAN, C-M.; LIAU, H.C.; TSAI, W.T. Surface \& Coatings Technology 201, 2994$3001,2006$.

59. NIU, L.Y. ; JIANG, Z. H. ; Li, G. Y. ; GU, C. D. ; LIAN,J. Surface \& Coatings Technology 200, 3021-3026, 2004.

60. UHLIG, H. H. The Corrosion Handbook. [S. I]: John Wiley \& Sons, Inc. 1948. 
61. KOUISNI, L.; AZZI, M.; ZERTOUBI, M.; DALARD, F.; MAXIMOVITCH, S. Surface \& Coatings Technology 185,58-67, 2004.

62.LIAN, J. LI,S.; NIU, G. Y.; GU, L. Y.; JIANG, C. D.; Z. H., JIANG, Q. Surface \& Coatings Technology 200, 5956-5962, 2006.

63.KOUISNI, L.; AZZI, M.; DALARD, F.; MAXIMOVITCH, S. Surface \& Coatings Technology 192, 239-246, 2005.

64.ZIMMERMANN, D.; MUÑOS, A. G.; SCHULTZE, J. W. Electrochemica Acta 48 3267- 3277, 2003.

65.LI, G. Y., LIAN, J. S., NIU, L. Y., JIANG, Z. H., JIANG, Q. Surface \& Coatings Technology 201,1814-1820, 2006.

66. DEEPA, L. C.; SATHIYANARAYANAN, S.; MARIKKANNU, C.; MUKHERJEE, D. Anti-Corrosion Methods and Materials 4, p.286-290, 2003.

67. GÓRECKI, G. Metal Finishing, 36-39, March, 1995.

68. WENG, D.; JOKIEL, P.; UEBLEIS, A.; BOEHNI, H. Surf.Coat. Technol. 88,147-156, 1996.

69. FLIS, J.; MANKOWSKI, J.; ZAKROCZYMSKI, T. Bell, Corrosion Science 43, 17111725, 2001.

70.PALRAJ, S.; SELVARAJ, M.; JAYAKRISHNAN, P. Progress in Organic Coatings $54,5-9,2005$.

71. SINHA, P. K.; FESER, R. Surface \& Coatings Technology 161,158-168, 2002.

72. AKHTAR, A. S.; SUSAC, D.; GLAZE, P.; WONG, K. C.; MITCHELL, K. A. R. Surface \& Coatings Technology 187,208-215, 2004.

73. SHOEIB, M.; FAROUK, M.; HANNA, F. Metal Finishing, Sept., 62-68, 1997.

74.ZIMMERMANN, D.; MUÑOS, A. G.; SCHULTZE, J. W. Electrochemica Acta 197,260-269, 2005.

75. WIMMER, W.; GOTTSCHLICH, J.; MOTORENWERKE, J.B. Metal Finishing, 16-19, may, 1998.

76. LI, G.; NIU, L; LIAN, J.; JIANG, Z. Surface \& Coatings Technology 176, 215-221, 2004.

77. TEGEHALL, E. Colloids and Surfaces Coatings, 42,155-164,1989.

78. TEGEHALL, E. Colloids and Surfaces Coatings, 49, 373-164, 1990. 
79. FRANQUET, A.; TERRYN , H.; VEREEKEN, J. IRSE Study on effect of thermal curing on the chemistry and thickness of organosilane films coated on aluminium. Applied Surface Science, Amsterdam, v.21, n.1-4, p. 259-269.Apr,2003.

80.VAN OOIJ, W.J.; ZHU, D. Electrochemistry impedance spectroscopy of bistriethoxysilypropyl-tetrasulfide on Al 2024-T3 substrates. Corrosion, Houston, v.57, n.5, p. 413-427, May, 2001.

81.ZUCCHI, F.; GRASSI, V.; FRIGNANI, A.; MONTICELLI, C.;TRABANELLI, G. Inhibition of copper corrosion by silane coatings. Corrosion Science, v.46,p.28532865,2004.

82. SUBRAMARIAN, V. Silane coupling agents for corrosion protection, DissertationDoctor of Philosophy, Department pf Materials Science and Engineering,University of Cincinnati,Ohio, 1999.

83. YUAN, W.; OOIJ, W.J VAN. Characterization of Organofuntional silanes films on zinc substrates. Journal of Colloid and Interface Science, v.185, p.197-209, 1997.

84.ZUCCHI, F.; GRASSI, V.; FRIGNANI, A.; MONTICELLI, C.; TRABANELLI, G. Influence of a Silane treatment on the corrosion resistanceof a W43E magnesium alloy. Surface \& Coating Technology, 2005.

85. PALANIVEL, V.; ZHU, D. van OOIJ, W.J.Nanoparticle-filled silane films as chromate replacements for aluminium alloys, Progress in Organic Coating, v.47, p.384-392, 2003.

86. PAVLOV, B.; TERENTYEV, A. Organic Chemistry: a textbook, Moscow, Mir Publishers,cap.2, 1969.

87. TERENTYEV, A.; PAVLOV, B. Organic Chemistry: a textbook, Moscow, Mir Publishers,cap 3, 1969.

88. RUHLMANN, K.; SCHEIM, U.; KAPLLER, K.; GEWALD, R. Nucleophilic substitution reactions of siloxanes. In: BASSINDALE, A.R., GASPAR, P.P., Frontiers of Organosilicon chemistry. Cambridge: The Royal Society of Chemistry, p. 208-217, 1991.

89. SHMIDBAUR, H.; HAGER, R.; ZECH, J. Small polysililalkanemolecules: feed stock gases for chemical vapour deposition of silicon and silicon alloys. In: BASSINDALE, A.R., GASPAR, P.P., Frontiers of Organosilicon chemistry. Cambridge: The Royal Society of Chemistry, p. 63-69, 1991.

90.PLUEDDMANN, E.P Silane adhesionpromoters in coatings. Progress in Organic Coatings, Lausanne, v.11, n.3, p.297-308, 1983. 
91. VAN OOIJ, W.J.; PALANIVEL, V.; STACY,M.; LAMAR, A.; AHUD, D. The use of organofunctional silanes as a major constituent in organic coatings for enhanced corrosion protection. ASM INTERNATIONAL SURFACE ENGINEERING CONFERENCE, 1., ANNUAL INTERNATIONAL FEDERATION FOR HEAT TREATMENT \& SURFACE ENGINEERING,13. Columbus, 2003. Disponível em < http:// www.eng.uc.edu/ wvanooij/SILANE/use orgfunsil.pdf> acesso em 3 de fevereiro de 2009.

92.ZHU, D. Corrosion protection of metals by water based silane mixtures of Bistrimethoxysilylpropyl-amine and vinyltriacetoxysilane. Progress in Organic Coating, v.49, p. 42-53, 2004.

93. CHILD, T.F.; VAN OOIJ, W.J. Application of Silane technology to prevent corrosion of metals and improve paint adhesion. TRANSACTIONS OF THE INSTITUTE OF METAL FINISHING, London, v.77, n.2, p. 64-70, 1999.

94. RESENDE, S. M. Materiais e dispositivos magnéticos. In : A Física de Materiais e dispositivos Eletrônicos. Recife: Editora Universidade Federal de Pernambuco, p. 367- 416, 1996.

95.ISO 10.993 Biological evaluation of medical devices - part:5: Tests for cytotoxicity: in vitro methods, p. 1-7, 1992.

96. ROGERO, S.O.; MALMONGE, S. M.; LUGÃO, A.B.; IKEDA, T.I.; MIYAMARU, L.; CRUZ, A.S. Biocompatibility study of polymeric biomaterials. Artif. Organs, v. 27, n. 5, p. 424-427, 2003.

97. DE LEVIE, R. On porous electrodes in electrolyte solutions - IV. Electrochimica acta, v. 9, n. 9, p. 1231-1245, Set. 1964.

98. PALOMINO, LUIS ENRIQUE M.; de CASTRO, JOÃO FÁBIO W.; AOKI, IDALINA V.; de MELO, HERCÍLIO G. Microstructural and electrochemical characterization of environmentally friendly conversion layers on aluminium alloys. Journal of the Brazilian Chemical Society,144, pp. 651-659, 2003.

99.XINGWEN, YU.; CHUNAN, CAO. Electrochemical study of the corrosion behavior of $\mathrm{Ce}$ sealing of anodized 2024 aluminum alloy Thin Solid Films, Volume 423, Issue 2, Pages 252-256, 15 January 2003.

100. JI-MING HU, XIANG-LIAN LIU, JIAN-QING ZHANG, CHU-NAN CAO. Corrosion protection of $\mathrm{Nd}-\mathrm{Fe}-\mathrm{B}$ magnets by silanization Progress in Organic Coatings, Volume 55, Issue 4, Pages 388-392, 2006. 
